\title{
Technical Activities Associated with the ZONAL Pacific Array
}

\author{
by
}

George H. Tupper

Woods Hole Oceanographic Institution

Woods Hole, Massachusetts 02543

December 1987

\section{Technical Report}

Funding was provided by the Office of Naval Research under contract Numbers NOOO14-76-C-0197, NR 083-400, and N00014-84-C-0134, NR 083-400.

Reproduction in whole or in part is permitted for any purpose of the United States Government. This report should be cited as:

Woods Hole Oceanog. Inst. Tech. Rept., WHOI-87-54.

Approved for publication; distribution unlimited.

Approved for Distribution:

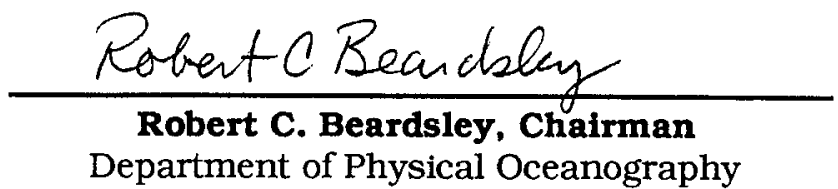




\section{Table of Contents}

Page No.

Abstract

Section I SCIENTIFIC BACKGROUND

Section II TECHNICAL BACKGROUND

A. Moorings $\quad 6$

B. Instrumentation $\quad 15$

Geodyne Model 850 Current Meter $\quad 15$

Vector-Averaging Current Meter (VACM) 21

Vector-Measuring Current Meter (VMCM) 26

Section III CRUISES $\quad 30$

1983 Cruise - 17 Oct-10 DeC $83^{\circ} .30$

Leg I 31

Leg II $\quad 32$

1984 Cruise - 19 Sep-3 Nov 84

$\begin{array}{ll}\text { Leg I } & 47\end{array}$

Leg II 53

1985 Cruise - 24 sep-2 Nov 85

Leg I 58

Leg II 61 .

Section IV RESULTS, IMPROVEMENTS, PROBLEMS

A. Data Return $\quad 68$

B. Wire Re-use 68

C. Release Tracking Using PGR and Towfish 70 
Page No.

D. Release Problems

$7 i$

Release Implosion

71

Release Actuation after Deployment

71

Release Firing after Mooring Recovery

72

Release Failure

72

E. VMCM Problems

73

ZONAL - VMCM Rotor Report (Valdes)

Section V ZONAL MOORING DRAWINGS

81

Acknowledgements

References 
Fig. 1 Recent Mooring Locations in the North Pacific

Fig. 2 Typical WHOI Intermediate Mooring 7

Fig. 3 Typical WHOI Syntactic Sphere Mooring 8

Fig. 4 Intermediate Mooring Performance - Eastern Current Profile 10

Fig. 5 Intermediate Mooring Performance - Western Current Profile 11

Fig. 6 Syntactic Sphere Mooring Performance - Western Current 12

Fig. 7 zONAI Mooring Array 13

Fig. 8 Geodyne 850 Current Meter 16

Fig. 9 Data Format, 850 Current Meter 19

Fig. 10 Vector-Averaging Current Meter (VACM) 22

Fig. 11 Vector-Measuring Current Meter (VMCM) 27

Fig. 12 Taft Mooring A 36

Fig. 13 Taft Mooring B . 37

Fig. 14 Taft Mooring C 38

Fig. 15 Taft Mooring D 39

Fig. 16 Taft Mooring A failure and dragging procedure 40

Fig. 17 Cruise Track, R/V Thomas G. Thompson Cruise No. 177, 41 17 oct $83-10$ Dec 83

Fig. 18 Cruise Track, R.V Thomas G. Thompson Cruise No. 184, 48 19 Sept $84-3$ Nov 84

Fig. 19 Extended Duration Subsurface Mooring 62

Fig. 20 Cruise Track, R/V Thomas G. Thompson Cruise No. 191, 63 24 Sept 85 - 2 Nov 85

Fig. 21 Data Return, ZONAL Pacific Experiment 69

Fig. 22 A VMCM data record from the first year's ZONAL 75

Fig. 23 A VMCM data record from the second year's zONAL 76 deployment (1984-1985) 
Page No.

Table 1 North Pacific Mooring Locations - zONAL Exploration

Fall 1983 - Fal1 1985

Table 2 CTD Stations taken on Leg I of zONAL Pacific Cruise, Fal1 1983

Table 3 A Summary of the mooring work conducted during Leg I of the

5 $\mathrm{R} / \mathrm{V}$ Thomas G. Thompson Cruise Number 177

Table 4 R/V Thomas G. Thompson, Cruise 177 Leg I, Seattle, Washington Midway Island, 17 Oct 83 - 8 Nov 83 - Personnel

Table 5 CTD stations taken on Leg II of ZONAI Pacific Cruise, Fal1 1983

Table 6 A Summary of the Mooring Work Conducted during Leg II of 45 $\mathrm{R} / \mathrm{V}$ Thomas G. Thompson Cruise Number 177

Table $7 \mathrm{R} / \mathrm{V}$. Thomas G. Thompson, Cruise Number 177 Leg II, Midway Island 46 Guam, 10 Nov 83 - 10 Dec 83 - Personnel

Table 8 CTD Stations taken on Leg I of ZONAI Pacific Cruise, Fal1 1984

Table 9 A Summary of the Mooring work conducted during Leg I of $\mathrm{R} / \mathrm{V}$ Thomas $\mathrm{G}$. Thompson Cruise Number 184

Table 10 R/V Thomas G. Thompson, Cruise Number.184 Leg I, Honolulu Midway Island, 19 Sep 84 - 16 Oct 84 - Personnel

Table 11 CTD stations taken on Leg II of ZONAL Pacific Cruise, Fall 1984

Table 12 A Summary of the Mooring Work conducted during Leg II of

R/V Thomas G. Thompson Cruise Number 184

Table 13 R/V Thomas G. Thompson, Cruise Number 184 Leg II, Midway Island Honolulu, 19 Oct 84 - 3 Nov 84 - Personnel

Table 14 A Summary of the Mooring Work conducted during Leg I of R/V Thomas G. Thompson Cruise Number 191

Table 15 R/V Thomas G. Thompson, Cruise Number 191 Leg I, Seattle Honolulu, 24 Sep 85 - 5 Oct 85 - Personnel

Table 16 A summary of the Mooring Work conducted during Leg II of R/V Thomas G. Thompson Cruise Number 191

Table 17 R/V Thomas G. Thompson, Cruise Number 191 Leg II, Honolulu 65 Guam, 10 Oct 85 - 2 Nov 85 - Personnel 
Geographical exploration of the eddy and mean fields in the world's oceans using moored instrumentation was concentrated in the North Atlantic in the 1970s. Initial efforts to obtain zeroorder coverage in the North Pacific were begun with an array across the Ruroshio Extension along $152^{\circ} \mathrm{E}$ with instruments in the water from. mid-1980 to mid-1982. An array designed to extend this exploration zonally with long-term moorings east of $152^{\circ} \mathrm{E}$ at mid-latitudes was first set in the fall of 1983 , redeployed in the fall of 1984, and recovered for the final time in late 1985. The array was located along four lines of longitude, $165^{\circ} \mathrm{E}$, $175^{\circ} \mathrm{E}, 175^{\circ} \mathrm{W}$, and $152^{\circ} \mathrm{W}$. Along the three westernmost longitudes, 24 one-year moorings were used, 12 each year, with three current meters per mooring at nominal depths of 150,650 , and 4,000 meters. The eastern longitude, $152^{\circ} \mathrm{E}$, was sampled by two additional moorings, each with 3 current meters at the above depths, which were deployed for a two-year period, a first for the Buoy Group.

This report addresses the technical activities associated with the 1983-1985 array, referred to hereafter as "ZONAL". 
Observational efforts to obtain a data base for the North Pacific comparable to that available in the North Atlantic (Schmitz, 1984a; Schmitz et al., 1983) were planned in the late 1970s. Long-term moored instrument observations spanning the Kuroshio Extension were first obtained in 1980-1982. Thirtyeight moored current-temperature meters were deployed for about two years along $152^{\circ} \mathrm{E}$ from $28^{\circ}$ to $41^{\circ}(\mathrm{Figure} 1)$. Ten moorings were involved at a planned latitudinal spacing of 1.25 degrees in the center of the array and 2 degrees at the extremes. Each mooring had instruments at nominal depths of 500, 1200 , and 4000 $m$, with four moorings also having instruments near $300 \mathrm{~m}$ depth as well as $200 \mathrm{~m}$ off the bottom. Data and results from the first setting of this array were discussed by Schmitz et al. (1982), and for the second setting and composite data set by Roblinsky et al. (1984), Niiler et al. (1985), Schmitz (1984b, c), and Schmitz et al. (1987). Technical considerations have been described in some detail by Bradley (1982), and a data report is available ( Levy and Tarbell, 1983).

In 1983,14 additional moorings were deployed in the North Pacific (Figure 1, Table 1), in order to extend the exploration near the Kuroshio Extension across the Pacific. These measurements were also designed to expand the model-data intercomparisons of Schmitz and Holland (1982) I see also Schmitz et al. (1982) and Holland and Schmitz (1985) ) to the North Pacific subtropical gyre, especially near the kuroshio Extension. Each mooring had current-temperature meters at nominal depths of 
150,650 , and $4000 \mathrm{~m}$. This ZONAL exploration array was redeployed in 1984 and recovered for the final time in 1985.

Data from the first setting of these instruments have been used

by Schmitz and Holland (1986). Results from the composite array (Schmitz, 1987, 1988) and a data report (Levy and Tarbel1, 1987) are also available. 


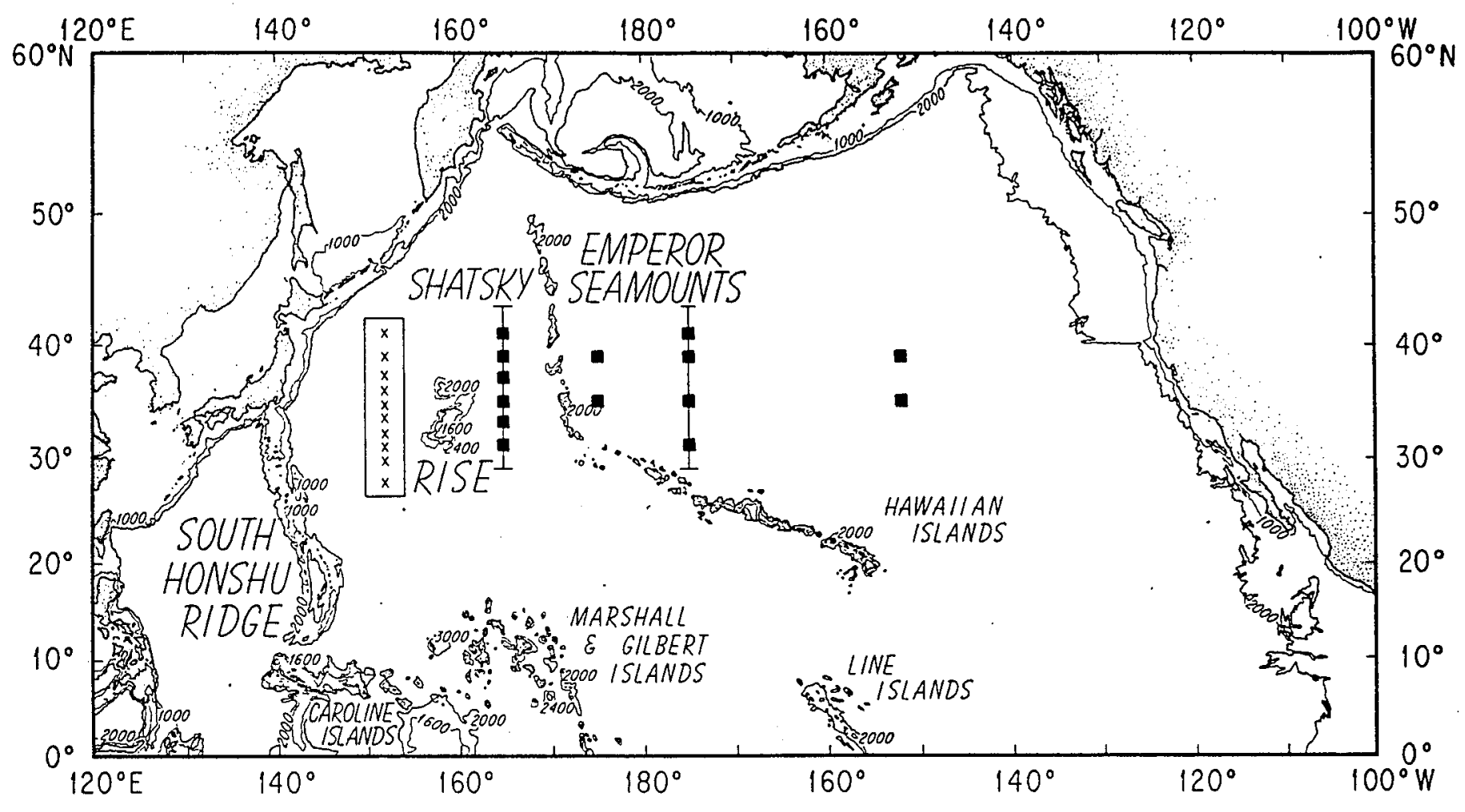

Fig. I Recent mooring locations in the North Pacific. The $152^{\circ} \mathrm{E}$ moorings (Schmitz et al., 1982) are denoted by X's, ZONAL exploration moorings (Table 1) by squares. Depth contours (in fathoms) and feature names taken from Chase et al. (1977). 
Table 1

North Pacific Mooring Locations - ZONAL Exploration

Fall 1983 - Fall 1985

Longitude \#1

$\left(165^{\circ} \mathrm{E}\right)$

$41^{\circ} \mathrm{N}$

$39^{\circ} \mathrm{N}$

$37^{\circ} \mathrm{N}$

$35^{\circ} \mathrm{N}$

$33^{\circ} \mathrm{N}$

$31^{\circ} \mathrm{N}$
Longitude \#2

- $\left(175^{\circ} \mathrm{E}\right)$
Longitude \#3

$\left(175^{\circ} \mathrm{W}\right)$
Longitude \#4

$\left(152^{\circ} \mathrm{W}\right)$

$41^{\circ} \mathrm{N}$

$39^{\circ} \mathrm{N}$

$39^{\circ} \mathrm{N}$

$39^{\circ} \mathrm{N}$

$35^{\circ} \mathrm{N}$

$35^{\circ} \mathrm{N}$

$35^{\circ} \mathrm{N}$

$31^{\circ} \mathrm{N}$ 


\section{TECHNICAL BACKGROUND}

\section{A. Moorings}

The WHOI Buoy Group has been making in situ current velocity measurements in the ocean since 1960. The majority of these measurements are made from subsurface, intermediate moorings. The term "intermediate" refers to the fact that flotation, in the form of clusters of glass balls, is distributed along the mooring at intermediate depths as well as at the top. The balls are distributed in such a way that if a component fails, there is sufficient buoyancy remaining below the failed component to allow recovery of the remainder of the mooring without dragging. All moorings for the ZONAL experiment except two were of this type (Fig. 2). The remaining two moorings were similar in design to the intermediates, but the upper flotation consisted of a syntactic foam sphere with 2,000 pounds of buoyancy. The sphere provides the same buoyancy as 40 glass balls with one-seventh the drag, thus improving the performance of the mooring in high currents. Since high currents were anticipated at two mooring sites in the western part of the array, sphere moorings were used at those sites. Figure 3 illustrates the sphere mooring.

The WHOI Buoy Group moorings are constructed of off-theshelf components. The upper 2000 meters of the mooring uses wire rope to minimize damage that could result from fish attack. The depth range and effects of fish bite on mooring lines have been documented by Berteaux and Prindle (1987). The wire rope used in the ZONAL moorings was $3 / 16$ inch in diameter, jacketed with 


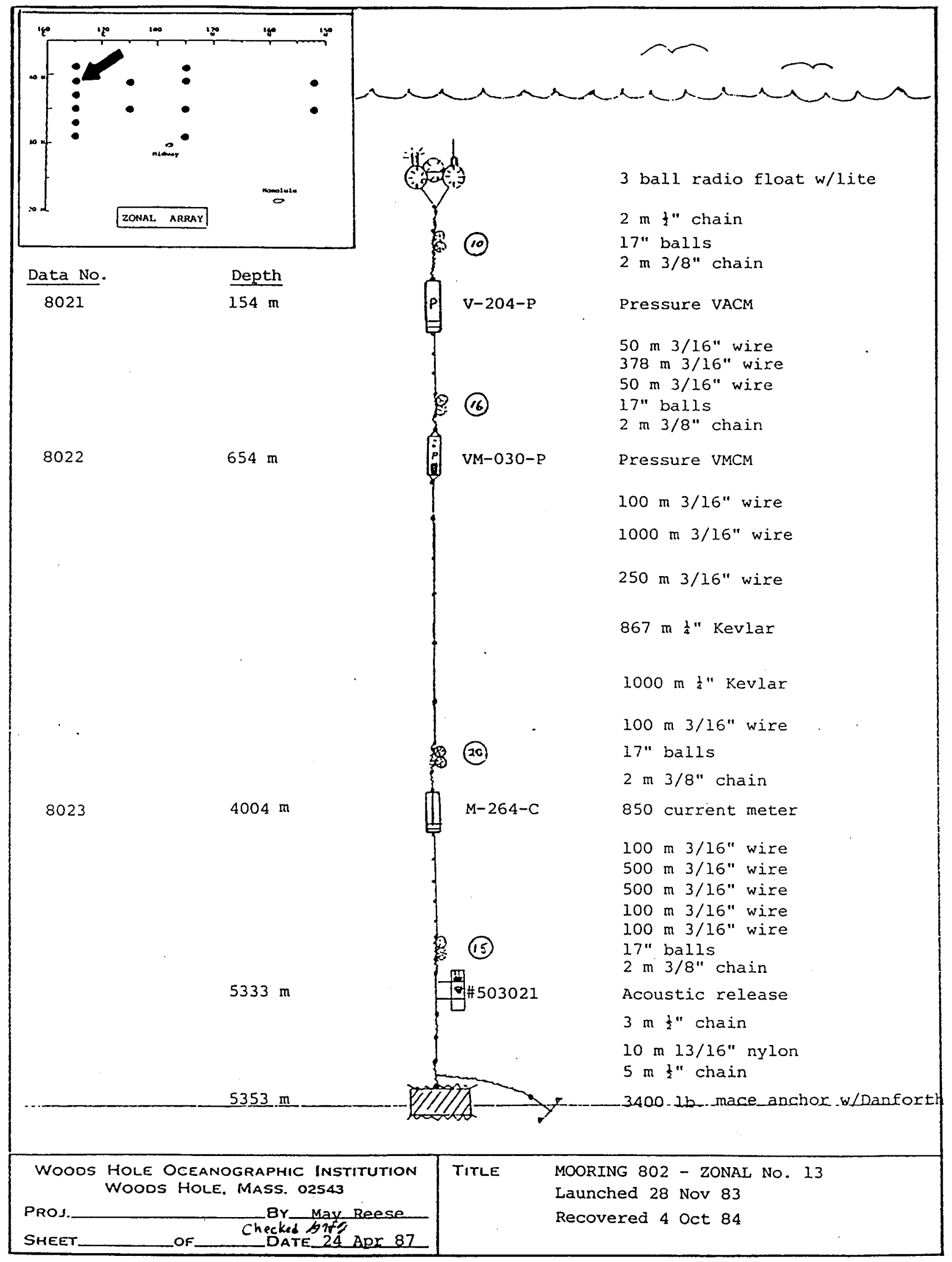

sp 112 ara

Fig. 2 Typical WHOI Intermediate Mooring 


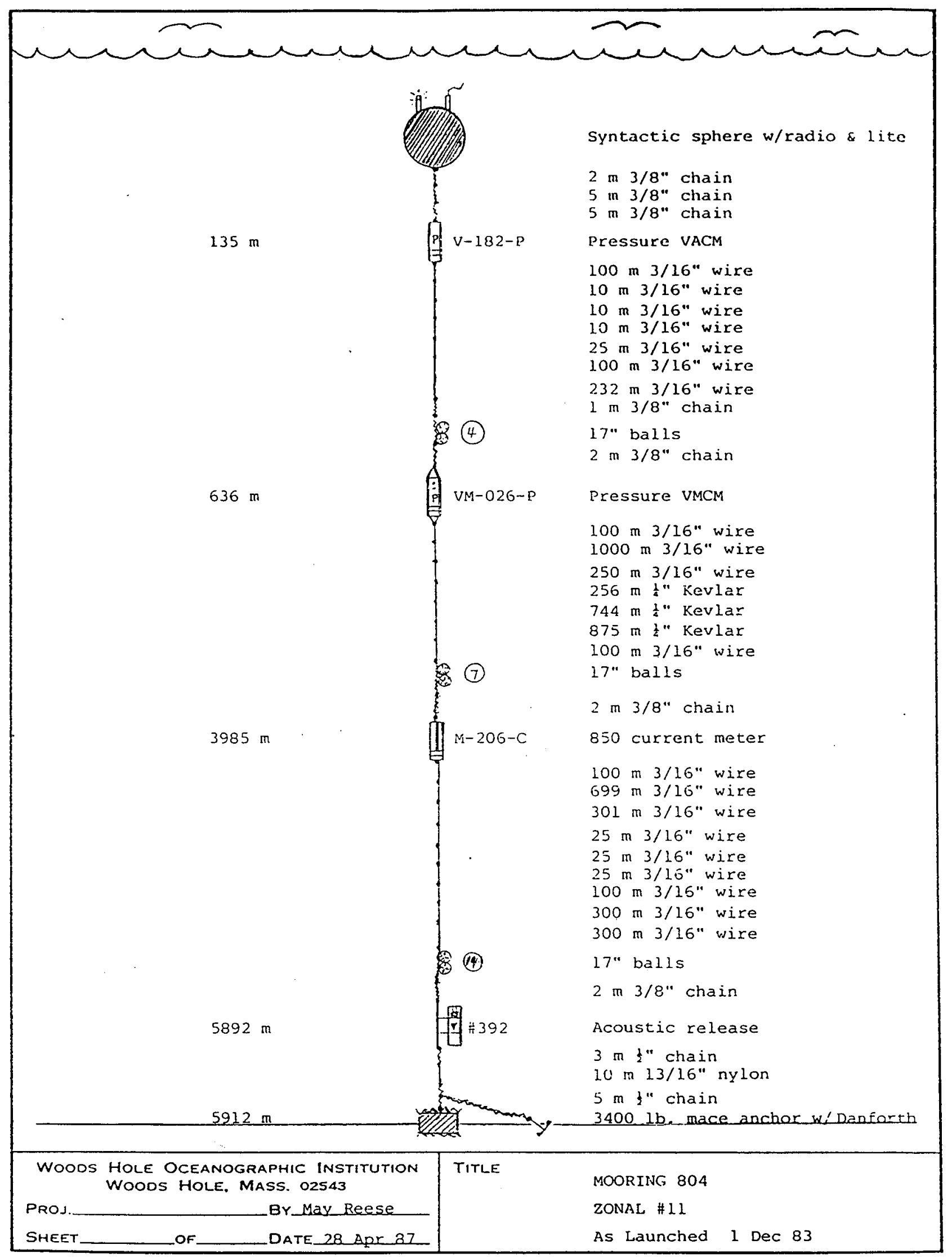

Fig. 3 Typical WHOI Syntactic Sphere Mooring 
polyethylene, with a nominal breaking strength of 4000 pounds. Below a depth of 2,000 meters these moorings used $1 / 4$ inch Kevlar, which has a nominal breaking strength of 6,000 pounds. Mooring components were connected with standard galvanized marine hardware, i. e.shackles, pear rings, eyebolts, etc. All mooring design, fabrication, launch, and recovery work was done by the WHOI Buoy Group. The ship used was the University of Washington's Research Vessel THOMAS G. THOMPSON.

A computer program entitled NOYFB (Moller, 1976) is used to design each mooring. This program mathematically constructs the mooring to the designer's specifications, subjects it to various current profiles, and predicts resultant performance. Two current profiles are usually tested. The first, or design current, represents the currents that the mooring will experience most of the time and must perform well in. The second is the worst case current profile that the mooring must be able to survive. Figures 4-6 show predicted performance of selected moorings from the array.

A total of fourteen moorings were deployed at mid-latitudes along four lines of longitude, $165^{\circ} \mathrm{E}, 175^{\circ} \mathrm{E}, 175^{\circ} \mathrm{W}$ and $152^{\circ} \mathrm{W}$ (Fig 7). All were launched for the first time in the fall of 1983. The two moorings along $152^{\circ} \mathrm{W}$ were of two years duration, and were recovered in the fall of 1985. The other twelve moorings were recovered after one year on station in october, 1984, re-deployed for another year, and recovered in the fall of 1985 during the same cruise the two-year moorings were recovered. Mooring drawings with nominal positions and launch and recovery 


\section{ZONAL MOORING NO. 2 PERFORMANCE}

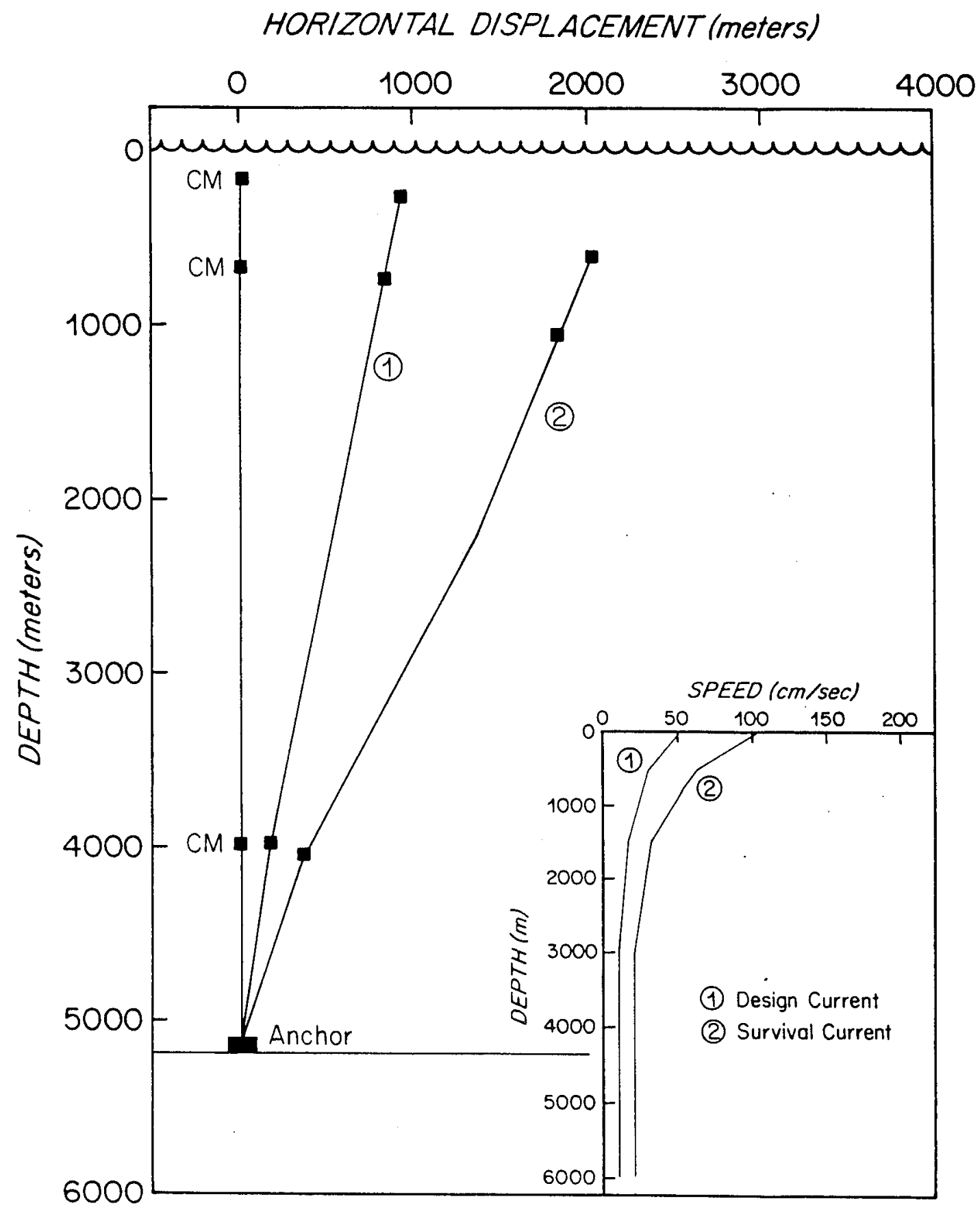

Fig. 4 Intermediate Mooring Performance - Eastern Current Profile 


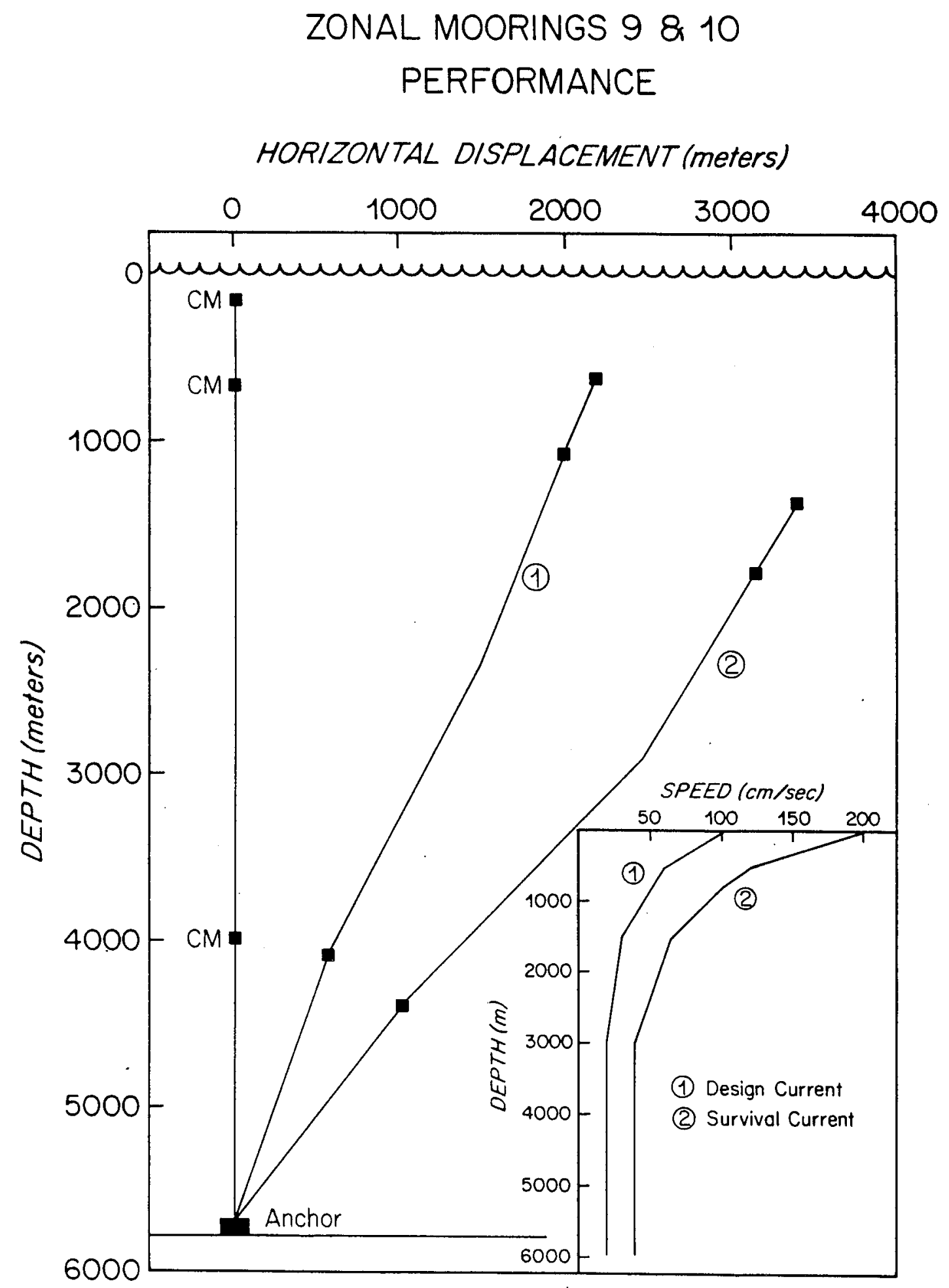

Fig. 5 Intermediate Mooring Performance - Western Current Profile 


\section{ZONAL MOORING NO. 11 PERFORMANCE}

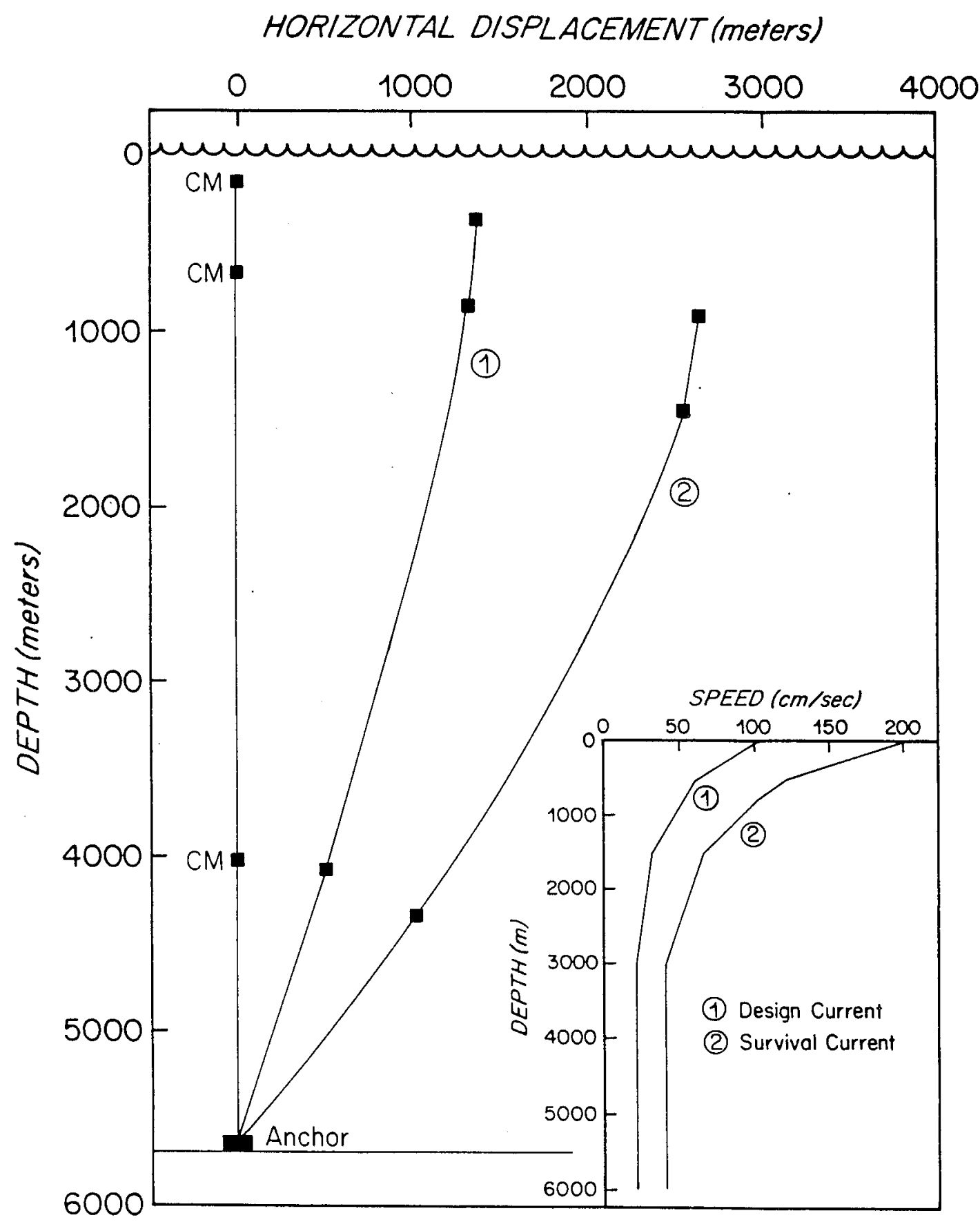

Fig. 6 Syntactic Sphere Mooring Performance - Western Current Profile 


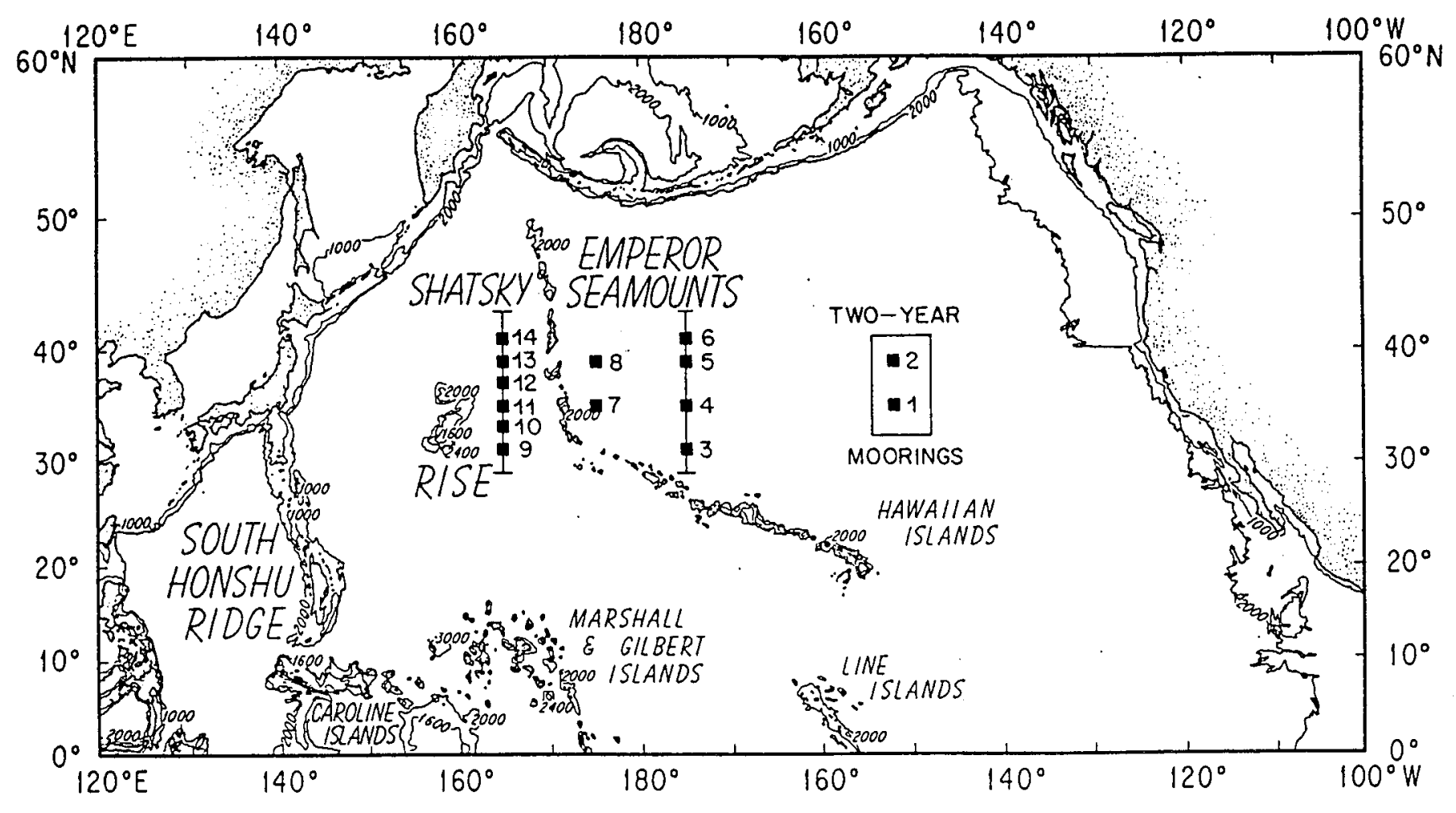

Fig. 7 ZONAL Mooring Array 


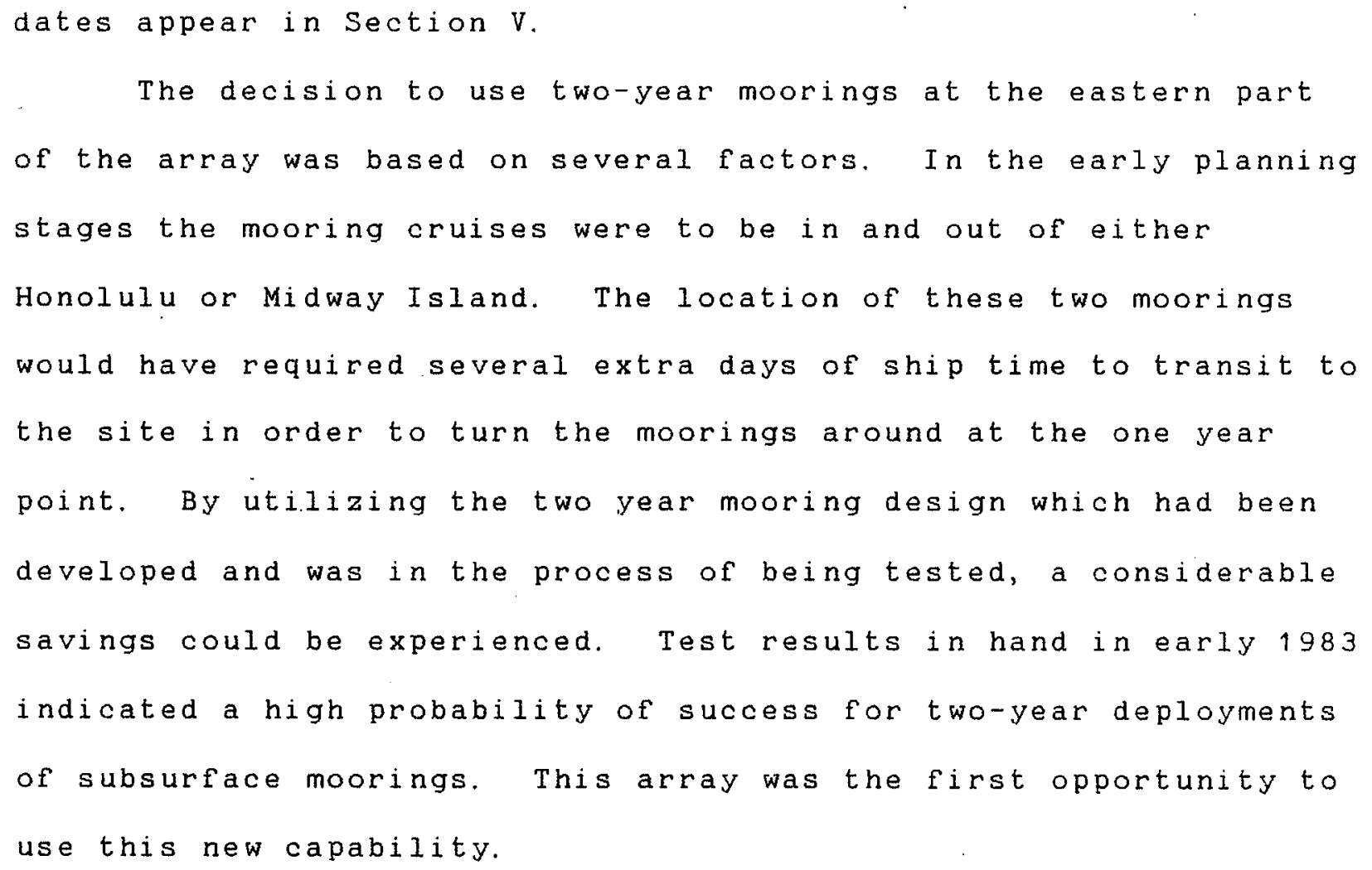




\section{B. Instrumentation}

Three types of current/temperature meters were used on the ZONAL moorings. They were Vector-Averaging Current Meters ( VACM), Vector-Measuring Current Meters (VMCM), and Geodyne Model 850 Current meters (850). The VACM and VMCM are manufactured by E.G. \& G. Sealink Systems. The 850 was built in the early'60s by Geodyne, a company which was later bought by E. G. \& G. There were 19 VACMs, 7 VMCMs, and 16850 s on the first setting of the ZONAL array. The second setting consisted of 25 VACMs, 7 VMCMs, and $10850 \mathrm{~s}$. The top current meter, at the 150 meter level on each of the ZONAL moorings, measured pressure in. addition to current speed, direction, and temperature. The pressure measurement shows to what degree the mooring leans in the current. It is also useful for determining the actual depth of the current measurements, especially if the launch site is in an area of rough bottom topography where actual depth of the mooring anchor is uncertain. Some moorings also had pressuremeasuring current meters at the 650 meter level.

\section{Geodyne Mode1 850 Current Meter}

The 850 current meter (Fig 8) measures current flow using a Savonius rotor and a direction-sensing vane, both mounted in a protective cage below the electronics and battery housing. The pressure housing, made of 7075-T6 aluminum, has an inside 


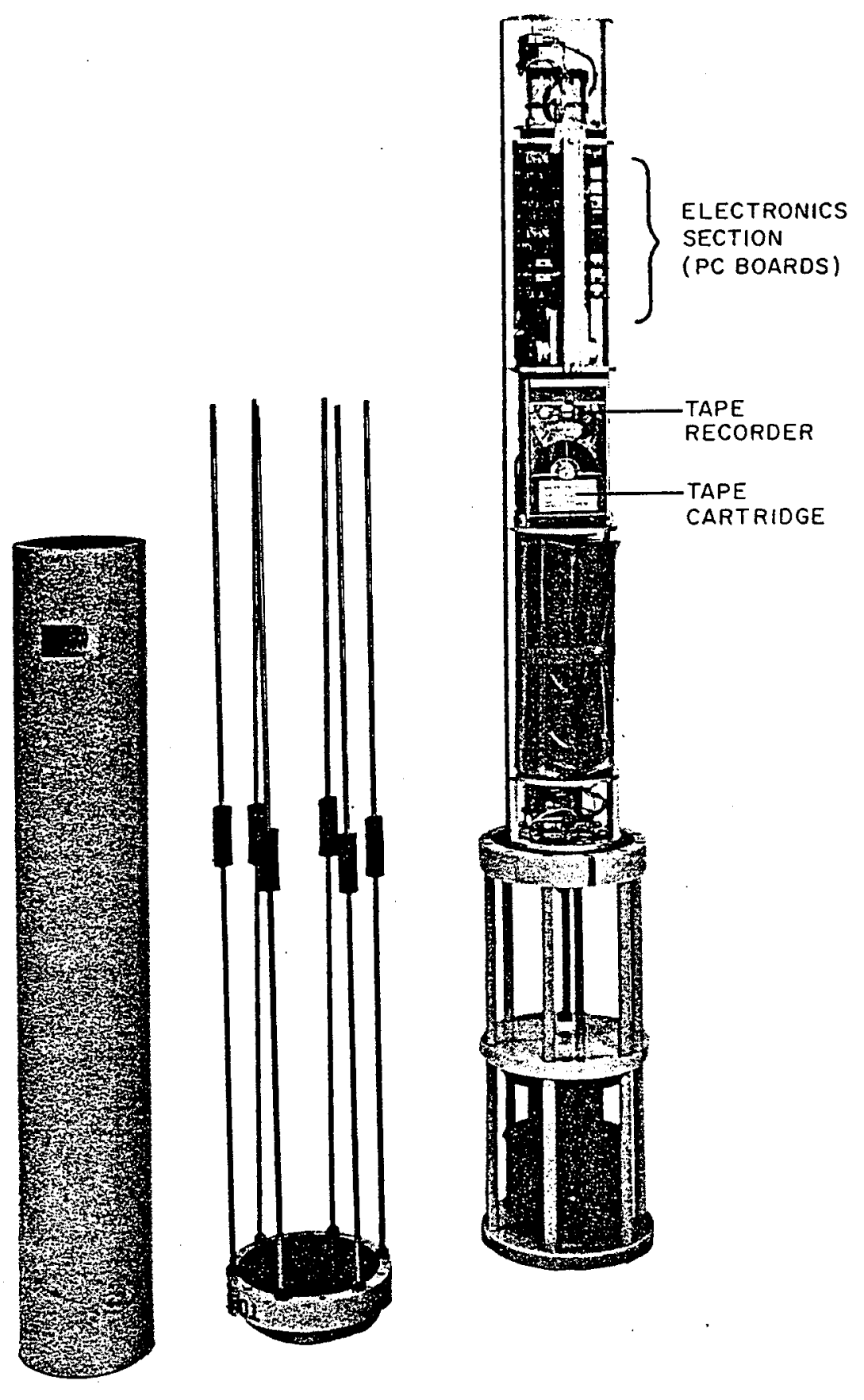

Fig. 8 Geodyne 850 Current Meter 
diameter of 6 inches and a wall thickness of $1 / 2$ inch, allowing deployments to a maximum pressure of 8,000 pounds per square inch (about 5300 meters). Maximum tensile load across the instrument is 5,000 pounds.

The Savonius rotor is an omnidirectional, cylindrical sensor which rotates about a vertical axis in response to the water flow. Sixteen magnets are equally spaced around the outer perimeter of the top plate of the rotor. As the rotor turns, a magnetic reed switch above it closes each time a magnet passes. The switch closures are counted for a specific time interval, 5. 191 seconds, giving the rotation rate.

The vane senses the current direction with respect to the instrument housing. Two parallel magnets are fitted to the top of the vane, and spaced equidistant from the center of rotation. Two parallel magnets with the same spacing from the center of rotation are enclosed in a fluid-damped vane follower inside the pressure case. They are magnetically coupled to the vane and free to rotate, "following" the vane. The vane follower's position is decoded by a 7-bit analog-to-digital converter, giving the direction of current flow with respect to the instrument housing. The housing's orientation with respect to magnetic north is measured by an internal fluid-damped, gimballed compass mounted in the top of the instrument. The compass position is also decoded by a 7-bit analog-to digital converter. The sum of the compass and vane readings is the direction TO HHICH the current is flowing (as opposed to conventional wind measurements, in which the wind is measured FROM a particular direction). 
Water temperature is measured by a thermistor, a device

whose electrical resistance varies with changes in temperature. Mounted on the bottom end plate of the instrument housing, the thermistor senses the temperature of the end plate. The end plate does not change temperature instantaneously with the temperature of the water but has a time constant of about two minutes.

Timekeeping and the initiation of each data recording cycle are controlled by a solid-state quartz clock. The accuracy of the clock is plus or minus 1 second per day.

The 850 is a burst-sampling current meter, meaning that a short burst of data is recorded periodically. The length of the burst, and the number of bursts sampled per unit time determine how long the instrument will run. The battery, consisting of four strings of 8 alkaline "D" cells, supplies enough energy to record a full data tape regardless of the sampling scheme selected. For this experiment one burst was recorded each hour, on the hour. The burst length was 80 seconds. The data record, or burst, for this experiment was composed of 15 "strobes" of data, gathered at the rate of one strobe each 5:27. seconds (Fig. 9). Each strobe contains thirty-two bits of information, divided into two 16-bit fields, the first of which is "rotor", the second is "compass/vane". The first two bits of each 16-bit field are zeroes, which leaves 14 bits in each field for data. The first two strobes of each record are unique. The rotor field of the first strobe of each record contains a fourteen bit temperature word; the second strobe rotor field contains the 14 bit time 
TIME (hours)

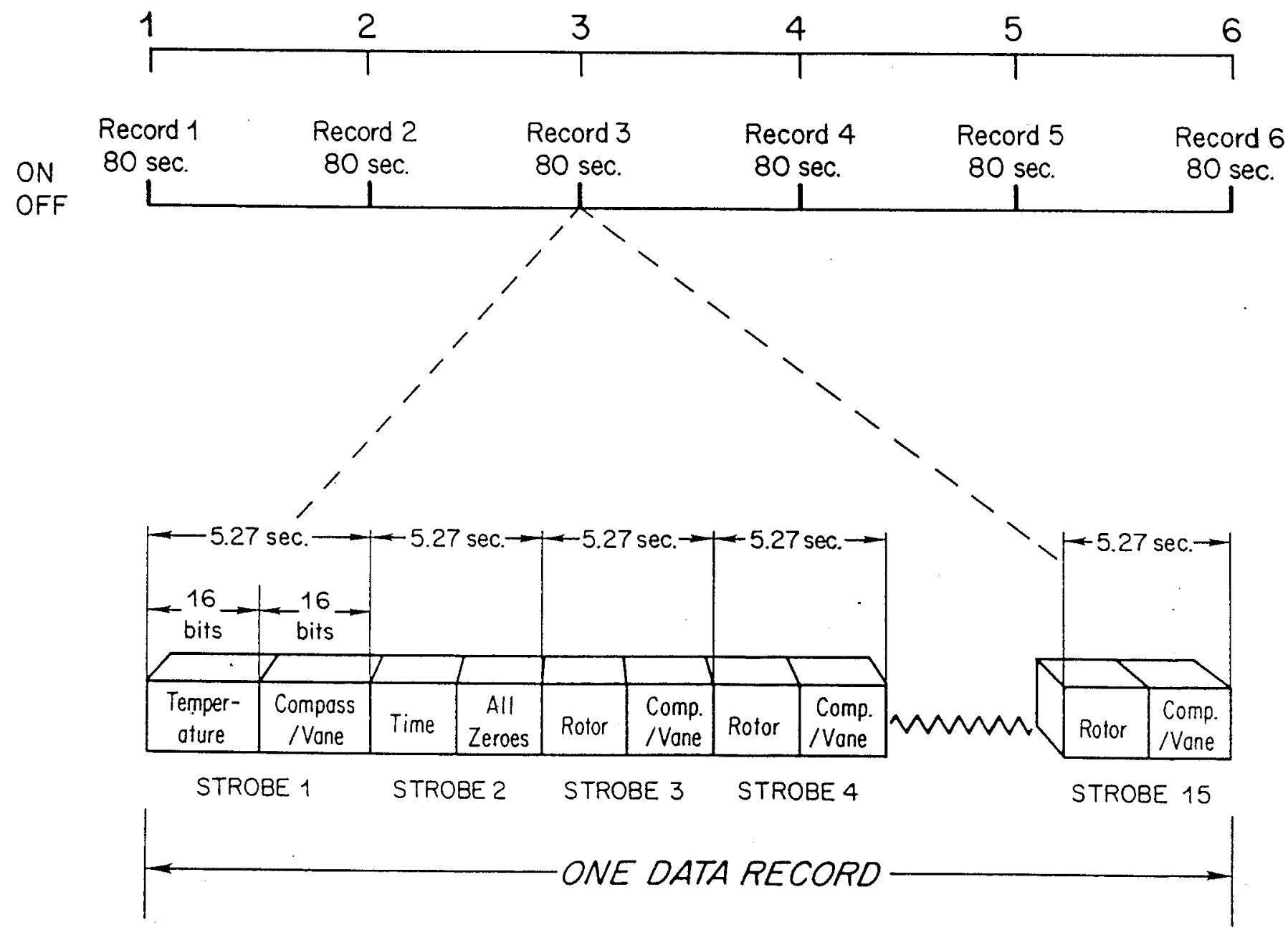

Fig. 9 Data Format, 850 Current Meter 
word. The time word is a binary value whose least significant bit has a weight of 15 minutes, the most significant bit representing 85 days and eight hours. Before deployment, the clock is reset to all zeroes at a known time. This time is logged on the data sheet. The clock counts up from the all zeroes condition, incrementing by one count each fifteen minutes. The burst sampling rate has no effect on the time word, i.e. if the record rate is one hour, the clock word will advance by 4 each record, indicating that one hour, or four 15-minute bits, has elapsed since the last recording cycle. If the record rate is 15 minutes, the clock word will increment by one, indicating that 15 minutes has elapsed since the last data record. The time word on tape indicates the time at which the current meter began its 80 second data recording cycle. Later, during the data processing, the "time of observation" of each record is adjusted to fall in the center of the 80 second sample period. For strobes 3 through 15, the format reverts to rotor-compass-vane, each set (strobe) sampled once every 5.27 seconds.

These data are recorded on an endless loop magnetic tape cartridge containing 400 feet of $1 / 4$ inch wide tape. The tape in an endless loop cartridge moves in one direction only, feeding from the center of the spool and taking up on the outside perimeter. The recorder is fitted with a two-track head. The data tracks are written one at a time; that is, the entire 400 feet of tape is written on track "A" first. At the end of track "A", the passage of an end-of-tape marker, a piece of metallic foil about an inch long glued onto the tape, is sensed by the 
tape recorder, switching the data recording from track "A" to track "B". Recording then continues on track "B" until the foil is sensed again, but this time the foil sensor shuts the current meter off.

In this experiment, as in most others, the data sampling is chosen such that at the planned time of recovery, the current meter will still be running. This is done partly to guard against automatic shutoff malfunctions, but primarily to be able to "mark" the data record after recovery with known events, usually rotor spins, occurring at a known time, providing a check on the clock. Also, ship scheduling can change, affecting recovery schedules.

\section{Vector-Averaging Current Meter (VACM)}

The VACM (Fig. 10), designed at WHOI, uses the same vane and Savonius rotor as the 850 . The instrument housing and the rotor/vane protective cage assembly, however, are much stronger, allowing a 10,000 pound tensile load across the instrument, compared to 5,000 pounds for the 850 . The pressure housing, made of 7075-T6 aluminum, has an inside diameter of 6 inches and a wall thickness of $3 / 4$ inch, allowing deployment to a maximum pressure of 10,000 pounds per square inch (about 6, 700 meters). Inside the pressure case, the VACM compass and vane follower are similar to those used in the 850. They are housed in aluminum cases, however, and contain no damping fluid. Damping is accomplished by the eddy currents of the moving magnets interacting with the aluminum housing. The analog to digital conversion of the compass and vane readings still utilizes a 7- 

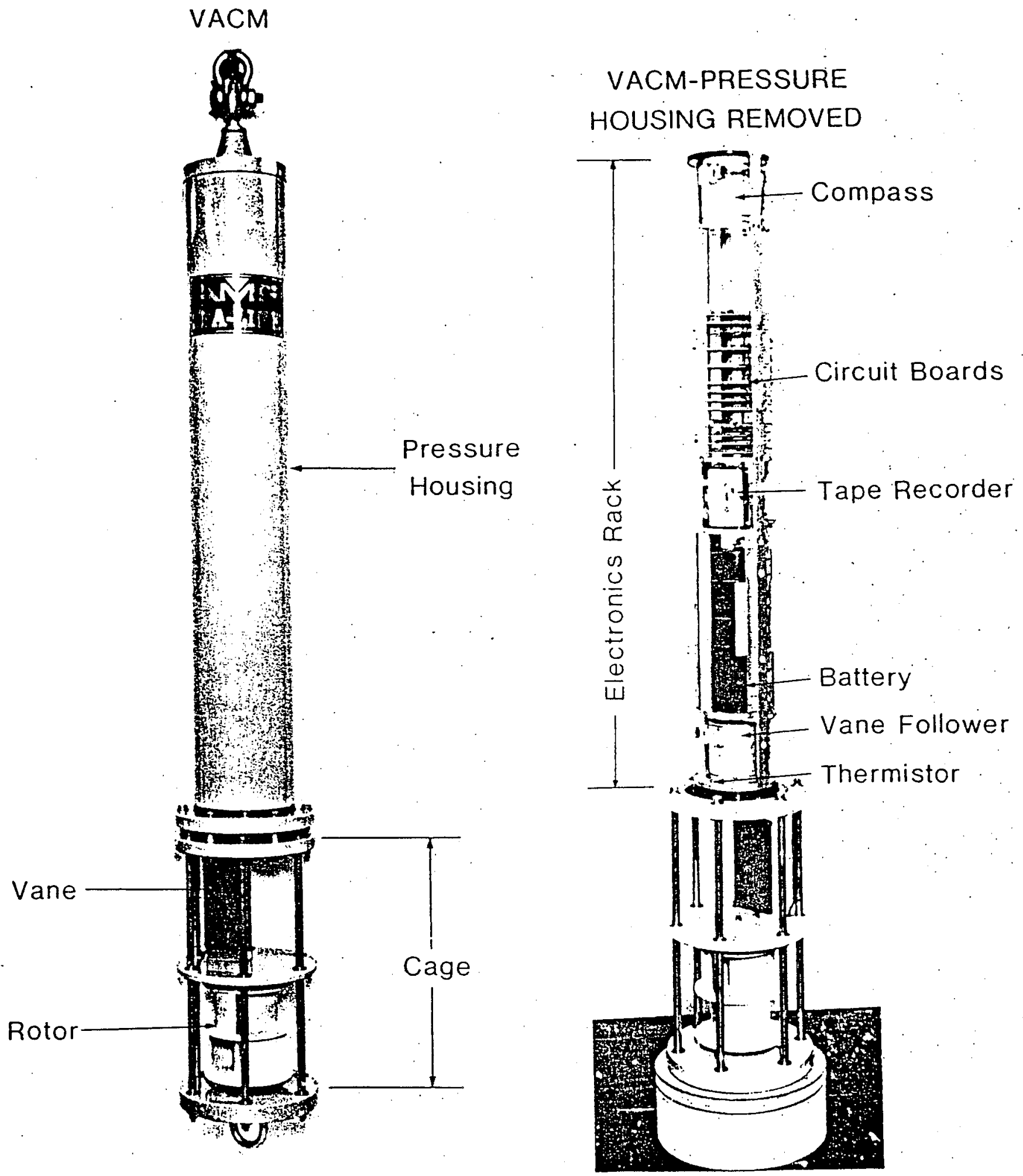

Fig. 10 Vector-Averaging Current Meter (VACM) 
bit converter, but with solid-state components capable of very high interrogation rates. The compass or vane follower can be read at rates up to 100,000 times per second.

The rotor motion is sensed by a magneto-diode rather than a mechanical reed switch. The magneto-diode is a solid-state device whose resistance to electrical current flow changes when a magnetic field is close by. The 16 magnets on the top rim of the rotor are oriented with alternate north and south poles on the outside edge. Each time a north and south magnet passage is sensed, the current meter begins a computation cycle. In other words, each time the rotor rotates one-eighth of a turn, corresponding to the passage of $4.6 \mathrm{~cm}$ of water, the instrument goes through a cycle which reads the compass, reads the vane, and adds the two numbers to get a resultant flow direction for that 4. $6 \mathrm{~cm}$ water parcel. The vector computer then converts the direction from polar coordinates to cartesian coordinates, resulting in a signed value of $x$ and $y$, or east and north, for the direction of that parcel of water. These values are stored in the east and north memory registers, respectively, completing the data cycle. On the next $1 / 8$ turn of the rotor, the cycle repeats, and the new values of east and north are added to those already in the storage registers. This summing process continues over a specific time interval, called the record interval - in the ZONAL experiment, 15 minutes lexcept for the two-year VACMs, which had a record rate of $1 / 2$ hourl. At the end of the record interval, the sums are written to tape, the East and North registers are reset to zero, and the process begins again. For 
example, if the current speed averaged one-half knot ( $25 \mathrm{~cm} / \mathrm{sec})$ during the fifteen minute record interval, the vector averaged current recorded for that interval would be the sum of 4,891 computation cycles.

Each tape record also contains a single instantaneous reading of the compass and vane follower. Since only the vector-averages are saved and the raw data is lost, sensor malfunctions would be more difficult to identify. For instance, if the compass were to stick (remain in one position), and the vane still functioned normally, it would be difficult to determine from the data which sensor was malfunctioning. Actually, if the instrument were not near another one, it might be impossible to detect any malfunction at all. This is why one compass and vane follower value are written each record interval.

Like the 850, temperature is sensed by a thermistor mounted in the bottom end plate of the instrument. Unlike the 850 , however, the thermistor is measured over the entire record interval rather than burst-sampled.

The record cycle is initiated by the clock circuit. Like the 850, the clock is quartz-controlled, with a maximum drift of plus or minus 1 second per day. It also has a register containing a time word which is part of the data record, identifying the time at which the record was written on tape. Since the data in a record has been accumulating for the fifteen minute period preceding the writing of that record on tape, the time of observation is adjusted backward during the data processing by 7.5 minutes to coincide with the mid-point of the vector-averaging period. Before deployment, the clock is reset 
to the all-zeroes condition at a known time and counts up incrementally from there. The time word is sixteen bits long the least significant bit representing a time increment of 7.5 minutes, each succeeding bit representing double the preceding value, with the most significant bit equaling 170 days, 16 hours.

The data is recorded on a standard digital 300 foot cassette in a four-track format. The standard record length is 32 characters, of four bits each for a total of 128 bits. At a fifteen-minute record rate, the cassette will hold 500 days of data. East, North, Rotor, and Temperature each are 24 bits long. The Time (clock) field and Compass/Vane field are each 16 bits long. The order of the variables on tape is: East, North, Rotor, Compass/Vane, Time, Temperature. Extra variables on a non-standard data record, Pressure, for instance, are added to the end of the data stream. The data format for the pressurerecording VACMs on ZONAL is East, North, Rotor, Compass/Vane, Time, Temperature, and Pressure, for a total of thirty-eight data characters.

Power for the VACM is supplied by an alkaline battery pack containing 70 "D" cells connected to provide voltages of +21 , -24 , and +18 volts. Maximum deployment time using this battery is 18-20 months, regardless of the record rate selected.

The two-year VACM power supply is a lithium thionyl-chloride battery built by GTE. Lifetime of this battery is two and onehalf years. 
Vector-Measuring Current Meter (VMCM)

The VMCM sensor is quite different than the $850 /$ VACM. It uses two pairs of vertical propellers, oriented ninety degrees from each other (Fig 11). That is, if the axis of one propeller set were oriented East-West, the other axis would be oriented North-South. Developed at the Scripps Institution of Oceanography, (Weller and Davis, 1980) this instrument was designed to measure currents accurately in the presence of surface waves and vertical mooring motion. It is housed in a 7075-T6 aluminum tube with an inside diameter of 6 inches and a wall thickness of $3 / 4$ inch, allowing deployment to a maximum pressure of 10,000 pounds per square inch - about 6,700 meters. The tube is clamped into a frame made of type 316 stainless steel which can accommodate tensile loads up to 10,000 pounds. The propeller sets are designed with accurate co-sinusoidal response and correctly average fluctuating flow. There is no direction sensing vane, only an internal compass. Each propeller's rotation rate and direction of rotation are sampled four times per second by an internal microprocessor; the current direction and velocity are computed, converted to East and North components using the internal flux-gate compass as a reference, and summed into the East and North storage registers. At the end of the recording interval selected - fifteen minutes for the ZONAL experiment - the summed vector components and the total propelier values for each propelier set are written on tape. A clock record, instantaneous compass value, and temperature are also 


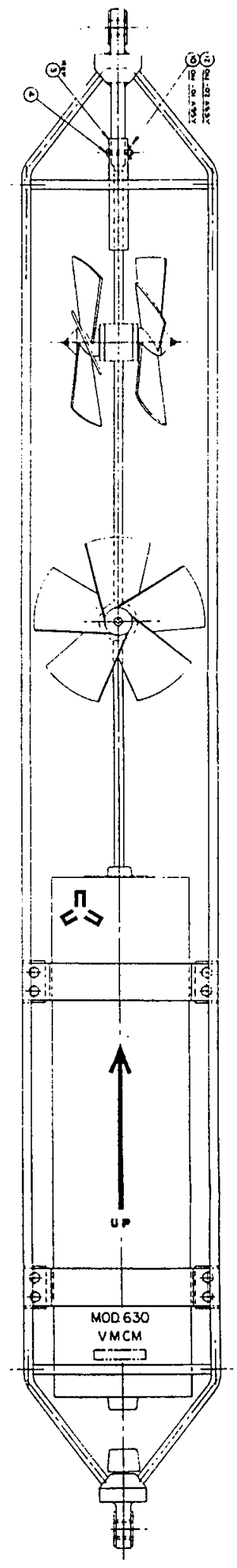

Fig. 11 Vector-Measuring Current Meter (VMCM) 
recorded.

Timing information and control are provided by a quartz crystal controlled clock, like the other two current meter types. This clock, however, is different in that it increments by one per record regardless of the recording rate selected. Expressed another way, the least significant bit of the 16-bit time word represents the record interval; if the record rate is once per hour, the clock LSB increments once per hour... if the record rate is seven and one-half minutes, the time word increments by one each seven and one-half minutes, or 8 times per hour. The clock actually functions more as a record counter than as a clock.

Temperature, as in the other two instrument types, is measured by a thermistor mounted in the end cap of the current meter. The time constant of the end cap is approximately two minutes. The thermistor is sampled for a very short period of time, 33 milliseconds, at the beginning of each tape recording cycle.

Of the seven VMCMs used in the first year's ZONAL deployment, three were modified to record pressure. The second year's deployment also used seven VMCMs with five modified to record pressure.

The VMCM is unique among the three types of instruments used in ZONAL in that the data can be accessed by a portable computer or terminal using a connector in the top end cap, thereby allowing verification of proper operation immediately before launch or after recovery without having to open the pressure case. 
Because the VMCMs were new to us and their reliability was not well known, they were deployed at the 650 meter level in the array, a level given a lower priority by the principal Investigator. 


\section{CRUISES}

The ZONAL array was deployed in the autumn of 1983 , turned around (recovered and re-deployed) one year later, and recovered for the final time in the fall of 1985. The same ship was used for all three cruises, the R/V THOMAS G. THOMPSON, operated by the University of Washington in Seattle.

Each cruise consisted of two legs, with part or all of the science party being replaced between legs. The mid-cruise stop for the 1983 and 1984 cruises was Midway Island. In addition to science party changes, mooring anchors for the next leg of the cruise were loaded. at Midway, as the ship could not hold all sixteen anchors (fourteen plus two spares) plus the rest of the mooring equipment and instrumentation. The mid-cruise stop for the 1985 cruise was Honolulu.

\section{Cruise -17 oct -10 Dec 83}

The 1983 cruise had as a primary goal the deployment of an array of fourteen subsurface moorings with forty-two current meters for Dr. William J. Schmitz, Jr. A secondary goal was an XBT and CTD section along two lines of longitude, $175^{\circ} \mathrm{W}$. and $165^{\circ}$ E. from 29 to 43 degrees North for Dr. Terrence Joyce of WHOI. This data is not discussed in this report. A tertiary goal was the recovery of four subsurface moorings (Fig. 12-15) for Dr. Bruce Taft and Dr. Gunnar Roden of the University of Washington, plus CTD work near the moorings and an XBT survey of. the Kuroshio Extension downstream of the southern pair of moorings. 


\section{Leq I.}

The R/V THOMAS G. THOMPSON sailed from seattle on cruise number 177 on october 17, 1983 at 0900 local time. The ship headed southwest toward the site of the first mooring to be launched, at $39^{\circ} \mathrm{N} ., 152^{\circ} \mathrm{W}$, arriving on 24 october. Enroute, the ship was slowed by heavy seas. The entire 1983 cruise was to be plagued with much rough weather, causing numerous injuries and making the deck work difficult.

ZONAL mooring no. 2 (Buoy Group station No. 793), the Group's first mooring intended for a deployment duration of two years, was launched on 24 october. ZONAL no. 1, (B. G. Station No. 794), the second two-year mooring, was launched on October $25 \mathrm{th}$.

The ZONAL mooring numbers, 1-14, were assigned to the moorings of the array during the design process as a means of identification. The Buoy Group Station numbers, on the other hand, are used as a data tracking tool and are assigned sequentially, as each mooring is launohed. Mooring 793, for example, is the seven hundred ninety-third mooring the group has launched since its inception. Each current meter data tape is identified using the mooring number and a suffix indicating the instrument's relative vertical, position on the mooring. For instance, the data number of the top current meter on mooring 793 would be 7931 ; the third current meter from the top on mooring number 823 would have a data number of 8233 , and so on. 
From mooring 794 , the ship headed northwest towards $42^{\circ} \mathrm{N}$, , $175^{\circ}$ H., the site of the first CTD station. CTD stations and positions appear in Table 2. After CTD Station No. 9, 2,000 meters of nearly new CTD wire had to be cut off due to an electrical short. This limited the maximum depth of CTD station No's 10-26 to 5, 300 meters. A new reel of CTD wire was airfreighted to Midway Island for use on leg II.

Moorings 795-798 were launched without incident as the ship proceeded south along the CTD section, although during the launch of mooring 796 , the wind was gusting over sixty knots, and the Chief Scientist described the fantail as "very lively".

After the last CTD, at $28^{\circ} \mathrm{N} ., 175^{\circ} \mathrm{W}$, the ship headed southwest to Midway Island, arriving on 8 November, 1983.

Table 3 summarizes the leg I mooring work. Science personnel appear in Table 4.

\section{Leg II.}

Leg II of the ' 83 ZONAL cruise departed Midway Island at 1800 local time on November 10, 1983. The ship proceeded northwesterly to the first of six CTD stations planned near the Taft moorings $A$ and $B$ (Figs. 12 and 13 ). See also cruise track (Fig 17). CTD work and initial mooring work went well, but the second mooring, Mooring A, had serious problems.

The acoustic release fired normally and the mooring began to ascend. Before anything appeared on the surface, however, the ascent of the release stopped. Range to the release was minimized by moving the ship but three kilometers was the minimum range obtainable. The most logical conclusion seemed to be 
Table 2

CTD Stations taken on Leg I of ZONAL Pacific Cruise, Fall 1983

\begin{tabular}{|c|c|c|c|c|c|c|c|c|c|}
\hline $\begin{array}{l}\text { Station } \\
\text { No. }\end{array}$ & $D A$ & MO & YR & $\begin{array}{l}\text { Start } \\
\text { Time } \\
\text { (GMT) }\end{array}$ & $\begin{array}{l}\text { Stop } \\
\text { Time } \\
\text { (GMT) }\end{array}$ & $\begin{array}{c}\text { North } \\
\text { Latitude }\end{array}$ & $\begin{array}{r}W \\
\text { Lone }\end{array}$ & $\begin{array}{l}\text { lest } \\
\text { jitude. }\end{array}$ & $\begin{array}{l}\text { Pressure } \\
\text { Maximum } \\
\text { (Decibars) }\end{array}$ \\
\hline 3 & 30 & 10 & 83 & 224 & 424 & 4245.01 & 175 & 0.02 & 6275.0 \\
\hline 4 & 30 & 10 & 83 & 1231 & 1410 & $42 \quad 0.07$ & 175 & 0.06 & 6039.0 \\
\hline 5 & 30 & 10 & 83 & 2148 & 2318 & 4115.08 & 174 & 59.99 & 5989.0 \\
\hline 6 & 31 & 10 & 83 & 1210 & 1335 & 4030.00 & 174 & 59.99 & 5915.0 \\
\hline 7 & 31 & 10 & 83 & 2025 & 2214 & 3944.96 & 175 & 0.00 & 5997.0 \\
\hline 8 & 1 & 11 & 83 & 533 & 708 & $39 \quad 0.00$ & 175 & 0.00 & 5747.0 \\
\hline 9 & 1 & 11 & 83 & 1948 & 2137 & $38 \quad 15.06$ & 175 & 0.30 & 5797.0 \\
\hline 10 & 2 & 11 & 83 & 1817 & 1930 & 3729.98 & 175 & 0.10 & 4013.0 \\
\hline 11 & 3 & 11 & 83 & 38 & 149 & $36 \quad 45.13$ & 174 & 59.96 & 5071.0 \\
\hline 12 & 3 & 11 & 83 & 941 & 1105 & $\begin{array}{ll}36 & 0.01\end{array}$ & 175 & 0.01 & 4983.0 \\
\hline 13 & 3 & 11 & 83 & 1515 & 1636 & $35 \quad 39.98$ & 175 & 0.02 & 4573.0 \\
\hline 14 & 3 & 11 & 83 & 2103 & 2250 & $\begin{array}{ll}35 & 19.94\end{array}$ & 175 & 0.22 & 5315.0 \\
\hline 15 & 4 & 11 & 83 & 414 & 547 & $\begin{array}{ll}35 & 0.00\end{array}$ & 175 & 0.30 & 5217.0 \\
\hline 16 & 4 & 11 & 83 & 1500 & 1628 & $34 \quad 40.14$ & 174 & 59.88 & 5265.0 \\
\hline 17 & 4 & 11 & 83 & 2035 & 2222 & $34 \quad 20.00$ & 174 & 59.87 & 5153.0 \\
\hline 18 & 5 & 11 & 83 & 244 & 409 & $\begin{array}{ll}34 & 0.12\end{array}$ & 174 & 59.94 & 5169.0 \\
\hline 19 & 5 & 11 & 83 & 954 & 1132 & $33 \quad 14.98$ & 174 & 59.91 & 5479.0 \\
\hline 20 & 5 & 11 & 83 & 2149 & 2228 & $32 \quad 29.96$ & 175 & 0.06 & 1919.0 \\
\hline 21 & 6 & 11 & 83 & 316 & 506 & 3144.35 & 174 & 59.00 & 5275.0 \\
\hline 22 & 6 & 11 & 83 & 1021 & 1139 & $30 \quad 59.92$ & 175 & 0.06 & 5213.0 \\
\hline 23 & 6 & 11 & 83 & 2235 & 30 & $30 \quad 15.00$ & 175 & 0.00 & 5287.0 \\
\hline 24 & 7 & 11 & 83 & 534 & 738 & 2930.03 & 175 & 0.07 & 5271.0 \\
\hline 25 & 7 & 11 & 83 & 1207 & 1332 & 28.45 .00 & 174 & 59.99 & 5261.0 \\
\hline 26 & 8 & 11 & 83 & 52 & 203 & $28 \quad 1.38$ & 175 & 0.11 & 5115.0 \\
\hline
\end{tabular}


Table 3

A Summary of the mooring work conducted during Leg I

of the $R / V$ Thomas G. Thompson Cruise Number 177

Moorings Deployed

№.

Date Launched

Position

793

24 Oct 83

$38^{\circ} \quad 57.57^{\prime} \mathrm{N}$

$152^{\circ} 01.82^{\prime} \mathrm{W}$

794

25 Oct 83

$35^{\circ} 00.57^{\prime} \mathrm{N}$

$152^{\circ} 00.67^{\prime} \mathrm{W}$

795

31 Oct 83

$41^{\circ} 02.00^{\prime} \mathrm{N}$

$175^{\circ} 00.97^{\prime} \mathrm{W}$

796

1 Nov 83 .

$38^{\circ} 56.92^{\prime} \mathrm{N}$

$174^{\circ} 55.09^{\prime} \mathrm{W}$

797

4 Nov 83

$35^{\circ} 01.59^{\prime} \mathrm{N}$

$174^{\circ} 58.29^{\prime} \mathrm{W}$

798

6 Nov 83

$31^{\circ} 00.75^{\prime} \mathrm{N}$

$175^{\circ} 03.10^{\prime} \mathrm{W}$ 


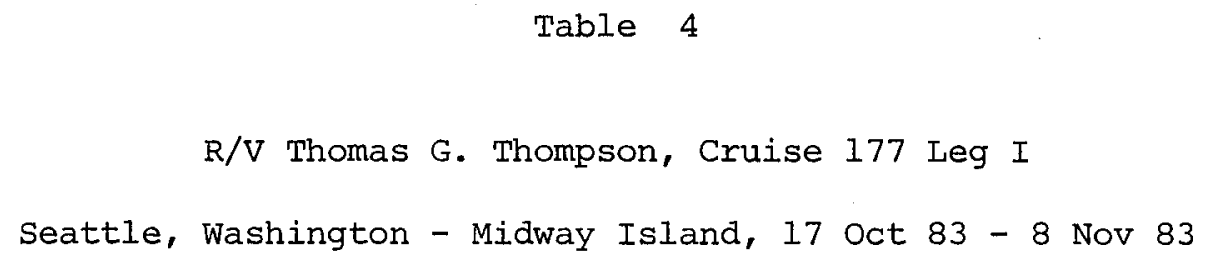

1. Alfred J. Ciesluk

2. William M. Ostrom

3. John N. Kemp

4. William H. Horn

5. Brian F. Skelly

6. Roderigue A. LaRochelle

7. Marvel C. Stalcup

8. Robert C. Millard, Jr.

9. Emile M. Bergeron

10. Margaret M. Francis.

11. Thomas Leahman
Chief Scientist WHOI

Mooring Supervisor WHOI

Mooring Technician WHOI

Current Meter Technician WHOI

Current Meter Technician WHOI

Release Technician WHOI

CTD Technician WHOI

CTD Technician WHOI

CTD Technician WHOI

CTD Technician WHOI

Marine Technician University of Washington 


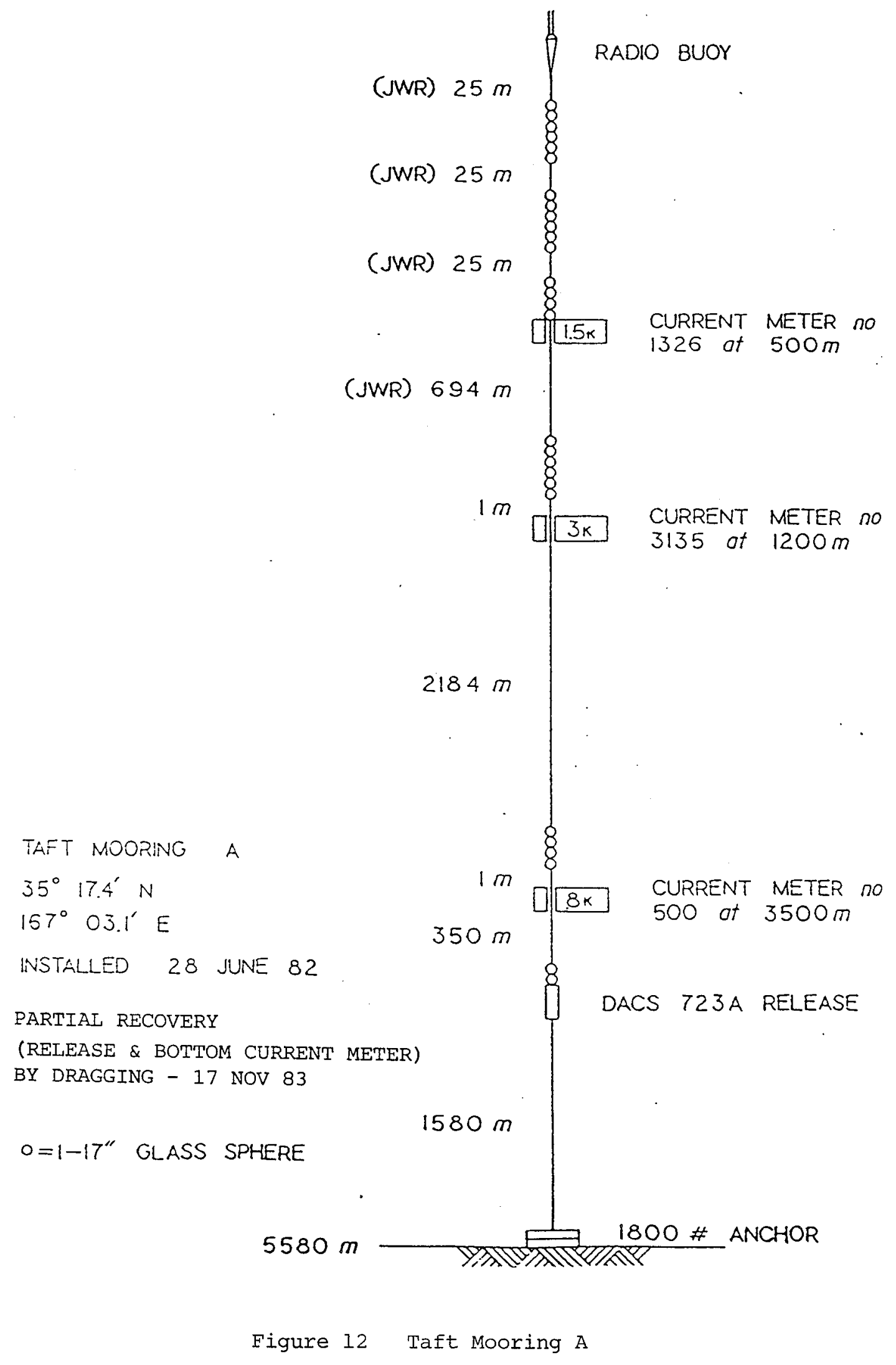




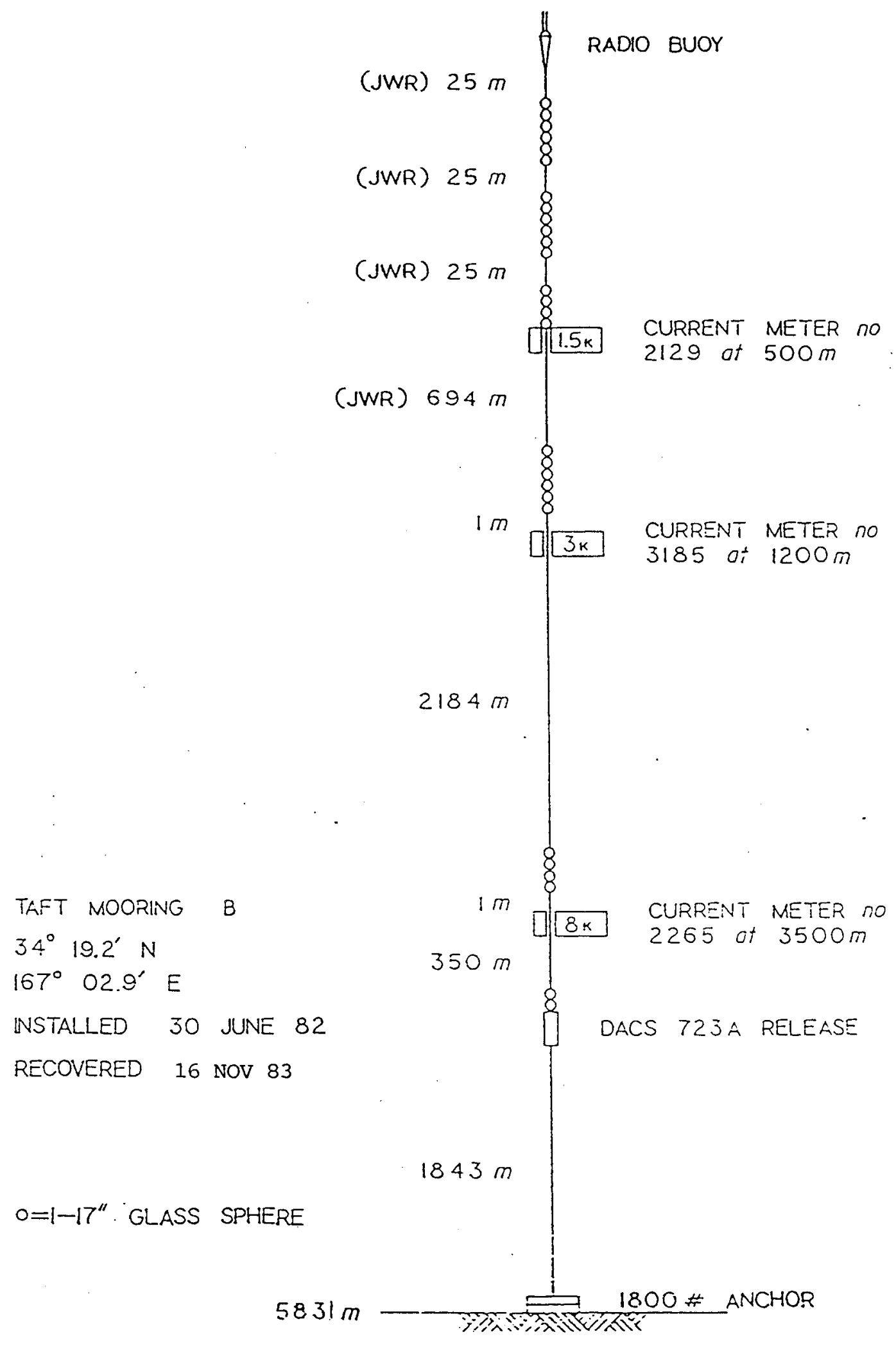

Figure 13 Taft Mooring B 


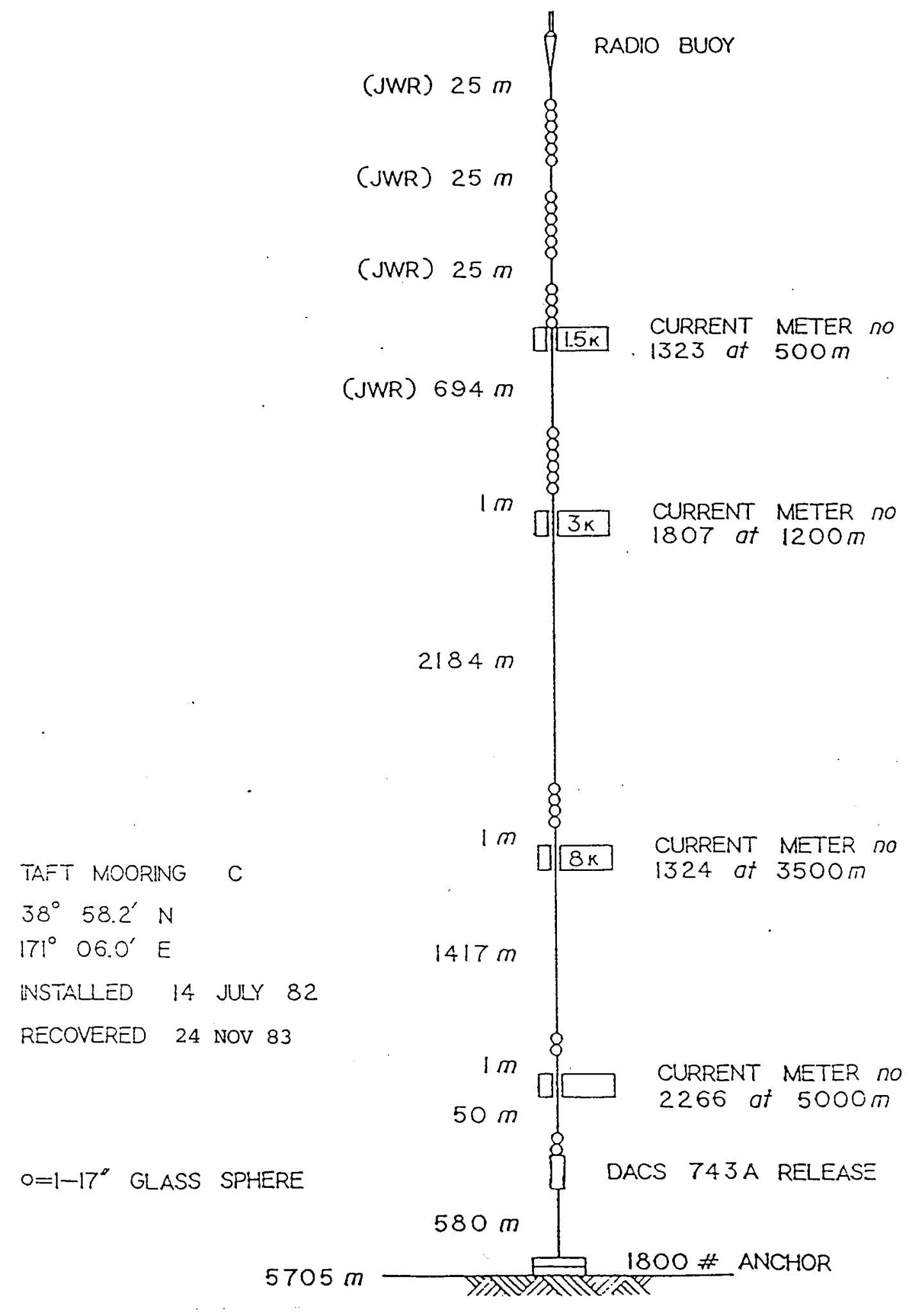

Figure 14 Taft Mooring C 


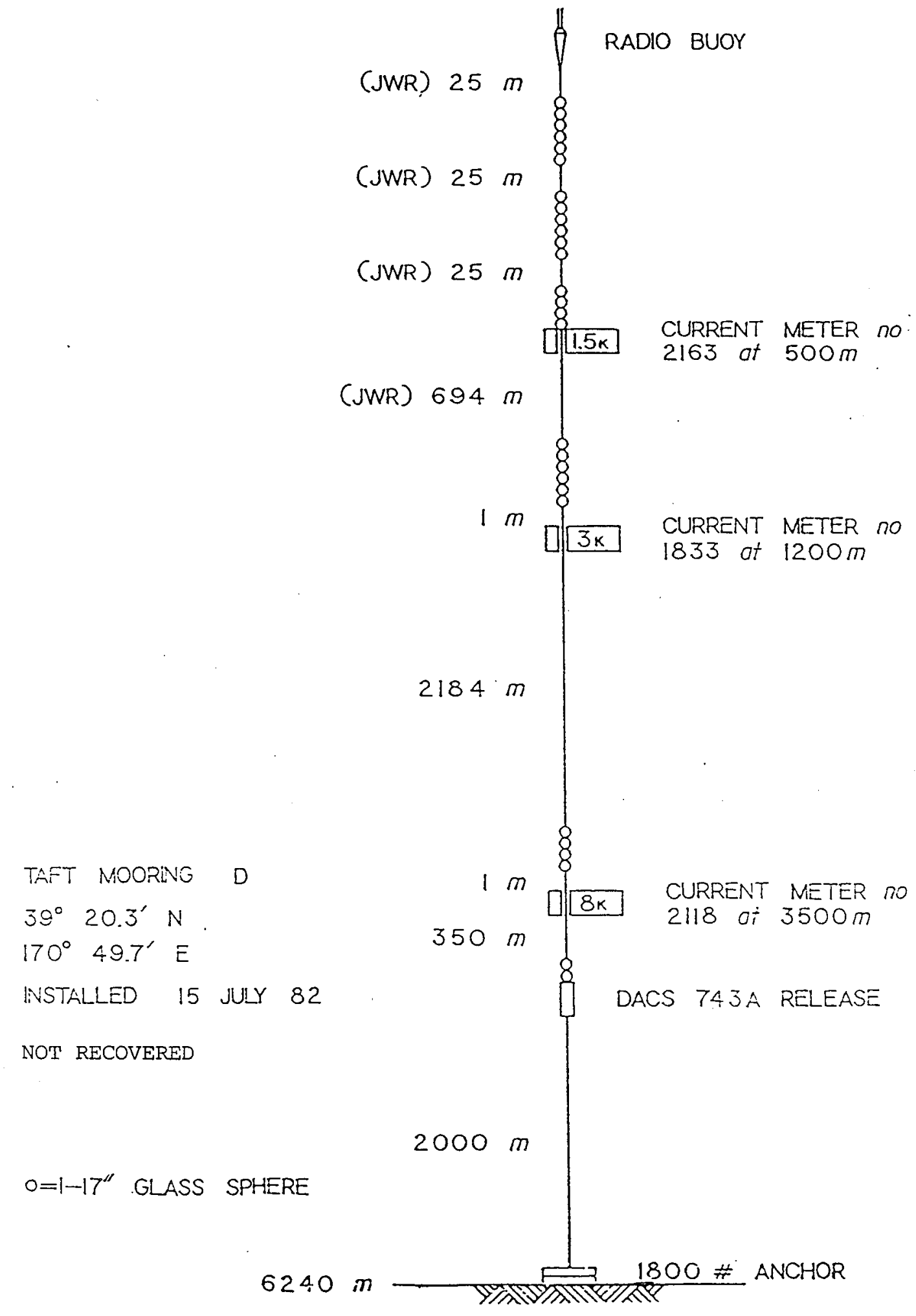

Figure 15 Taft Mooring D 


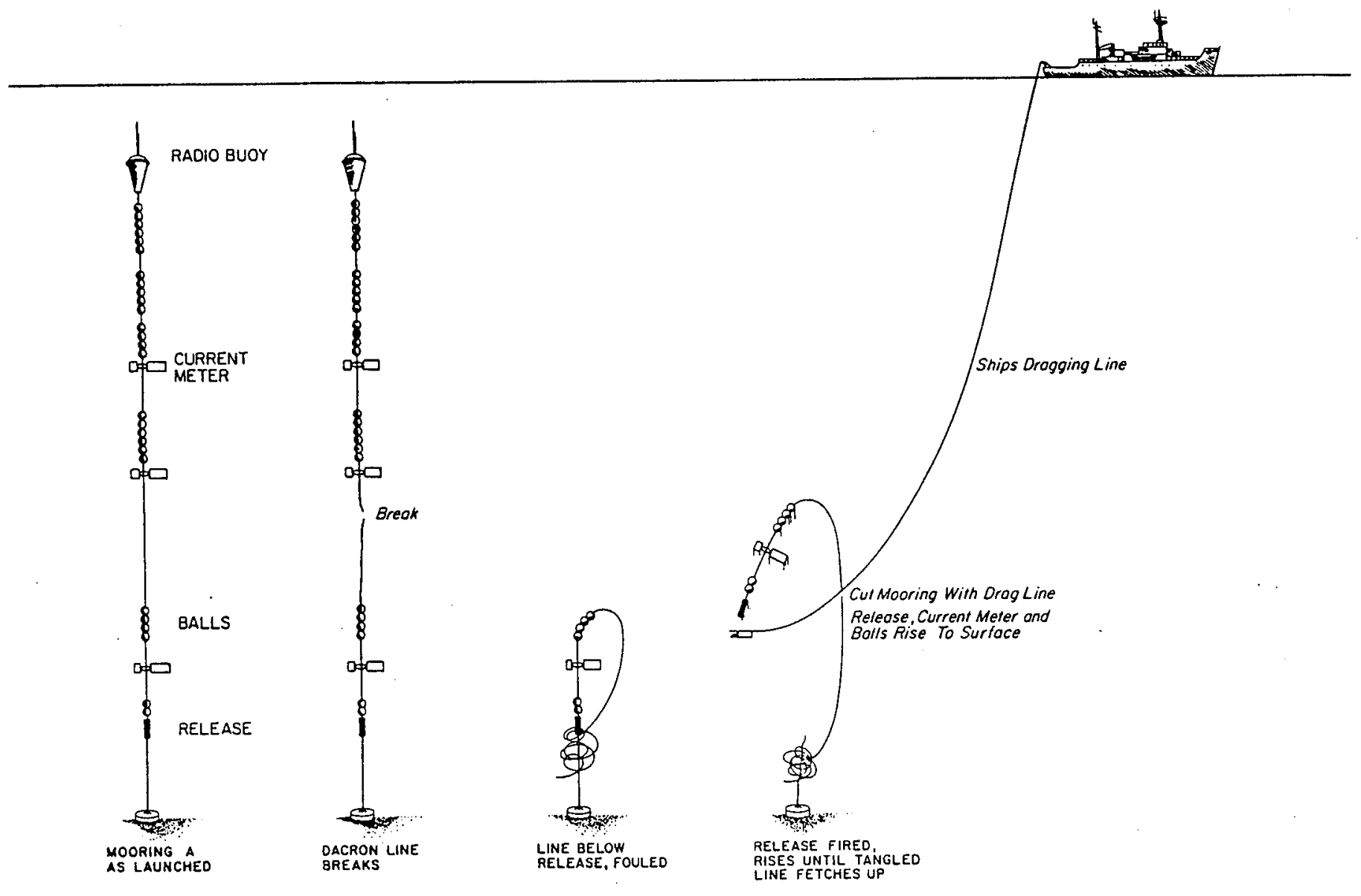

Fig. 16 Taft Mooring A failure and dragging procedure 


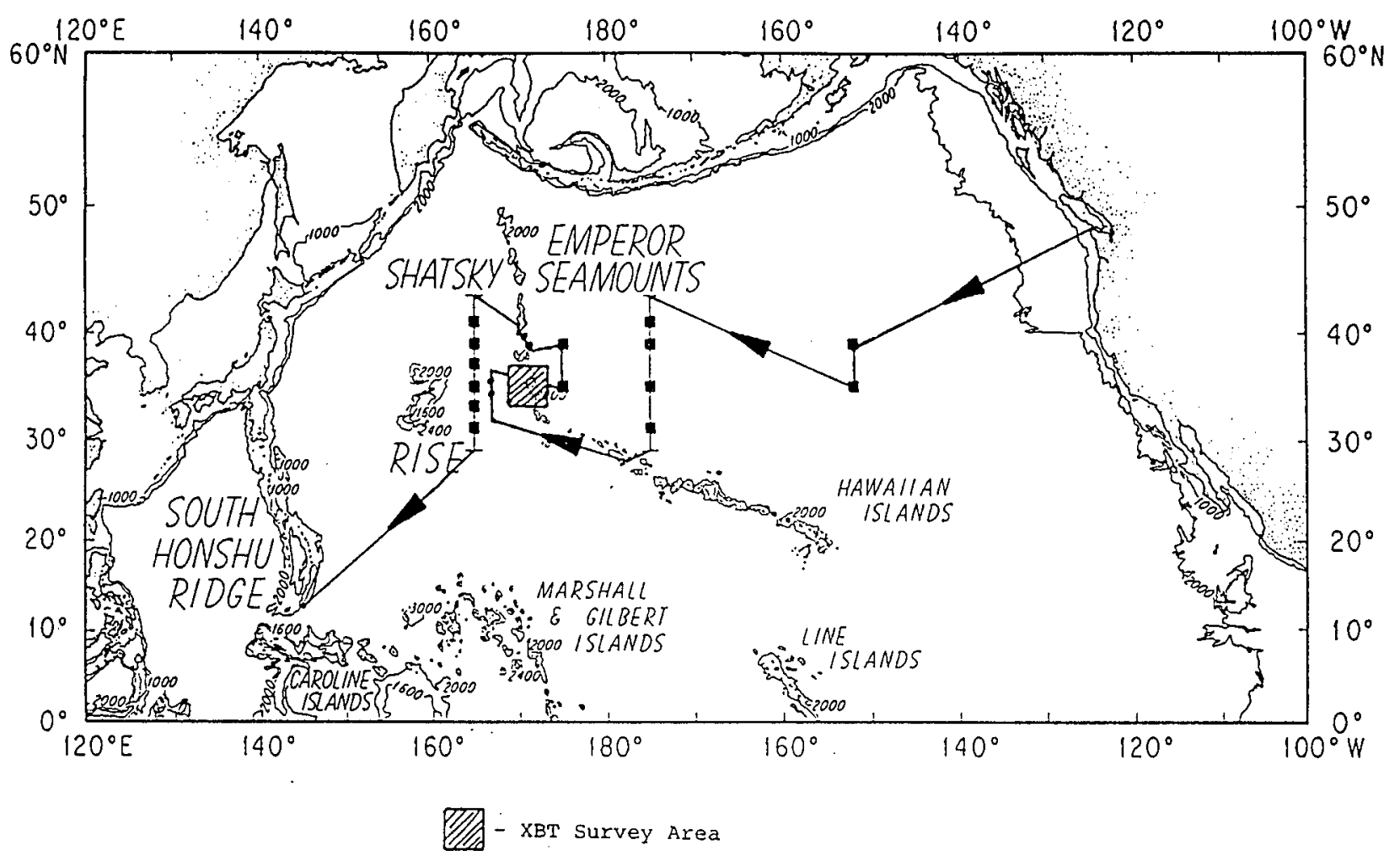

Fig. 17 Cruise Track, R/V THOMAS G. THOMPSON Cruise No. 177, 17 Oct 83 - 10 Dec 83. 
that the mooring had parted somewhere in the 2,184 meter dacron section and the remainder of the dacron had fallen to the sea floor, tangling with the line below the release (Fig. 16). When the release fired, the glass balls remaining pulled it up until it fetched up on the tangle.

The decision was made to drag for the mooring using the trawl wire. The drag was successful, and proved the failure mode was as suspected - the Iine below the release was fouled with dacron from above the current meter. Recovered items were the release, one current meter, and six glass balls.

An XBT survey downstream of the two moorings was done next for Taft/Roden, followed by the launch of moorings 799 and 800 . Mooring 799 was 1 aunched about 20 miles north of its intended position of $35^{\circ} \mathrm{N}$, $175^{\circ} \mathrm{E}$. because of a seamount discovered there during the pre-launch bottom survey.

Leaving mooring 800 and steaming west to the second pair of Taft moorings for CTDs and mooring recoveries, another mooring failure was encountered - seemingly identical to the earlier failure of mooring A. Again, when the release on mooring $D$ was fired, the release started to ascend, then stopped. This time, however, worsening weather and approaching darkness precluded a dragging attempt. With the promise of another day of bad weather and cruise time running out, the decision was made to abandon the mooring. Disable commands were sent to the release, and we left the area, hoping to return in 1984 for a dragging attempt if the release was still responding.

The ship steamed northwest to $43^{\circ} \mathrm{N}$., $165^{\circ} \mathrm{E}$. to begin the 
CTD/Mooring section (Tables 5 and 6). XBTs were taken every fifteen minutes of latitude from $43^{\circ} \mathrm{N}$. to $30^{\circ} \mathrm{N}$. The mooring work was routine with one exception. Mooring 805 was launched normally. The release was tracked to the bottom acoustically, and the normal post-launch testing was done. This testing consists of sending interrogate signals to the transponder to measure the range to the release, and testing the enable and disable functions. Tests are also done using different power levels to ascertain whether or not the receiver has weak spots, or "holes"; i.e. certain power levels which it will not respond to. All tests done, the ship got underway and was leaving the area when the radio transmitter was heard, indicating that the radio float was on the surface. The mooring was recovered. During the recovery, repeated attempts were made to interrogate the releaşe with negative results. When the release, or rather, the release tension rod, came aboard the mystery was solved. The release had imploded and separated from the mounting clamps, taking one clamp with it. the tension rod was bent, and yellow paint near the bottom of it suggested the release had exited downward. One glass ball about two meters away from the release had also imploded. Sympathetic implosion is suspected, although which one went first will never be known.

$$
\text { At the time of failure the release was about } 10 \text { years old }
$$
and had been deployed several times for periods of one year at depths greater than 5,000 meters. The depth of the release at this failure was 6,236 meters, about two percent deeper than its rated depth. Although the consensus on board was that the safety 
Table 5

CTD Stations taken on Leg II of ZONAL Pacific Cruise, Fall 1983

\begin{tabular}{|c|c|c|c|c|c|c|c|c|c|}
\hline $\begin{array}{l}\text { Station } \\
\text { No. }\end{array}$ & $\mathrm{DA}$ & MO Y & $\mathbf{Y R}$ & $\begin{array}{c}\text { Start } \\
\text { Time } \\
\text { (GMT) }\end{array}$ & $\begin{array}{l}\text { Stop } \\
\text { Time } \\
\text { (GMT) }\end{array}$ & $\begin{array}{c}\text { North } \\
\text { Latitude }\end{array}$ & $\begin{array}{r}\mathrm{E} \\
\text { Long }\end{array}$ & $\begin{array}{l}\text { ast } \\
\text { itude }\end{array}$ & $\begin{array}{c}\text { Pressure } \\
\text { Maximum } \\
\text { (Decibars) }\end{array}$ \\
\hline 1 & 14 & 118 & 83 & $1926^{\circ}$ & 2056 & $33 \quad 0.00$ & 167 & 0.00 & 6111.0 \\
\hline 2 & 15 & 118 & 83 & 109 & 235 & 3240.00 & 166 & 59.99 & 6153.0 \\
\hline 3 & 15 & 118 & 83 & 838 & 1007 & $33 \quad 19.84$ & 167 & 0.65 & 6211.0 \\
\hline 4 & 15 & 118 & 83 & 1421 & 1544 & $33 \quad 39.83$ & 167 & 0.10 & 6103.0 \\
\hline 5 & 15 & 118 & 83 & 1943 & 2105 & $34 \quad 0.03$ & 167 & 0.07 & 6125.0 \\
\hline 6 & 16 & 118 & 83 & 401 & 522 & 3420.00 & 167 & 0.10 & 5847.0 \\
\hline 7 & 20 & 118 & 83 & 953 & 1117 & 3521.70 & 174 & 59.80 & 5077.0 \\
\hline 8 & 21 & 118 & 83 & 2020 & 2137 & $39 \quad 1.40$ & 175 & 0.20 & 5001.0 \\
\hline 9 & 24 & 118 & 83 & 521 & 700 & 3921.41 & 170 & 44.84 & 6363.0 \\
\hline 10 & 25 & 118 & 83 & 2102 & 2222 & $43 \quad 0.15$ & 165 & 0.03 & 5505.0 \\
\hline 11 & 26 & 118 & 83 & 438 & 600 & $42 \quad 14.27$ & 164 & 58.48 & 5083.0 \\
\hline 12 & 26 & 118 & 83 & 1059 & 1220 & 4144.90 & 164 & 59.70 & 4899.0 \\
\hline 13 & 26 & 118 & 83 & 1709 & 1818 & 4115.00 & 165 & 0.20 & 5105.0 \\
\hline 14 & 27 & 118 & 83 & 601 & 716 & $40 \quad 45.10$ & 165 & 0.10 & 5519.0 \\
\hline 15 & 27 & 118 & 83 & 1142 & 1319 & 4014.83 & 164 & 57.91 & 5557.0 \\
\hline 16 & 27 & 118 & 83 & 1936 & 2057 & 3929.80 & 164 & 59.90 & 5275.0 \\
\hline 17 & 28 & 118 & 83 & 939 & 1119 & $38 \quad 44.37$ & 164 & 59.71 & 5399.0 \\
\hline 18 & 28 & 118 & 83 & 1726 & 1845 & 3759.80 & 164 & 59.80 & 5535.0 \\
\hline 19 & 29 & 11 & 83 & 1012 & 1137 & 3717.10 & 165 & 0.00 & 3869.0 \\
\hline 20 & 30 & 11 & 83 & 1306 & 1508 & $\begin{array}{ll}36 & 0.69\end{array}$ & 164 & 59.64 & 5591.0 \\
\hline 21 & 1 & 12 & 83 & 503 & 650 & $35 \quad 5.60$ & 165 & 0.90 & 6053.0 \\
\hline 22 & 1 & 12 & 83 & 1432 & 1639 & 3428.35 & 165 & 2.04 & 6037.0 \\
\hline 23 & 2 & 12 & 83 & 32 & 219 & $33 \quad 59.90$ & 165 & 0.10 & 6207.0 \\
\hline 24 & 2 & 12 & 83 & 831 & 1027 & 3329.90 & 164 & 59.80 & 6259.0 \\
\hline 25 & 3 & 12 & 83 & 417 & 617 & 3244.95 & 165 & 0.00 & 6375.0 \\
\hline 26 & 3 & 12 & 83 & 2205 & 2359 & 3159.90 & 165 & 0.00 & 6123.0 \\
\hline 27 & 4 & 12 & 83 & 848 & 1044 & 3058.70 & 164 & 58.80 & 6183.0 \\
\hline 28 & 4 & 12 & 83 & 2042 & 2224 & 3030.00 & 164 & 59.30 & 6039.0 \\
\hline
\end{tabular}


Table 6

A Summary of the Mooring Work conducted during Leg II of R/V Thomas G. Thompson Crüise Number 177

\section{Moorings Deployed}

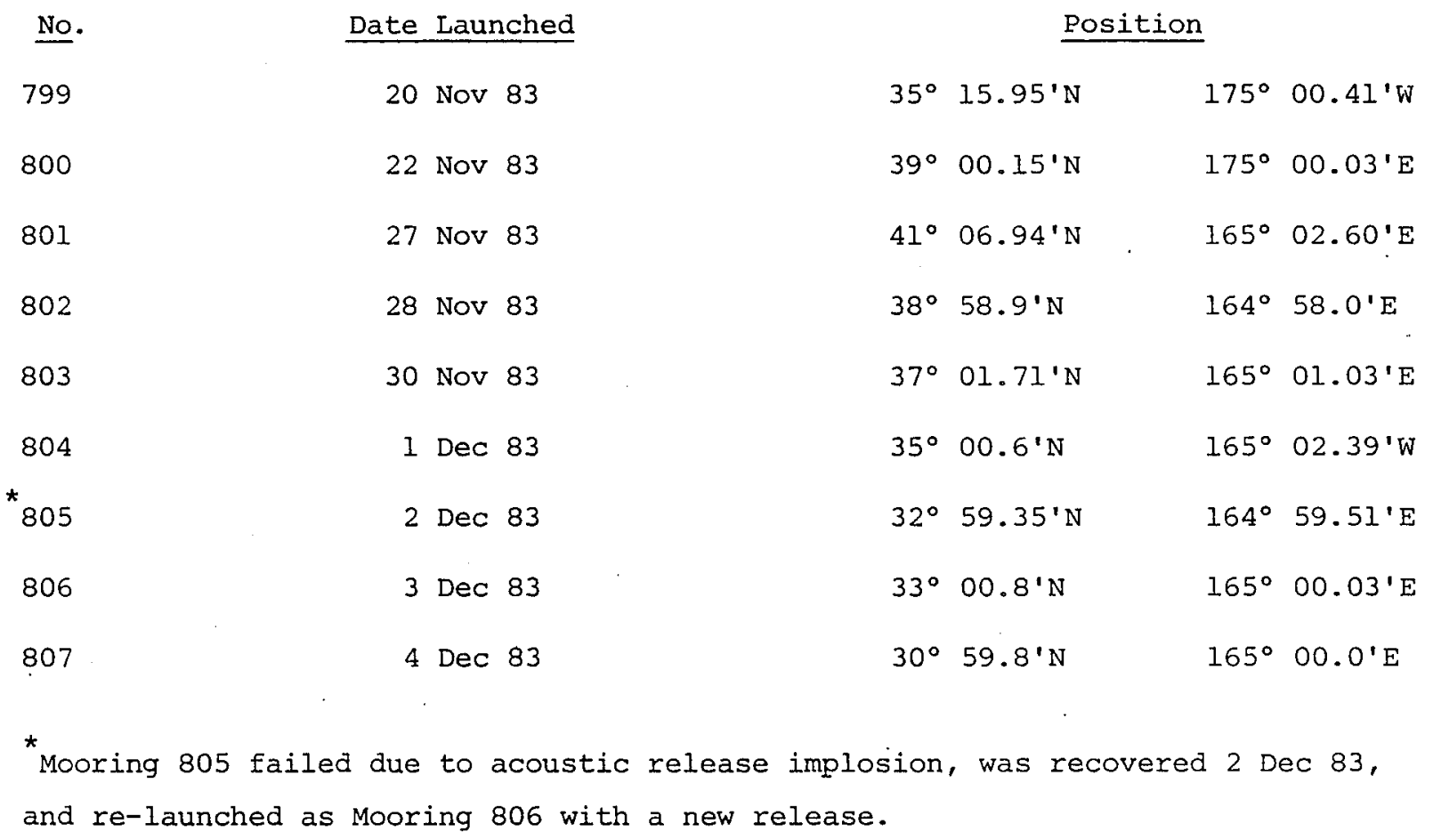

Moorings Recovered

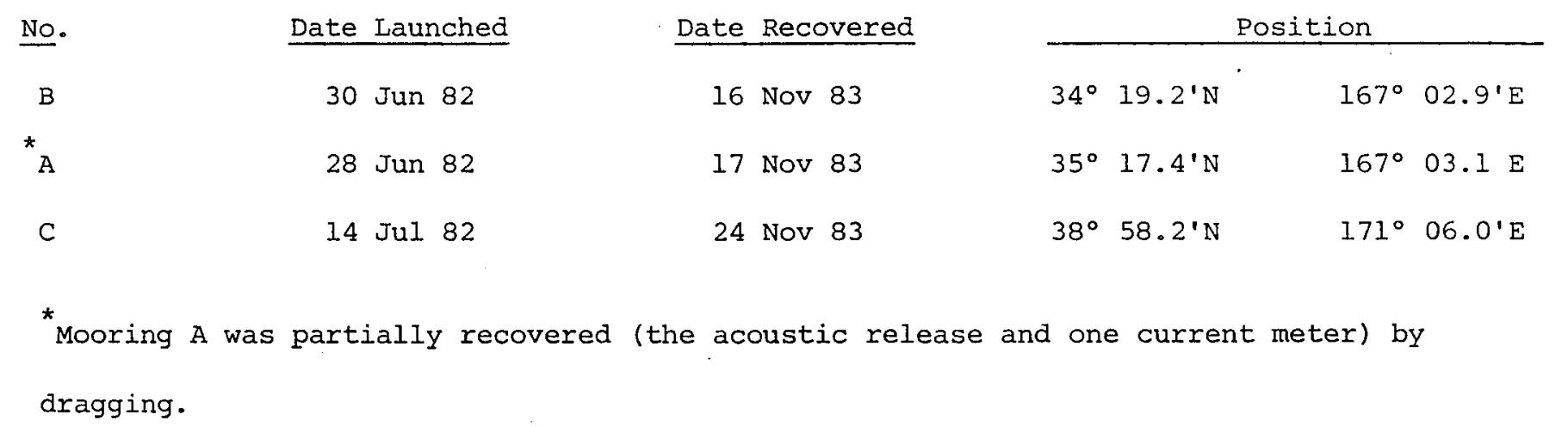


Table 7

R/V Thomas G. Thompson, Cruise Number 177 Leg II

Midway Island - Guam, 10 Nov 83 - 10 Dec 83

1. George H. Tupper

2. R. David Simoneau

3. John B. Reese

4. Joseph R. Poirier

5. Craig D. Marquette

6. Scott E. Worrilow

7. Marguerite E. Zemanovic

8. Terrence M. Joyce

9. Ronald Kroll

10. Thomas Crook

11. Cynthia H. Lanyon

12. Edward Seifert

13. Dennis Root

14. John Konecki
- Chief Scientist

Mooring Supervisor

Mooring Technician

Current Meter Technician

Current Meter Technician

Release Technician

Data Processor

Associate Scientist

CTD Technician

CTD Technician

CTD Technician

Current Meter Technician

Current Meter Technician

Marine Technician
WHOI

WHOI

WHOI

WHOI

WHOI

WHOI

WHOI

WHOI

WHOI

WHOI

WHOI

Oregon State University

Oregon State University

University of Washington 
factor used when rating these units was probably greater than 2 percent, when the mooring was re-launched, the replacement release was moved up to just within its rated depth capability.

The weather was poor throughout the cruise, with winds averaging 30-35 knots and seas of 10-20 feet. The mooring work went well in spite of this and no instruments were banged on the rail or the deck during launch. After launch of the last mooring, one more CTD was done at $30^{\circ} 30^{\prime} \mathrm{N}$ after which the ship headed for Guam, arriving on the morning of 10 December 1983. Personnel on the cruise are shown in Table 7.

\section{Cruise -19 Sep-3 Nov 84}

The goal of the 1984 ZONAL cruise was to recover and redeploy 12 subsurface moorings launched, the previous year. A secondary goal was the occupation for a second year of two cTD sections, one along $165^{\circ} \mathrm{E}$, the other along $175^{\circ} \mathrm{W}$, both sections extending from $28^{\circ} \mathrm{N}$. to $44^{\circ} \mathrm{N}$, for Dr. Terrence Joyce. The cruise would be staged out of Honolulu, with a stop in Midway Island to change personnel and load the remaining anchors. The cruise track is shown in Figure 18 .

\section{Leg I.}

The first leg of R/V THOMAS G. THOMPSON cruise no. 184 departed Honolulu on the 19th of September, 1984, one day later than planned. The reason for the late departure was the discovery enroute to Honolulu of a crack in the hull below the waterline on the starboard bow. Repairs to the hull took an 


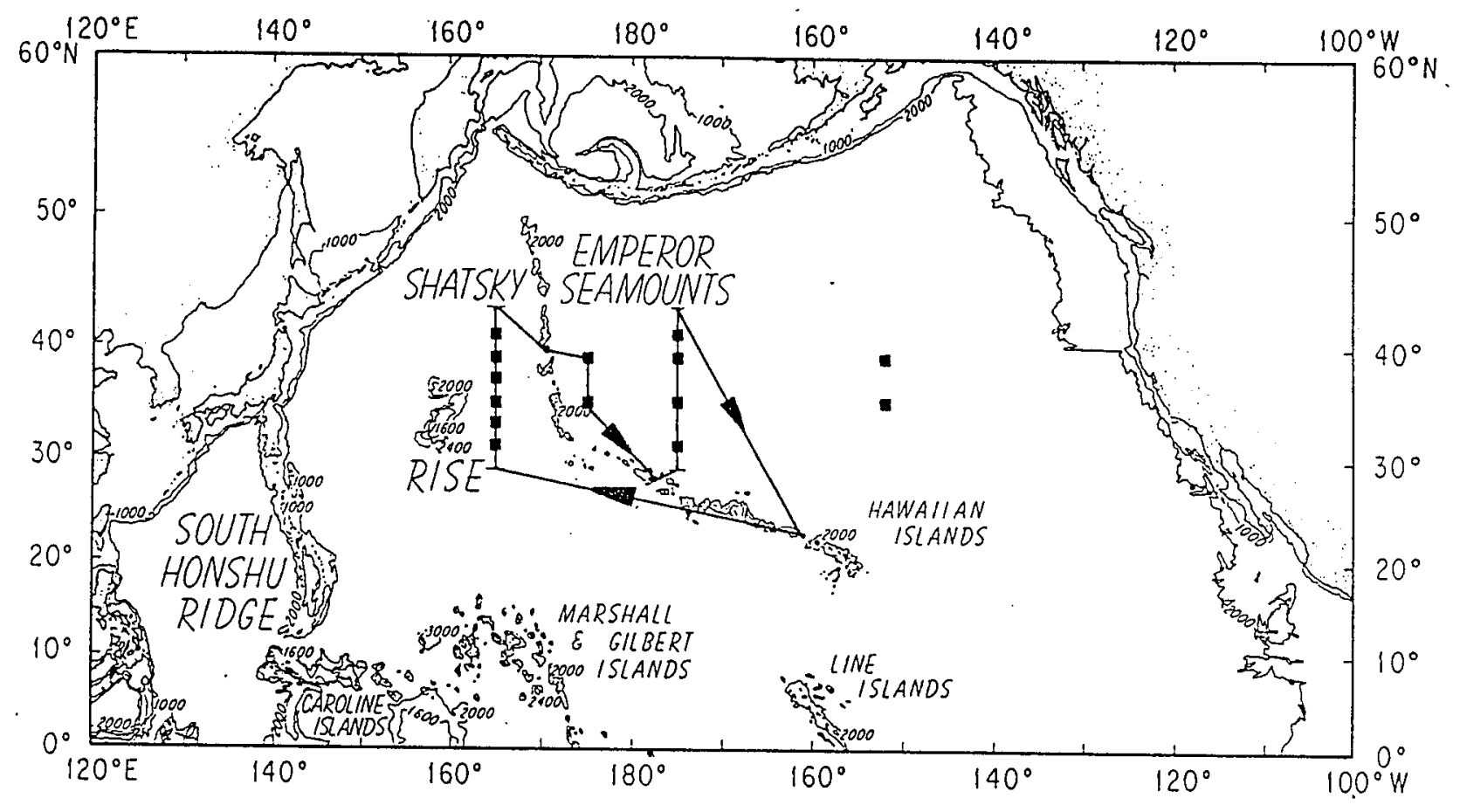

Fig. 18 Cruise Track, R/V THOMAS G. THOMPSON Cruise No. 184, 19 Sept 84 - 3 Nov 84 . 
Table 8

CTD Stations taken on Leg $I_{\text {. of }}$ ZONAL Pacific Cruise, Fall 1984

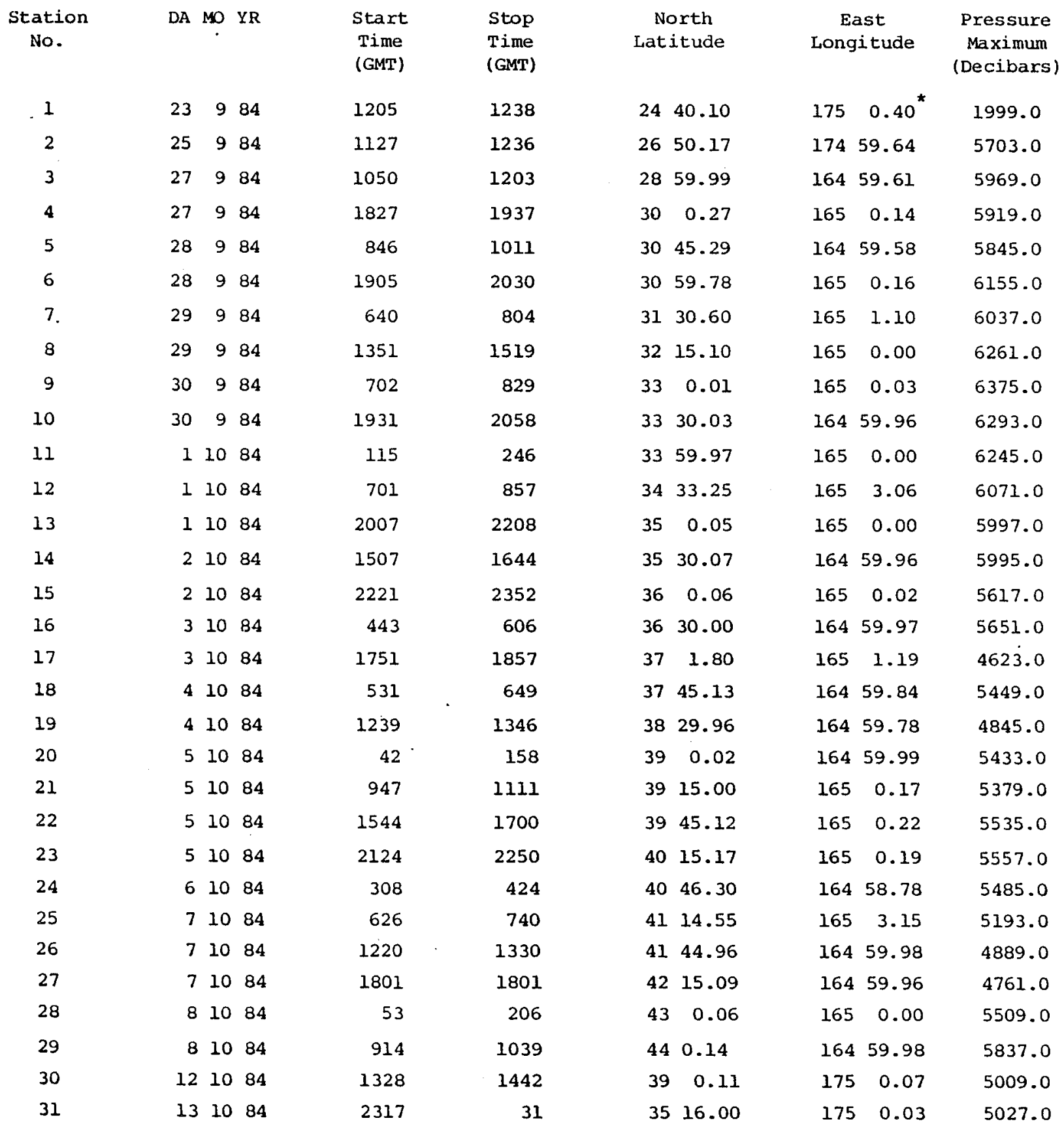

*West Longitude, Sta. 1 only 
extra day.

A course was set for $29^{\circ} \mathrm{N} ., 165^{\circ} \mathrm{E}$, the position of the first CTD station (Table 8). Along the way, two test stations were taken to verify proper CTD operation.

Mooring work for this leg was the recovery of moorings 799804, and 806-807. Replacement moorings for the second year's deployment were numbered 815-819 and 821-823 (Table 9). As on the 1983 cruise, mooring work was routine except for one mooring, number 820. During the final checks on the release after it was on the bottom, the release malfunctioned and fired, releasing the anchor. The mooring was recovered and re-deployed with a fresh release as mooring 821 . Mooring $820^{\prime} \mathrm{s}$ release problem was found to be electrical arcing between two adjacent circuit connector pins each time the pinger pinged, causing a false fire signal. This problem did not show up on the release lowering test. Before deployment, each release is tested to 2,000 meters on the CTD wire as a final check on its operation in the water, at temperature and pressure. Later testing showed the transducer was a little loose inside the rubber boot, raising the possibility that if the transducer shifted somehow at the greater pressure below 5,000 meters, it could have overloaded the pinger drive circuitry, causing the arcing that sent the false fire signal.

After finishing the $165^{\circ} \mathrm{E}$. work, the ship headed for the site of the failed Taft mooring $D$ which had been abandoned the previous year. On arrival, nothing could be heard from the release. Without acoustic contact, it was felt that a dragging 
Table 9

A Summary of the Mooring Work conducted during Leg $I$ of R/V Thomas G. Thompson Cruise Number 184

$\begin{array}{ll}\text { No. } & \text { Date Launched } \\ 807 & 4 \text { Dec } 83 \\ 806 & 3 \text { Dec } 83 \\ 804 & 1 \text { Dec } 83 \\ 803 & 30 \text { Nov } 83 \\ 802 & 28 \text { Nov } 83 \\ 801 & 27 \text { Nov } 83 \\ 800 & 22 \text { Nov } 83 \\ 799 & 20 \text { Nov } 83\end{array}$

$\frac{\text { Moorings Recovered }}{\text { Date Recovered }}$

28 Sep 84
30 Sep 84
1 Oct 84
3 Oct 84
4 Oct 84
6 Oct 84
12 Oct 84
13 Oct 84

\begin{tabular}{ll}
\multicolumn{3}{c}{ Position } \\
\hline $30^{\circ} 59^{\prime} 8^{\prime} \mathrm{N}$ & $165^{\circ} 00.00^{\prime} \mathrm{E}$ \\
$33^{\circ} 00.8^{\prime} \mathrm{N}$ & $165^{\circ} 00.03^{\prime} \mathrm{E}$ \\
$35^{\circ} 00.6^{\prime} \mathrm{N}$ & $165^{\circ} 02.39^{\prime} \mathrm{E}$ \\
$37^{\circ} 01.71^{\prime} \mathrm{N}$ & $165^{\circ} 01.03^{\prime} \mathrm{E}$ \\
$38^{\circ} 58.9^{\prime} \mathrm{N}$ & $164^{\circ} 58.0^{\prime} \mathrm{E}$ \\
$41^{\circ} 06.9^{\prime} \mathrm{N}$ & $165^{\circ} 02.6^{\prime} \mathrm{E}$ \\
$39^{\circ} 00.15^{\prime} \mathrm{N}$ & $175^{\circ} 00.03^{\prime} \mathrm{E}$ \\
$35^{\circ} 15.95^{\prime} \mathrm{N}$ & $175^{\circ} 00.41^{\prime} \mathrm{E}$
\end{tabular}

Moorings Deployed

$\begin{array}{ll}\text { No. } & \text { Date Launched } \\ 815 & 29 \text { Sep } 84 \\ 816 & 30 \text { Sep } 84 \\ 817 & 2 \text { Oct } 84 \\ 818 & 4 \text { Oct } 84 \\ 819 & 5 \text { Oct } 84 \\ * 820 & 6 \text { Oct } 84 \\ 821 & 6 \text { Oct } 84 \\ 822 & 12 \text { Oct } 84 \\ 823 & 14 \text { Oct } 84\end{array}$

\begin{tabular}{|c|c|c|c|c|}
\hline \multicolumn{4}{|c|}{ Position } & Replaced Moorin \\
\hline $31^{\circ}$ & $02.13^{\prime} \mathrm{N}$ & $164^{\circ}$ & $55.05 \mathrm{E}$ & 807 \\
\hline $33^{\circ}$ & $00.3^{\prime} \mathrm{N}$ & $164^{\circ}$ & $58.9^{\prime} \mathrm{E}$ & 806 \\
\hline $34^{\circ}$ & $59.66^{\prime} \mathrm{N}$ & $164^{\circ}$ & $59.65^{\prime} \mathrm{E}$ & 804 \\
\hline $37^{\circ}$ & $02.59^{\prime} \mathrm{N}$ & $165^{\circ}$ & $02.4^{\prime} \mathrm{E}$ & 803 \\
\hline $38^{\circ}$ & $59.48^{\prime} \mathrm{N}$ & $164^{\circ}$ & $59.42^{\prime} \mathrm{E}$ & 802 \\
\hline $41^{\circ}$ & $06.64^{\prime} \mathrm{N}$ & $165^{\circ}$ & $03.52^{\prime} \mathrm{E}$ & 801 \\
\hline $41^{\circ}$ & $04.86^{\prime} \mathrm{N}$ & $165^{\circ}$ & $02.85^{\prime} \mathrm{E}$ & 820 \\
\hline $38^{\circ}$ & $59.61^{\prime} \mathrm{N}$ & $175^{\circ}$ & $00.74^{\prime} \mathrm{E}$ & 800 \\
\hline $35^{\circ}$ & $16.51^{\prime} \mathrm{N}$ & $174^{\circ}$ & $56.95^{\prime} \mathrm{E}$ & 799 \\
\hline
\end{tabular}

*Mooring 820 failed due to acoustic release malfunction, was recovered 6 Oct 84 , and re-launched as Mooring 821 with a new release. 
Table 10

R/V Thomas G. Thompson, Cruise Number 184 Leg I

Honolulu - Midway Island, 19 Sep 84 - 16 oct 84

1. George H. Tupper

2. R. David Simoneau

3. Scott Worrilow

4. John B. Reese

5. Carol A. Mills

6. Cynthia H. Lanyon

7. Roderigue A. LaRochelle

8. Kelly G. Luetkemeyer

9. Kevin Lange

10. Robert E. MCDevitt

11. Marvel C. Stalcup

12. Douglas Kaye

13. Thomas Leahman
Chief Scientist

Mooring Supervisor

Release Technician

Mooring Technician

Data Processor

CTD Technician

Release Technician

Mooring Technician

Mooring Technician

CTD Technician

CTD Technician

Guest Investigator

Marine Technician
WHOI

WHOI

WHOI

WHOI

WHOI

WHOI

WHOI

WHOI

WHOI

WHOI

WHOI

Burlington Battery Corp.

University of Washington 
operation would be futile because of the poor navigation available.

The rest of the mooring work went well. The moorings had been designed with wire and Kevlar re-usability in mind; $74 \%$ of the wire was re-used, $77 \%$ of the kevlar was. The last mooring to be launched was number 823. From there, the ship steamed southeast for Midway Island, arriving on October $16,1984$.

Leg I Cruise personnel are shown in Table 10.

\section{Leg II.}

The second leg of the 1984 ZONAL cruise departed Midway Island on the $19 \mathrm{th}$ of October at 1400 local time enroute to position $28^{\circ} \mathrm{N} ., 175^{\circ} \mathrm{W}$, where the first CTD station (number 32 of the cruisel was taken. From there the cruise proceeded north along $175^{\circ} \mathrm{H}$. taking XBTs every 15 minutes of latitude and CTDs at positions designated by Dr. Terrence Joyce (WHOI) prior to the cruise. Throughout the second leg of the cruise a total of 24 CTD stations were made. Table 11 summarizes them.

The mooring work conducted consisted of turning around four subsurface current meter moorings as they were encountered during the trip northward. Four moorings that had been deployed in 1983 were to be recovered and re-deployed with fresh instrumentation for an additional year, thereby occupying each mooring site for two years. Following the recovery of each mooring a replacement mooring with the same instrument placement (but not necessarily the same current meter type) was deployed (Table 12).

All of the mooring operations were routine with the 
Table 11

CTD Stations taken on Leg II of ZONAL Pacific Cruise, Fall 1984

\begin{tabular}{|c|c|c|c|c|c|c|c|c|c|}
\hline $\begin{array}{l}\text { Station } \\
\text { No. }\end{array}$ & $\mathrm{DA}$ & MO & YR & $\begin{array}{l}\text { Start } \\
\text { Time } \\
\text { (GMT) }\end{array}$ & $\begin{array}{l}\text { Stop } \\
\text { Time } \\
\text { (GMT) }\end{array}$ & $\begin{array}{c}\text { North } \\
\text { Latitude }\end{array}$ & $\begin{array}{l}\text { We } \\
\text { Long }\end{array}$ & $\begin{array}{l}\text { lest } \\
\text { gitude }\end{array}$ & $\begin{array}{c}\text { Pressure } \\
\text { Maximum } \\
\text { (Decibars) }\end{array}$ \\
\hline 32 & 19 & 10 & 84 & 1338 & 1534 & $\begin{array}{ll}28 & 0.22\end{array}$ & 174 & 59.44 & 5241.0 \\
\hline 33 & 19 & 10 & 84 & 2339 & 100 & $29 \quad 0.02$ & 175 & 0.15 & 5437.0 \\
\hline 34 & 20 & 10 & 84 & 841 & 1008 & $29 \quad 59.98$ & 175 & 0.05 & 5419.0 \\
\hline 35 & 20 & 10 & 84 & 1553 & 1712 & $30 \quad 39.91$ & 175 & 0.05 & 5461.0 \\
\hline 36 & 21 & 10 & 84 & 1359 & 1525 & 3119.98 & 175 & 0.01 & 5703.0 \\
\hline 37 & 21 & 10 & 84 & 2120 & 2245 & $\begin{array}{ll}32 & 0.01\end{array}$ & 175 & 0.03 & 5777.0 \\
\hline 38 & 22 & 10 & 84 & 426 & 523 & 3240.00 & 174 & 59.99 & 3765.0 \\
\hline 39 & 22 & 10 & 84 & 1032 & 1200 & 3320.01 & 175 & 0.37 & 5601.0 \\
\hline 40 & 22 & 10 & .84 & 1739 & 1904 & 3359.97 & 175 & 0.03 & 5677.0 \\
\hline $4 I$ & 23 & 10 & 84 & 255 & 1613 & $34 \quad 40.18$ & 174 & 59.98 & 5531.0 \\
\hline 42 & 24 & 10 & 84 & 132 & 255 & $35 \quad 20.28$ & 174 & 59.30 & 5275.0 \\
\hline 43 & 24 & 10 & 84 & 823 & 941 & $36 \quad 0.16$ & 175 & 0.20 & 5011.0 \\
\hline 44 & 24 & 10 & 84 & 1456 & 1625 & 3640.03 & 17.4 & 59.99 & 5857.0 \\
\hline 45 & 24 & 10 & 84 & 2150 & 2302 & $37 \quad 19.82$ & 175 & 0.16 & 4687.0 \\
\hline 46 & 26 & 10 & 84 & 411 & 526 & $38 \quad 0.06$ & 174 & 59.92 & 4691.0 \\
\hline 47 & 25 & 10 & 84 & 1107 & 1238 & $38 \quad 40.08$ & 175 & 0.00 & 5779.0 \\
\hline 48 & 26 & 10 & 84 & 706 & 837 & 3920.00 & 174 & 59.94 & 5587.0 \\
\hline 49 & 26 & 10 & 84 & 1356 & 1531 & $39 \quad 59.91$ & 175 & 0.01 & 6003.0 \\
\hline 50 & 26 & 10 & 84 & 2120 & 2248 & $40 \quad 40.01$ & 175 & 0.10 & 5953.0 \\
\hline 51 & 27 & 10 & 84 & 1510 & 1636 & $41 \quad 19.88$ & 174 & 59.86 & 5963.0 \\
\hline 52 & 27 & 10 & 84 & 2212 & 2319 & $42 \quad 0.00$ & 175 & 0.04 & 5919.0 \\
\hline 53 & 28 & 10 & 84 & 512 & 644 & $42 \quad 39.96$ & 175 & 0.21 & 6129.0 \\
\hline 54 & 28 & 10 & 84 & 1156 & 1334 & $43 \quad 19.78$ & 175 & 0.22 & 6513.0 \\
\hline 55 & 28 & 10 & 84 & 1858 & 2030 & $44 \quad 0.00$ & 175 & 0.21 & 5813.0 \\
\hline
\end{tabular}


A Summary of the Mooring Work conducted during Leg II of R/V Thomas G. Thompson Cruise Number 184

Moorings Recovered

\begin{tabular}{|c|c|c|c|}
\hline №. & Date Launched & Date Recovered & Position \\
\hline 798 & 6 Nov 83 & 21 Oct 84 & $\begin{array}{rr}31^{\circ} & 00.75^{\prime} \mathrm{N} \\
175^{\circ} & 03.10^{\prime} \mathrm{W}\end{array}$ \\
\hline 797 & 4 Nov 83 & 23 Oct 84 & $\begin{array}{rr}35^{\circ} & 01.59^{\prime} \mathrm{N} \\
174^{\circ} & 58.29^{\prime} \mathrm{W}\end{array}$ \\
\hline 796 & 1 Nov 83 & 25 Oct 84 & $\begin{array}{rr}38^{\circ} & 56.92^{\prime} \mathrm{N} \\
174^{\circ} & 55.09^{\prime} \mathrm{W}\end{array}$ \\
\hline 795 & 31 Oct 83 & 27 Oct 84 & $\begin{array}{rr}41^{\circ} & 02.00 \\
175^{\circ} & 00.97^{\prime} \mathrm{W}\end{array}$ \\
\hline
\end{tabular}

Moorings Deployed

№.

Date Launched

Position

Replaced Mooring No.

824

21 Oct 84

$31^{\circ} 01.14^{\prime} \mathrm{N}$

798

$175^{\circ} 03.72^{\prime} \mathrm{W}$

825

23 Oct 84

$35^{\circ} 03.17^{\prime} \mathrm{N}$

797

$174^{\circ} 57.99^{\prime} \mathrm{W}$

826

26 Oct 84

$38^{\circ} 56.83^{\prime} \mathrm{N}$

796

827

27 Oct 84

$41^{\circ} 01.40^{\prime} \mathrm{N}$

$175^{\circ} 01.26^{\prime} \mathrm{W}$

795 
Table 13

R/V Thomas G. Thompson, Cruise Number 184 Leg II

Midway Island - Honolulu, 19 Oct 84 - 3 Nov 84

1. Richard P. Trask

2. William M. Ostrom

3. Matthew R. Gould

4. William Sadler

5. Scott E. Worrilow

6. William H. Horn

. 7. Ellen Levy

8. Ronald Kroll

9. Margaret M. Francis

10. Jane A. Dunworth

11. William G. Metcalf

12. John Konecki
Chief Scientist WHOI

Mooring Supervisor WHOI

Mooring Technician WHOI

Mooring Technician . WHOI

Release Technician WHOI

Current Meter Technician WHOI

Data Processor WHOI

CTD Technician WHOI

CTD Technician WHOI

CTD Technician WHOI

Guest Investigator. WHOI

Marine Technician University of Washington 
exception of mooring 797. During the recovery of the third cluster of glass balls it was necessary to make use of several crosby clips in order to transfer the active part of the mooring to the rehaul winch. When the transfer was made, the crosby clips could not hold the tension, allowing the remaining part of the mooring ( 1567 meters of wire rope, the fourth cluster of glass balls, and an acoustic release) to go adrift. Meanwhile, the third cluster of balls still had to be brought aboard before the ship could go off searching for the lower part of the mooring. While recovering the third cluster of glass balls, a similar failure occurred (slipping crosby clips). As a result, the glass ball cluster dropped back into the water. The ship's crew then had to re-maneuver the ship so that the glass balls could be recovered. Once that cluster was on board, the cluster of balls and release that were adrift were re-located by navigating on the acoustic release. Course changes were made to minimize acoustic ranges until visual contact could be made. The night recovery made it necessary for the ship to get relatively close $(.15 \mathrm{~km})$ to the glass ball cluster before it could be spotted.

Throughout the mooring work every attempt was made to save as much of the recovered mooring wire and Kevlar as possible for re-use on the replacement moorings. As a result of the mooring design and care taken during recovery, $62 \%$ of the wire and $88 \%$ of the Kevlar were re-used during the leg I operations.

Following the last mooring operation, the cruise continued to the north taking CTD stations. The final CTD station of the 
cruise (number 55) was taken at $44^{\circ} \mathrm{N} ., 175^{\circ} \mathrm{W}$. From there the ship steamed southeast toward Hawail, arriving in Honolulu on the $3 r d$ of November, 1984.

Personnel on leg II appear in Table 13.

\section{Cruise -24 Sep-2 Nov 85}

The goal of the third ZONAL cruise was the successful recovery of 14 subsurface moorings with 42 current meters for Dr. William J. Schmitz, Jr. A secondary goal was the recovery of two moorings along $152^{\circ} \mathrm{H}$, requested by Dr. Peter Niiler, Scripps Institution of oceanography.

\section{Leg I.}

Leg I of the 1985 ZONAL cruise sailed from seattle on 24 September, 1985. As the 1983 cruise had more than its share of bad weather, this cruise was to have almost no bad weather. Arriving at the site of the first mooring to be recovered, Niller's mooring number 193, the release fired the first time, the mooring was recovered, and we were on our way in about 3 hours. On september 30 , the ship arrived at the site of the first two-year mooring, mooring number 793. This mooring, like 794, the other two-year mooring, had tandem acoustic releases mounted side-by-side such that proper actuation of either of them would release the mooring from the anchor. One of the releases 
Table 14

A Summary of the Mooring Work conducted during Leg I of

R/V Thomas G. Thompson Cruise Number 191

Moorings Recovered

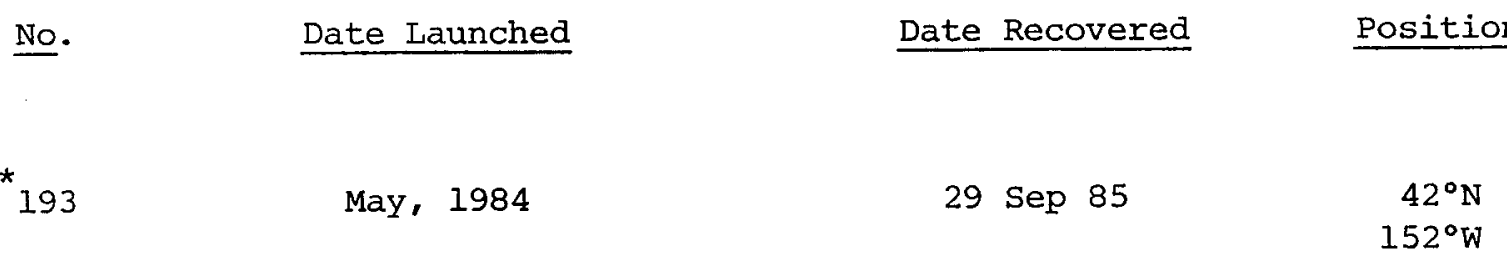

$793 \quad 24$ Oct 83

30 Sep 85

$38^{\circ} 57.57^{\prime} \mathrm{N}$

$152^{\circ} 01.82^{\prime} \mathrm{W}$

794

25 Oct 83

1 Oct 85

$35^{\circ} 00.57^{\prime} \mathrm{N}$

$152^{\circ} 00.67^{\prime} \mathrm{W}$

${ }^{*} 192$

May 1984

3 Oct 85

$28^{\circ} \mathrm{N}$

$152^{\circ} \mathrm{W}$

*Moorings 192 and 193 were not part of the zONAL experiment, but belonged to Dr. Peter Niiler of the Scripps Institution of Oceanography, and were recovered at his request. 
Table 15

R/V Thomas G. Thompson, Cruise Number 191 Leg I Seattle - Honolulu, 24 Sep 85 - 5 Oct 85

1. George H. Tupper

2. William M. Ostrom

3. Steven $P$. Longworth

4. Bryan S. Way

5. Craig D. Marquette

6. Ellen Levy

7. Samuel Hocker

8. Thomas Leahman
Chief Scientist

Mooring Supervisor

Mooring Technician

Current Meter Technician

Current Meter Technician

Data Processor

Mooring Technician

Marine Technician
WHOI

WHOI

WHOI

WHOI

WHOI

WHOI

University of Miami

University of Washington 
had a lithium receiver battery, the other an alkaline battery and an electronic cycling clock which let the receiver listen one hour out of four, saving $75 \%$ of the power necessary for the receiver. Both releases on mooring 793 answered the first time. The clock release was arbitrarily chosen to release this mooring. It fired the first time. Because it was the middle of the night, the ship was navigated acoustically very close to the mooring before release. As a result, the radio float surfaced within 200 yards of the ship.

During recovery of this mooring, the releases caught under the counter of the fantail, ripping the protective transducer cage off the lithium release. Later on in the cruise, this release fired in the lab when a door slammed. This is discussed further in section IV.

Mooring 794, the other two-year mooring, had to be fired using the clock release because the lithium release would not fire. It received all commands and responded to them, but would not accept the fire command. After recovery, the firing battery was found completely discharged, the result of a leaky squib.

The remaining mooring to be recovered, Niller's mooring number 192, was recovered without difficulty and the ship headed southwest to Honolulu, arriving on the fifth of October, 1985.

A summary of Leg I mooring operations appears in Table 14. Cruise personnel are shown in Table 15.

\section{Leg II.}

The purpose of this leg was to recover the remaining eight 


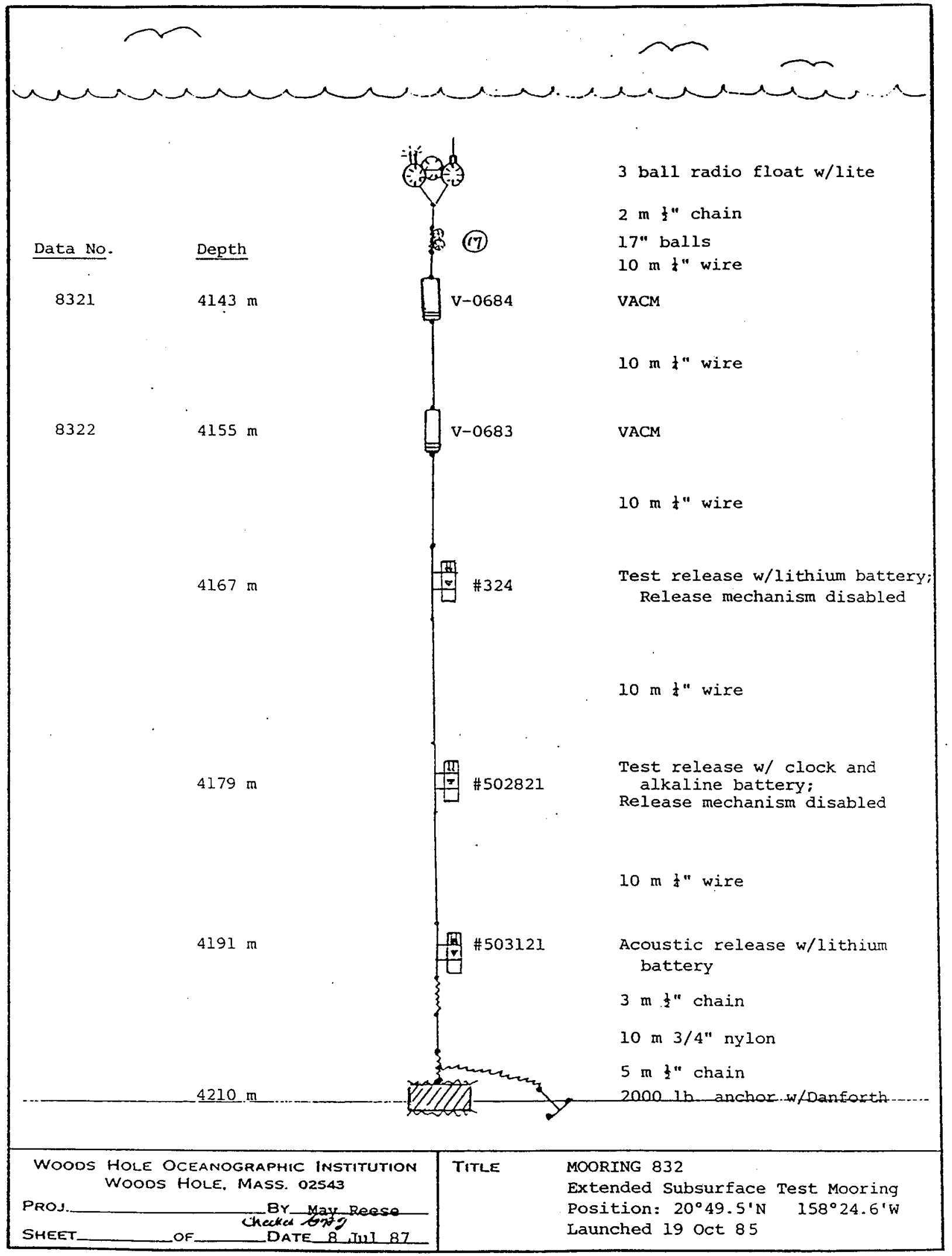

Fig. 19 Extended Duration Subsurface Mooring 


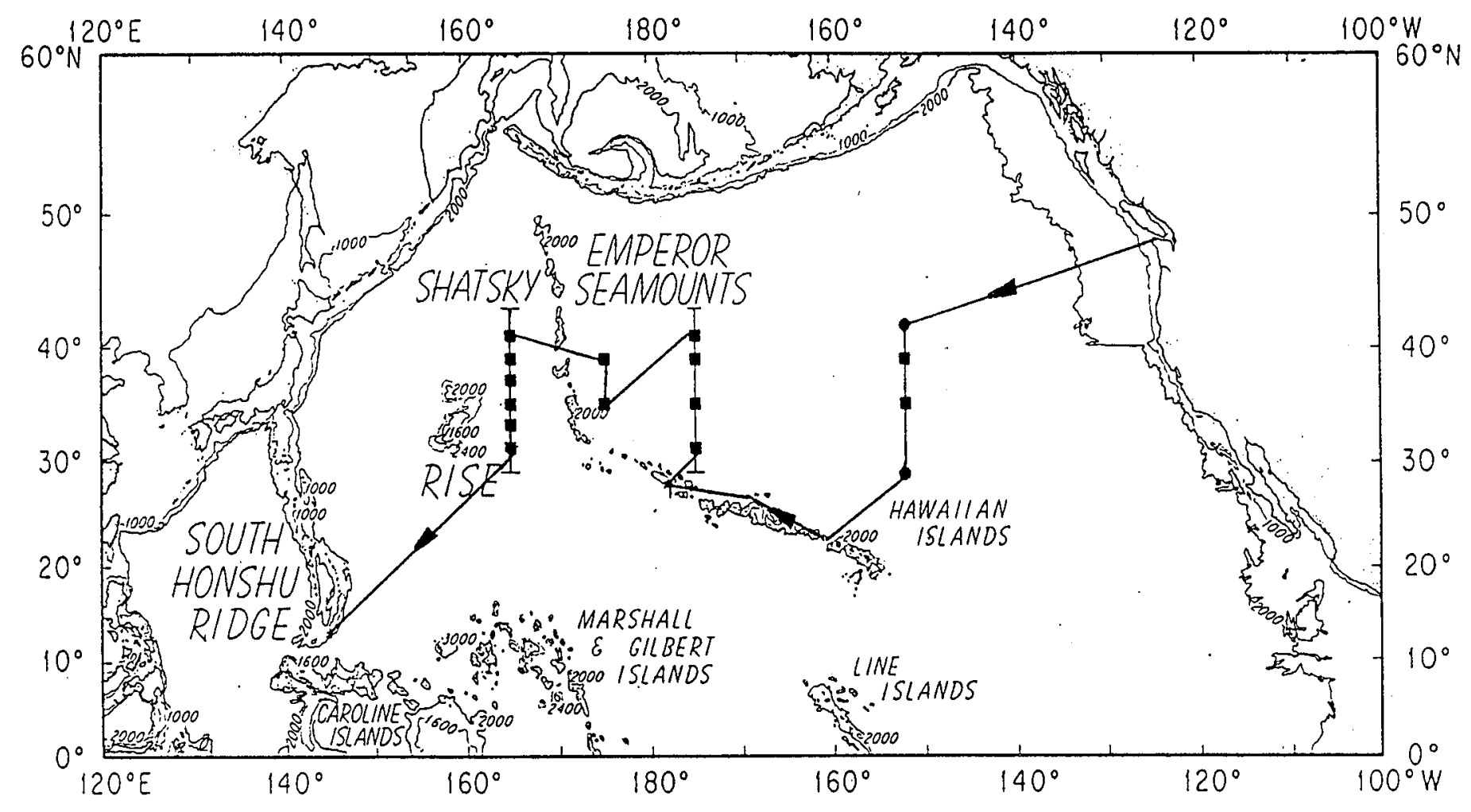

Fig. 20 Cruise Track, R/V THOMAS G. THOMPSON Cruise No. 191, 24 Sep $85-2$ Nov 85. 
Table 16

A Summary of the Mooring Work conducted during Leg II of

R/V Thomas G. Thompson Cruise Number 191

Moorings Recovered

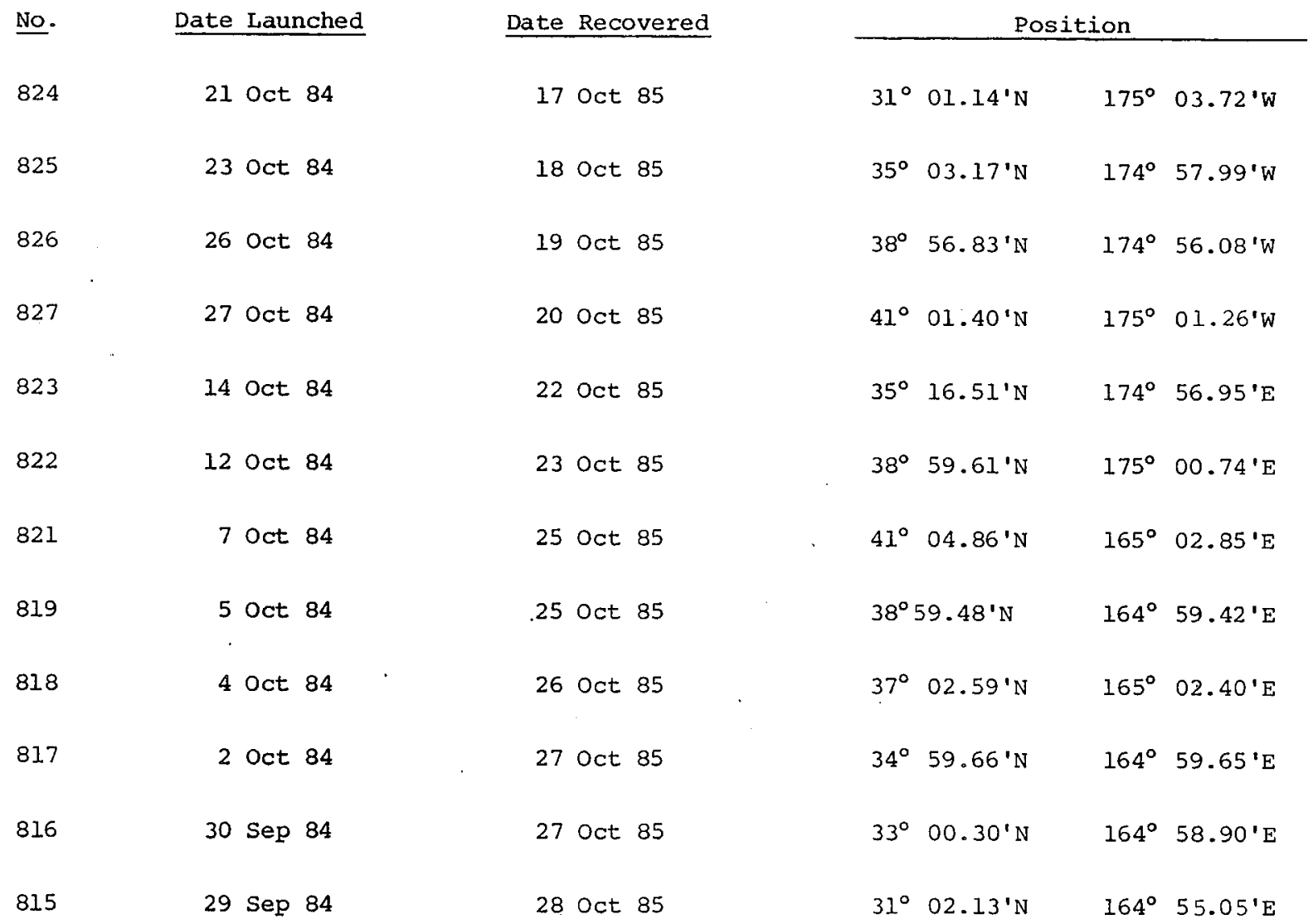

Moorings Deployed

No. Date Launched

* 832
10 oct 85
Position

$20^{\circ} 49.5^{\prime} \mathrm{N} \quad 158^{\circ} 24.6^{\prime} \mathrm{W}$

* Mooring deployed for Extended Duration Subsurface Mooring Project. 
Table 17

R/V Thomas G. Thompson, Cruise Number 191 Leg II

Honolulu - Guam, 10 Oct 85 - 2 Nov 85

1. George H. Tupper

2. William M. Ostrom

3. Sean M. Kery

4. Bryan S. Way

5. Brian Littlefield

6. John H. Thomson

7. Scott E. Worrilow

8. Ellen Levy

9. Thomas Leahman
Chief Scientist

Mooring Supervisor

Mooring Technician

Current Meter Technician

Current Meter Technician

Current Meter Technician

Release Technician

Data Processor

Marine Technician
WHOI

WHOI

WHOI

WHOI

WHOI

WHOI

WHOI

WHOI

University of Washington 
moorings of the ZONAL array, take XBTs every fifteen miles along $175^{\circ} \mathrm{W}$. and $165^{\circ} \mathrm{E}$. between the moorings, and launch a near-bottom extended subsurface test mooring near Honolulu.

The R/V THOMAS G. THOMPSON sailed from Honolulu at 1600 local time. The first task was the launch of mooring 832 , an extended test of two releases and two current meters just recovered from the two-year moorings (Fig. 19). A fresh release with a two-year battery is at the bottom of the mooring as the active release. The goal of the program is to evaluate the three to four year potential of our instruments.

After the Iaunch; the ship headed northwest toward mooring 824 (Fig. 20) On the way, a seaman suffered a head injury severe enough to divert us to Midway Island. After he was examined and treated, the ship sailed again, headed for mooring 824 , but he had a seizure, making a second diversion to Midway necessary. This cost about two days of shiptime, but the good weather helped make up the difference by allowing faster cruise speeds.

All the moorings were recovered routinely except for the last one, number 815. As the third cluster of balls was taken aboard, somehow a turn of wire wound around the sheave and broke. This meant that the release and the bottom cluster of balls was free of the ship, about a mile away, on a dark night. The acoustic towfish was re-deployed over the stern and we began ranging on the release, using the clocked keyer to send out an interrogate pulse precisely every two seconds. With the echo sounder on the two second sweep, the range to the release was displayed graphically, making it a simple matter to steer the 
ship to the release. It was sighted when about 100 yards ahead. After this recovery, the ship steamed southwest, arriving in Guam on the 2nd of November, 1985.

Table 16 summarizes the mooring work on leg II. Cruise personnel appear in Table 17. 


\section{RESULTS, IMPROVEMENTS, PROBLEMS}

\section{A. Data Return}

Figure 21 shows the overall data return for the ZONAL

experiment. Each current meter symbol represents the two years of the array. The top half represents the first year of the deployment, the bottom half represents the second. For example, a totally black symbol means that the data was good both years; white on top half, black on bottom means bad first year. good second year. The partial symbol represents a current meter whose battery ran down early. If a current meter did not record current speed and direction, but recorded temperature and pressure, it was called bad (white).

\section{B. Wire Re-use}

During the planning of the ZONAL array, it was realized that 12 of the moorings would be turned around (recovered and redeployed) after the first year. Careful attention to the design of the moorings and care during recovery at sea has resulted in the successful re-use of a large percentage of the mooring wire and Kevlar. Short, "sacrificial" shots (lengths) of wire were designed into the moorings near the glass ball clusters to bear the brunt of the tangles usually found there, leaving the long shots to survive virtually tangle-free. Of 41,000 meters of mooring wire, 28,600 meters, or $70 \%$ was re-used. Of 22,000 meters of Kevlar, 17,900 meters were re-used, or $81 \%$. 


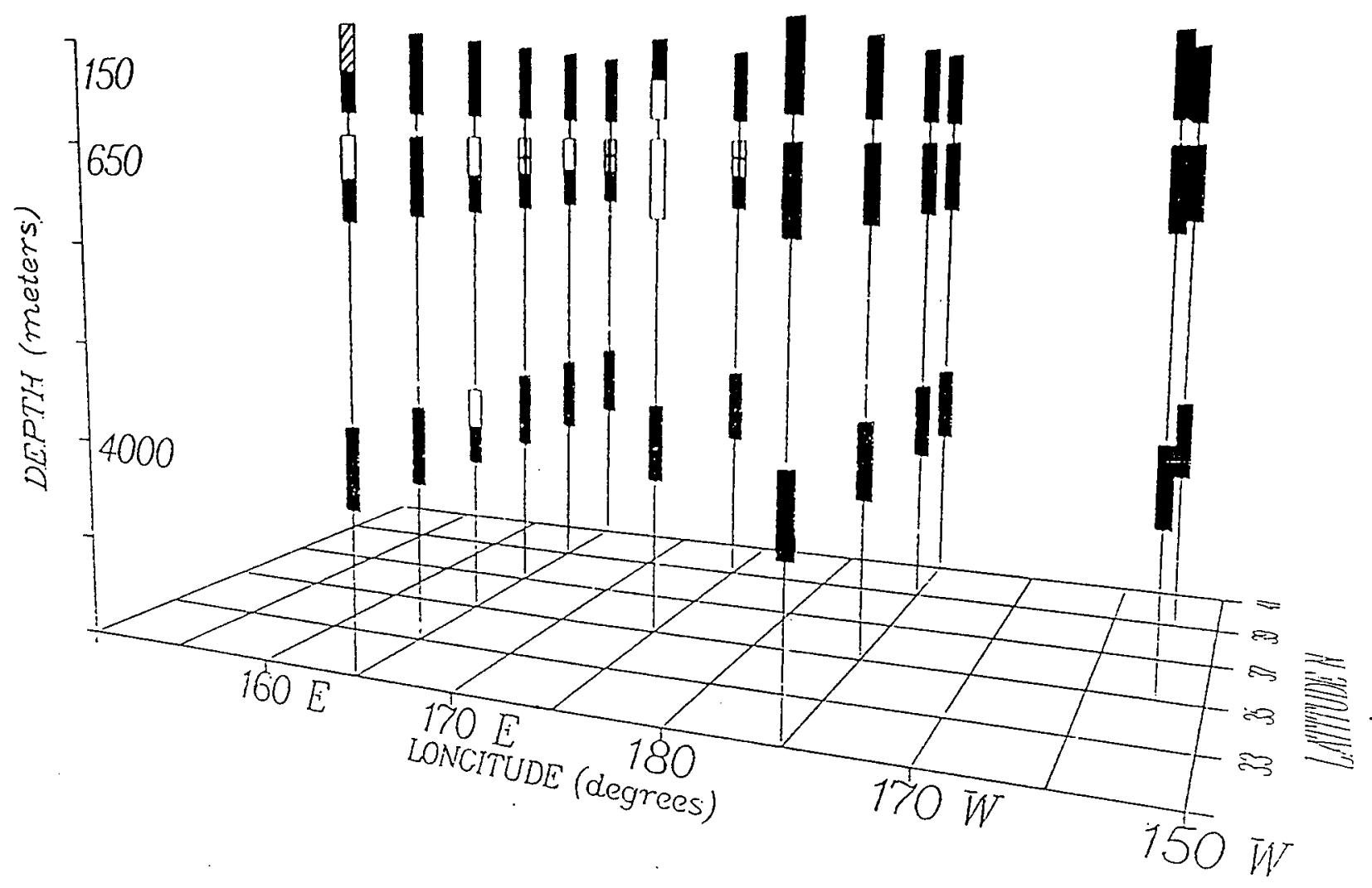

= GOOD
$=$ PARTIAL
$=$ BAD
$\square=$ VMCM with Possible
High Threshold

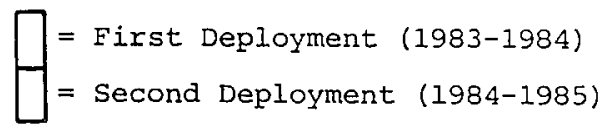

EXAMPLES

Q

Good Data Second Year

Good Data Both Years

Fig. 21 Data Return, ZONAL Pacific Experiment 
Two things have combined to make re-location of moorings with acoustic releases easier.

1. A clock has been built to trigger the transponder output pulse from the deck gear at precise intervals. This allows a visual presentation of the range to the release on the PGR, or echo sounder.

2. An inexpensive towfish has been built which can be towed by the ship at speeds up to 6 knots. The acoustic transducer is mounted in this fish, allowing release interrogation and ranging without stopping the ship. Hull-mounted transducers are another alternative, but not all ships have public transducer wells.

Hull mounts also pick up a fair amount of ship's noise and when. the weather is rough, cavitation, bubbles, and heaving in and out of the water make them less than ideal acoustic receivers.

The usefulness of this technique was demonstrated during the recovery of the last ZONAL mooring, number 815 , in the middle of the night of 27 october, 1985. For some reason, the wire near the third glass ball cluster fouled on the rehaul sheave, breaking the wire, leaving the bottom cluster of glass balls with the release hanging under it drifting free about a mile from the ship. The towfish was re-deployed over the stern and began interrogating the release at two second intervals. With the PGR on a two second sweep, the range to the release could be easily seen. The ship got under way and was guided to the ball cluster in 28 minutes. In 1981 an identical thing happened during the recovery of mooring 703 (Bradley, P. 25). Re-locating the ball cluster at night without this system required six hours. 
D. Release Problems

1. Acoustic Release Implosion, Mooring 805,3 Dec 83

It is still unclear why release number 601 imploded on mooring 805. It had been owned by the group for 10 years and had been deployed many times at depths greater than 5, 000 meters for periods of one year. 6,236 meters was, however, the deepest it had been. One clue, perhaps, is the fact that a glass ball about two meters away had imploded also. This raises the possibility of sympathetic implosion. Even if that is what happened, we don't know which one caused it. Logic says the ball did it, because I have seen many imploded balls and only one imploded instrument, but the facts are that we will never know for sure.

\section{Release Actuation after Deployment-Mooring 820 , 6 oct 84}

on ingpection after the failure, pins $J$ and $k$ of circuit connector $\mathrm{J} 4$ were found to arc when the pinger pinged, causing a false fire signal. Why it didn't show up when lowered to 2,000 meters for testing was not clear. Subsequently, in February, 1985, it was rejected from being used on a mooring for failing the air acoustics pre-launch checks. The transducer ceramic was subsequently found to be cracked, and was replaced. The problem with arcing could not be duplicated, but it is conceivable that a cracked transducer could shift position under great pressure. If 
it shifted to a low impedance or shorted position, the pinger circuitry could be overloaded to the point of arcing.

This release is presently deployed off Hawaii as the active release on mooring 832 , the extended duration subsurface mooring. No problems were encountered during the deployment. In December, 1986, it was interrogated by $\mathrm{s}$. Worrilow and was working fine.

3. Release Firing after Mooring Recovery-Number 502721 , Sep 85 This release was stored in the main $l a b$ of the ship and fired when a door slammed loudly. This release was badly damaged near the transducer area during recovery. It got caught under the stern of the ship and the transducer protective cage was ripped off. Mechanical shock has to be suspected here, since the release stayed in the water for two years without firing prematurely. On inspection, the listening amplifier was very noisy and needed replacement, and the D1 board was found to be out of tune and would receive receiver $2,3,4$, and 5 .

\section{Release No. 324, Failed to Release, Mooring 794,1 oct 85}

on inspection, the squib firing battery was dead. In the lab this was traced to a leaky squib. This is a very disturbing malfunction, because every squib which goes into a Buoy Group release is checked for leakage. The only conclusion that fits is that sometime during the deployment, the squib began to leak, drawing down the firing battery. 
E. VMCM Problems

Of the seven VMCMs deployed in the first setting of ZONAL, 1983-1984, one flooded, three had water in the sting, and the remaining three had suspicious rotor drop-out problems. Jim Valdes, Head of Buoy Group Technical Support, has spent much of his time troubleshooting this problem. The following "zonaL VMCM Rotor Report" is his conclusion as to what was wrong with the first setting of VMCMs in ZONAL. 
ZONAL - VMCM Rotor Report

Summary

The first group of Vector measuring Current Meters recovered from the ZONAL Pacific Array presented several unique problems. Three of the instruments experienced flooded stings and four others had rotor problems characteristic of missing counts (Fig. 22, 23). Figure 23 is a typical VMCM time series; note the smooth transition through zero for Rotor 1 and Rotor 2 . Figure 22 is a time series from ZONAL I; note the disconinuity about zero.

\section{Background}

This was the first major deployment of VMCMs several hundred meters deep on subsurface moorings. The deployments prior to ZONAL had been on surface moorings under a toroid (CODE) or discus (LOTUS) buoy. The results from lotus were disappointing. The bearing assemblies in the VMCMs were literally falling apart from the dynamics under the buoy. In an effort to reduce the axial forces on the bearing assemblies, the bearing endplay was reduced to zero, effectively preloading the bearings. In the presence of this preloading the dynamics introduced by the surface float are adequate to maintain the VMCM rotors above threshold, those on a quiet subsurface mooring are not. Unfortunately, this assembly procedure carried through to those instruments prepared for deployment on ZONAL as well."

The VMCMs recovered from the first setting of the ZONAL 
ZONAL Position 14, first setting, depth $669 \mathrm{~m}$

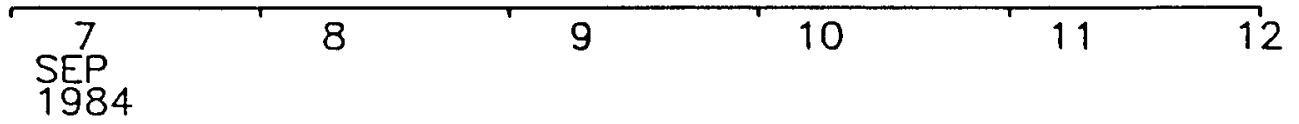

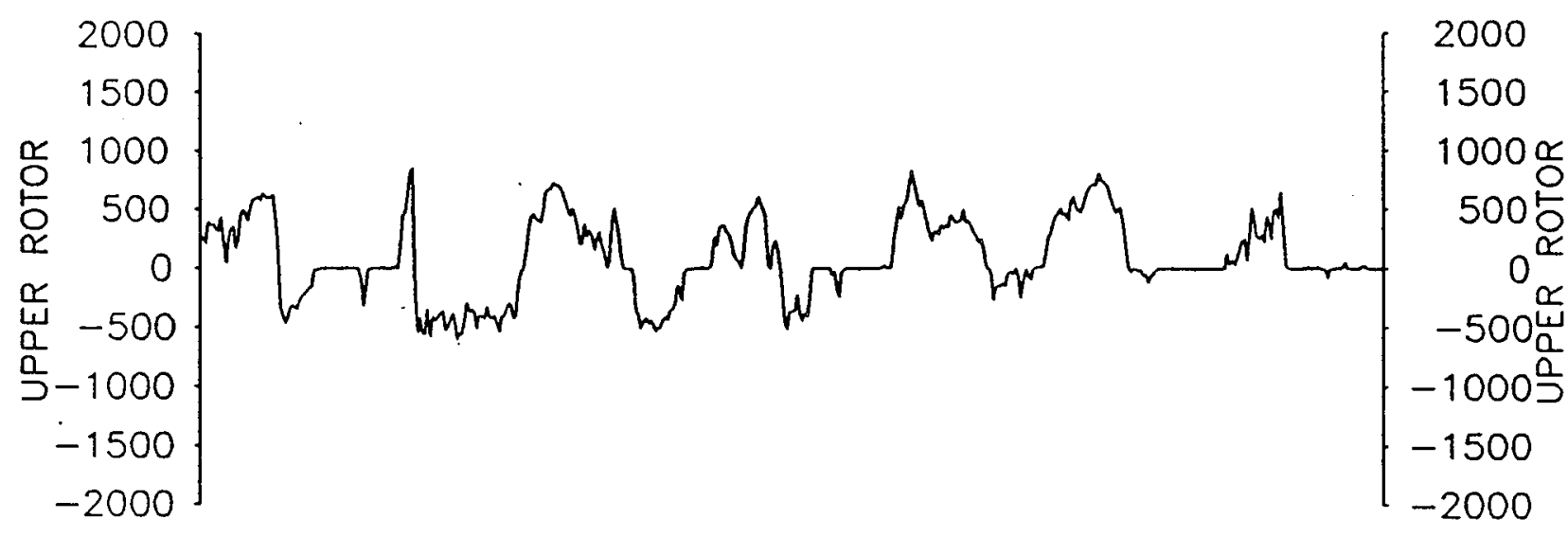
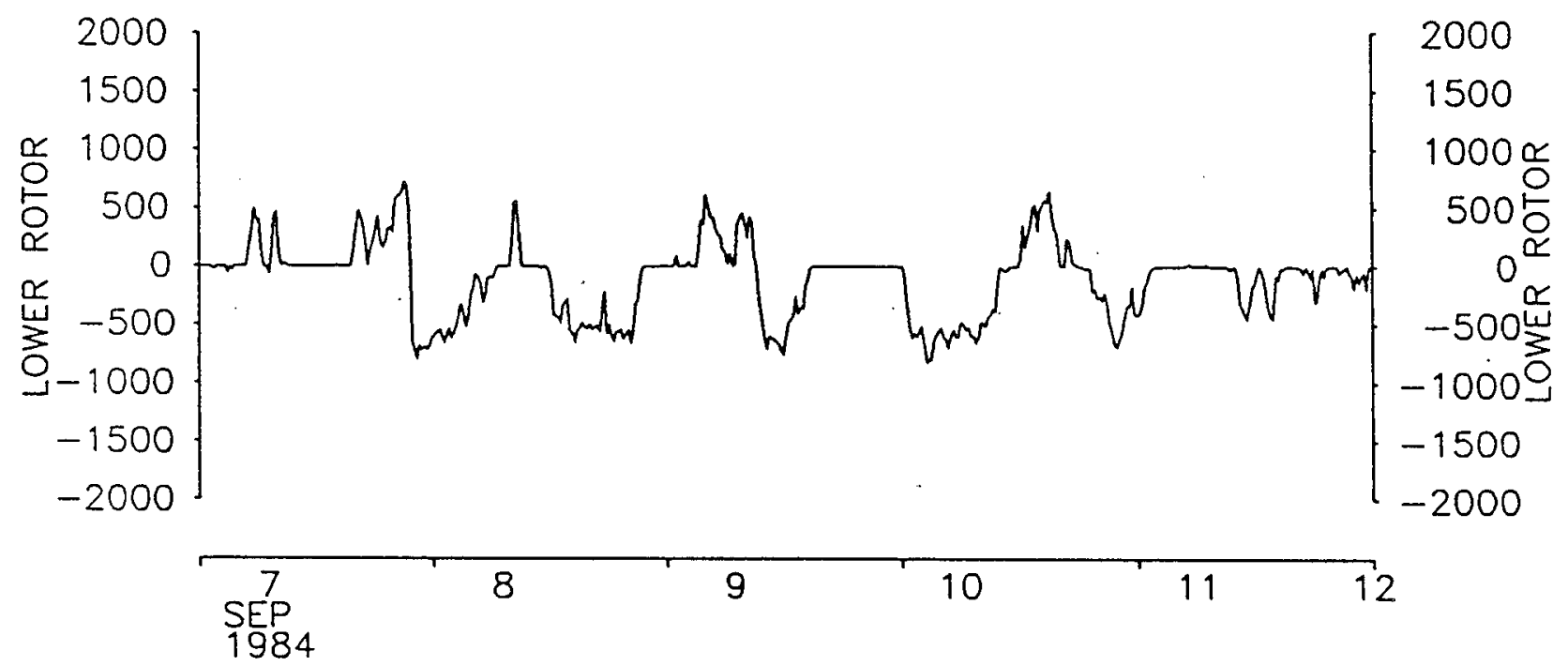

Fig. 22 A VMCM data record from the first year's zONAL deployment (1983-1984) 
array exhibited several electro-mechanical problems, most of which were related to the sting assembly. An analysis of the hub assembly indicated the possibility of inadequate o-Ring compression between the window and the face as well as an interference fit between a foil run on the sony board and the shoulder on which it rests. This contact resulted in the sony signal being shunted to ground with a corresponding loss in rotor counts. The interference problem is aggravated with depth. As the ambient pressure increases the likelihood of contact increases. Of the seven instruments recovered from ZONAL I, three had shallow-water leaks in the sting, one main housing leaked, and the remaining three had rotor dropout problems. After the recovery, our efforts concentrated on trying to duplicate the problem in the laboratory. These tests indicated that the Sony interference would duplicate the dropout over a very narrow range of signal leakage to ground. In retrospect, this was most likely not the cause of our rotor failures. The faulty diode boards were redesigned and replaced. More importantly, the instruments were modified to permit a vacuum to be pulled on the sting assembly. The vacuum ensures that all o-Rings are properly seated, thus precluding any possibility of shallow-water leaks.

After completing these modifications a short-term subsurface mooring was set to test the VMCMs, with a VACM included as a reference. The results were shocking. It appeared as though all of the VMCMs had rotor dropout problems similar to those observed on ZONAL I. One improvement was noted; none of the instruments 
leaked. An evaluation, using the reference vaCM, suggested a VMCM rotor threshold of nearly $6 \mathrm{~cm}$. / sec. This indicated a mechanical problem as the instruments tested fine electronically in the cold. After recovery the instruments had been placed in a cold chamber at $3^{\circ}$ C. for monitoring. Mechanically the rotors seemed a bit sluggish. Some would turn freely in the recirculating air of the cold chamber and others would not. Rotor shaft endplay was noted as .000/.001 in., an indication that the bearing assemblies were preloaded. At room temperature the endplay was noted as $.001 \% .002$ in. and the rotors turned freely. Clearly, there was a mechanical binding at the low temperature. An analysis of the hub assembly revealed a differential shrinkage due to temperature of .0012/.0015 in., between the stainless steel shaft and the aluminum hub combined with the delrin endcap. In addition, the procedure recommended for affixing the bearings to the shaft was in error. The method utilized recommended a shaft endplay of .003/.005 inches before the bearings were locked to the shaft, which is essentially the internal clearance of the bearings. After locking the bearings in place the endplay at room temperature is .000/.001 in. When one considers the shrinkage due to temperature it's obvoius that there wili be a problem. In a related item, the inside of the delrin cap also shrinks by .001 in., effectively grabbing the outer race of the bearing, fixing it in position relative to the hub. The procedure for locking the bearings on the shaft evolved during the LOTUS program in an effort to prolong the life of the bearings. Post-Lotus accelerated lab tests suggested that 
locking the inner race to the shaft significantly prolonged the Iife of the bearings.

This was a satisfactory explanation for the results of the test mooring but not for ZONAL I. Those bearings had not been fixed to the shaft. In the intervening period ZONAL II was recovered and yielded nearly 100\% data return. Why? During the time ZONAL I was in the water several of the mechanical parts of the hub assembly were "fine tuned" to ease in assembly. New shafts were procured. This new design provided tenths of a thousandth clearance between the shaft and the inner race of the bearing. The older shafts had essentially been a press fit.

This, I believe, was the ZONAL I scenario - the shaft endplay was set to .003 in., and the bearings were a tight fit on the shaft. At depth, the decrease in temperature locked the bearing in the endcap and the differential shrinkage preloaded the bearings resulting in a high rotor threshold. Examination of the records suggests a threshold in the order of 3 to $4 \mathrm{~cm}$. / sec, , for those instruments which did not flood. Unlike the more conventional VACM which has a unidirectional sensor, the VMCM has two rotors mounted orthogonally on the sting, which reverse direction of rotation in response to the driving current. We then are dealing with the cosine response of the sensors and their individual thresholds. The only significant difference between the settings of ZONAL I and II was the fit between the bearings and the shaft. Clearances were again .003 in., minus the shrinkage of .0015 in., leaving approximately.001 in. of endplay remaining IF the inner race of the bearing can slide on the shaft. 
Since the ZONAL experiment, the procedures for setting and verifying the instrument bearing clearances have been modified. All instruments are checked in the cold chamber prior to deployment and all endplays are noted. As a final check, the shaft is tested to ensure that it is free to turn and is able to cog in the cold due to the attraction between the sony diodes and the magnetic pick-up. 
V. ZONAL MOORING DRAHINGS

This section contains every mooring launched or recovered for the ZONAL experiment. They are presented in the order they were launched, beginning with mooring $793.793,794$, etc. are the WHOI Buoy Group Mooring Numbers, assigned sequentially as moorings are launched by the group. The "ZONAL NUMBER", 1-14, is simply a way of identifying the mooring's position in the array and was assigned long before the moorings went in the water. The instrument data numbers consist of the mooring number followed by a single digit signifying the vertical placement of the instrument in the mooring. For example, data number 7943 is the third current meter from the top on mooring $794 ; 8251$ is the data record from the top current meter on mooring 825 . 


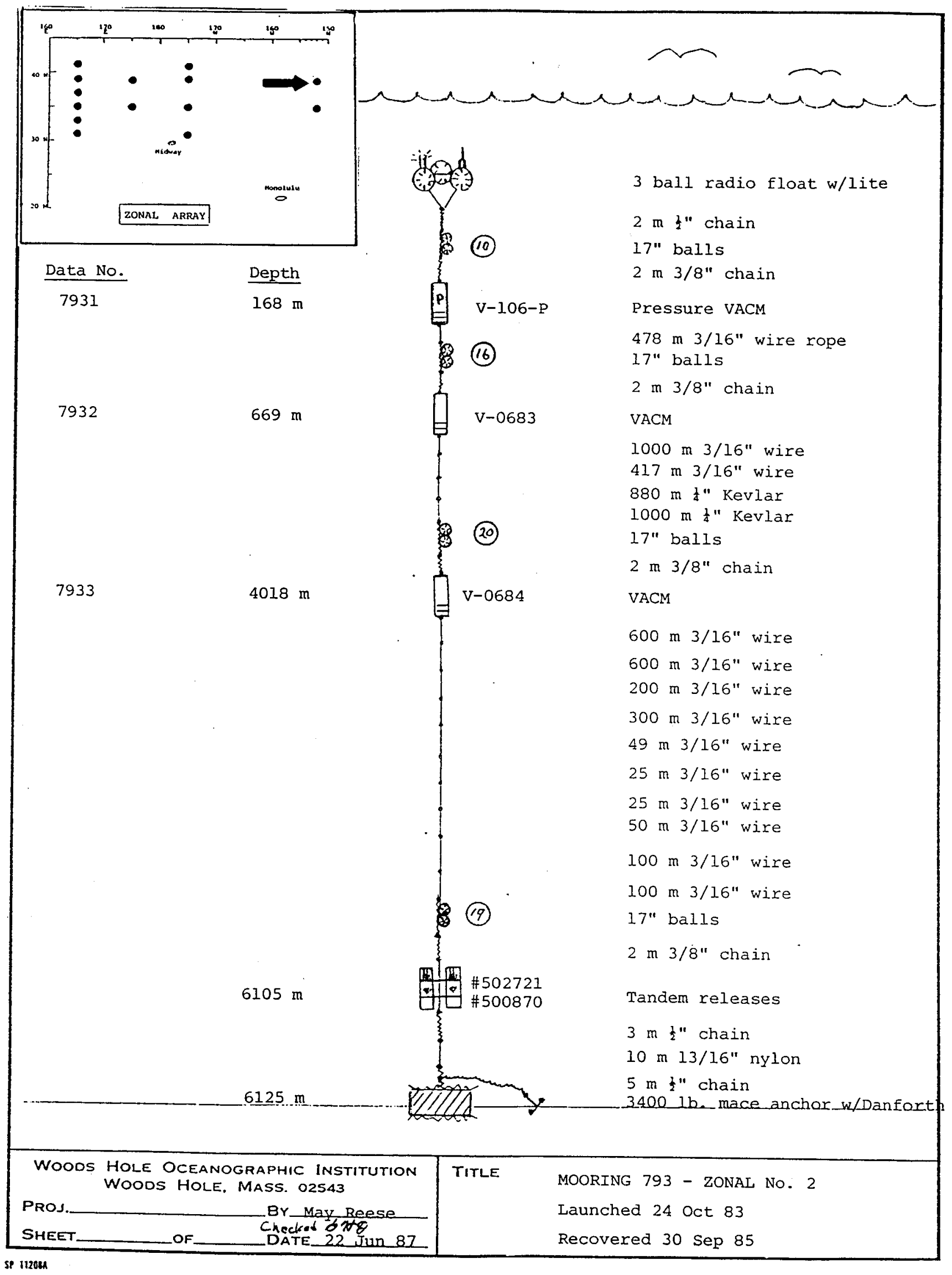




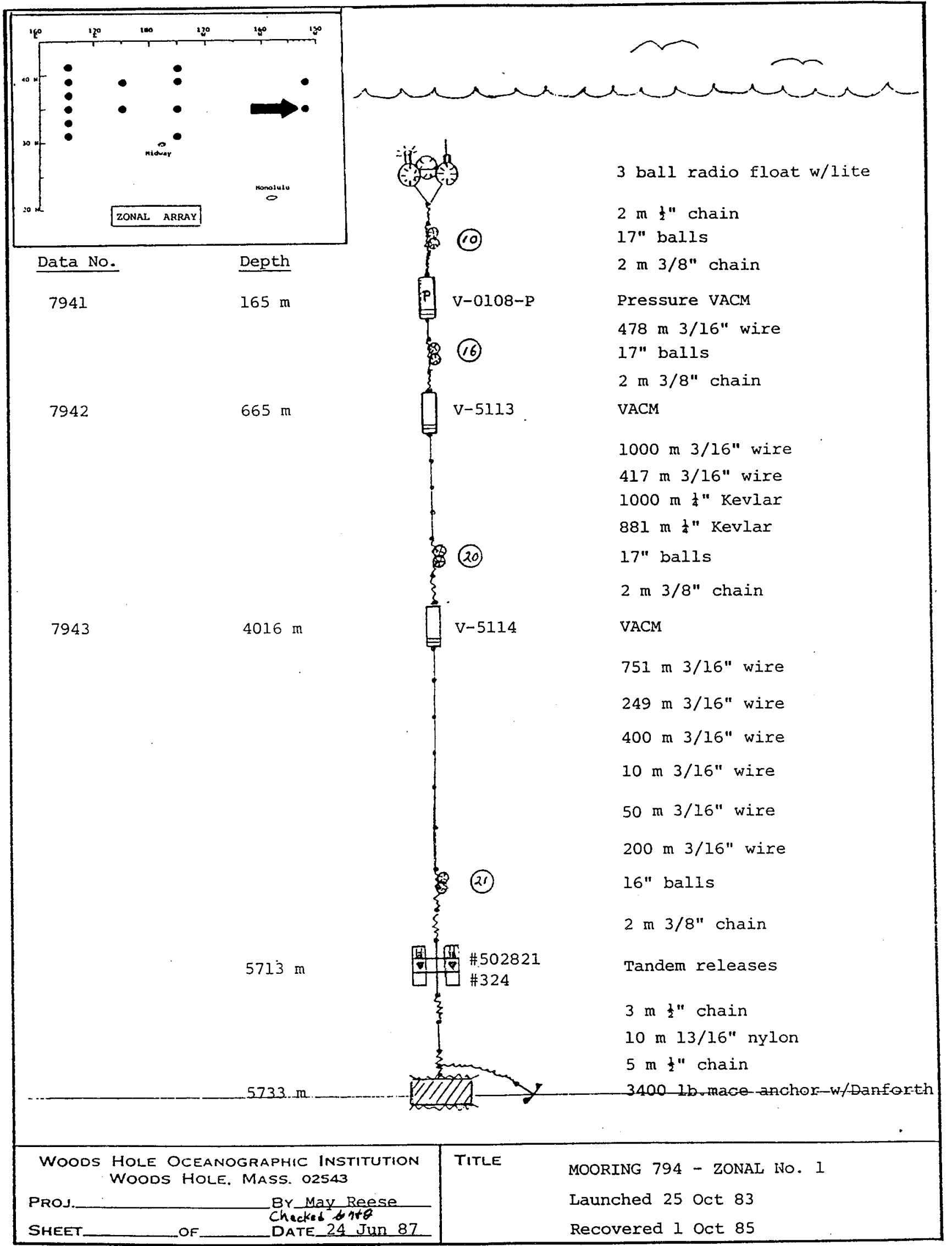

SP $1120 \mathrm{~A}$ 


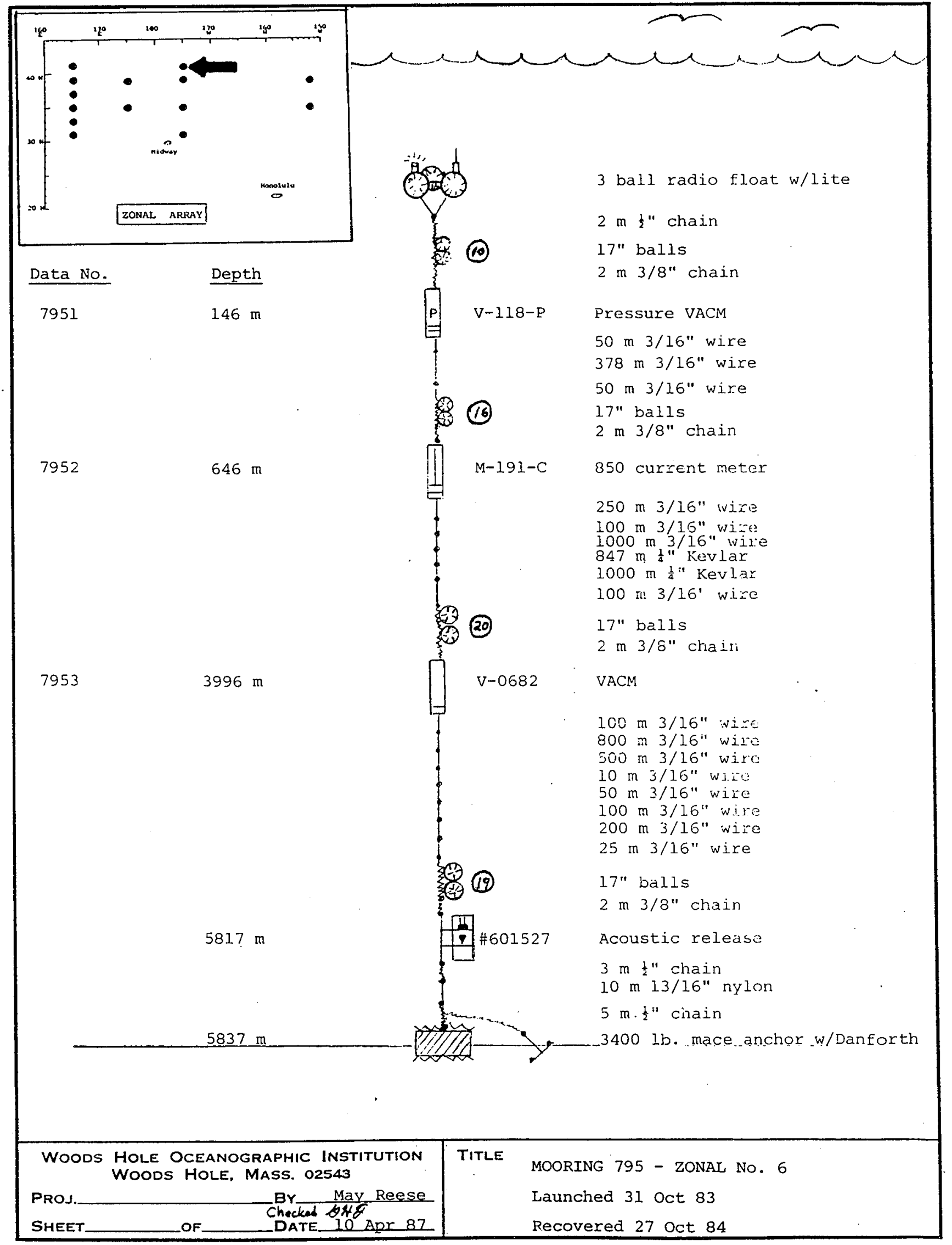

SP 112089 


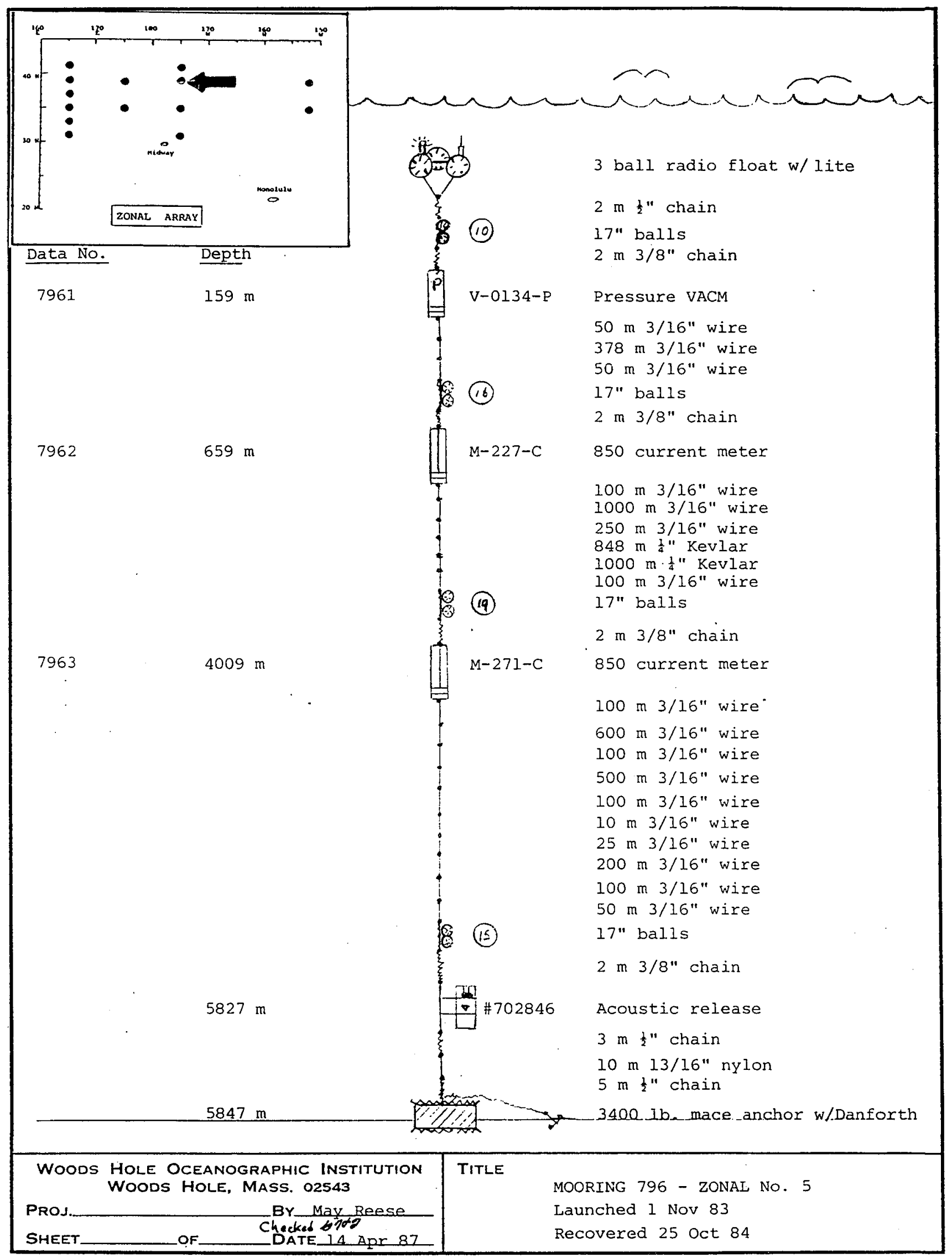

SP 112084 


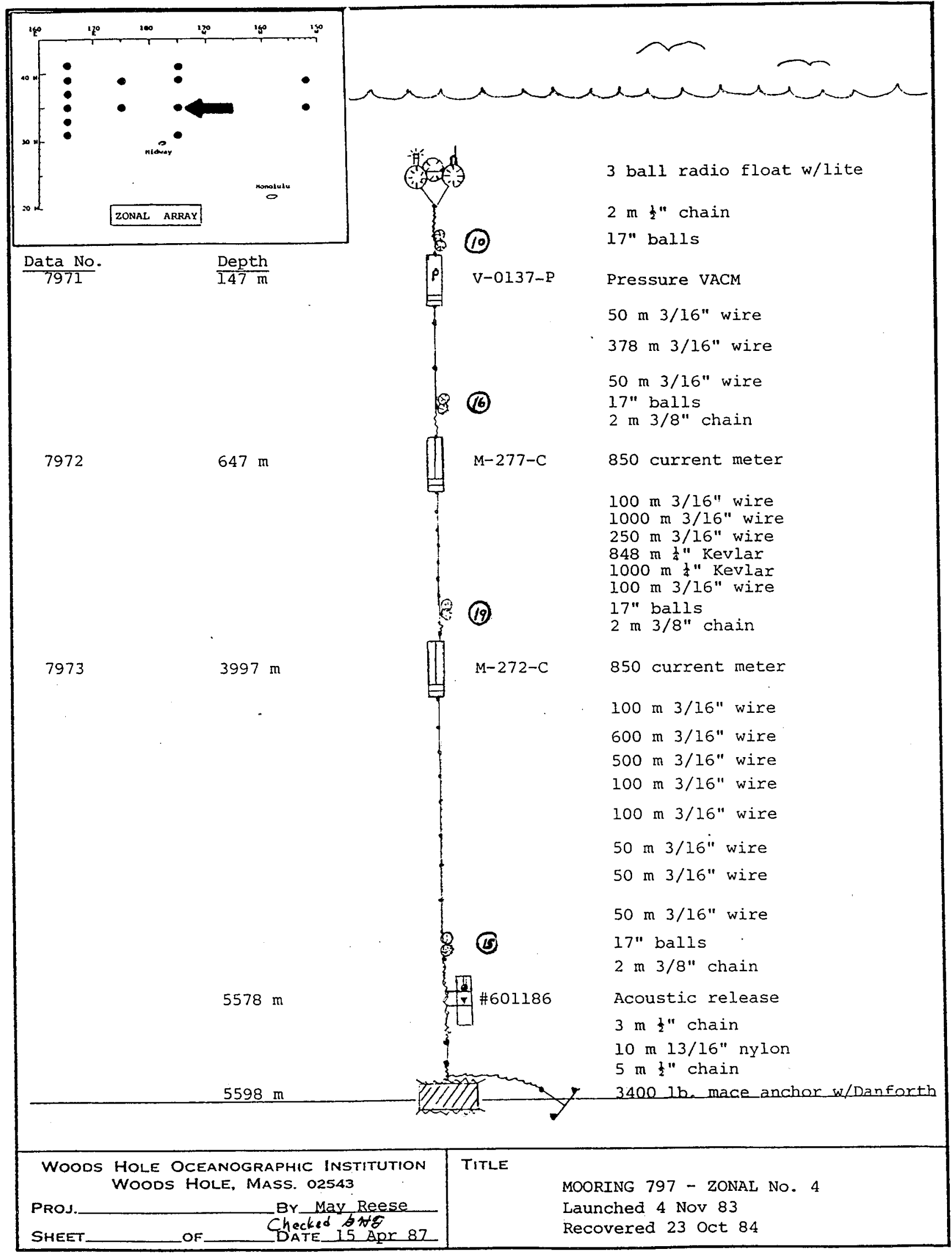

SP $1120 \mathrm{ses}$ 


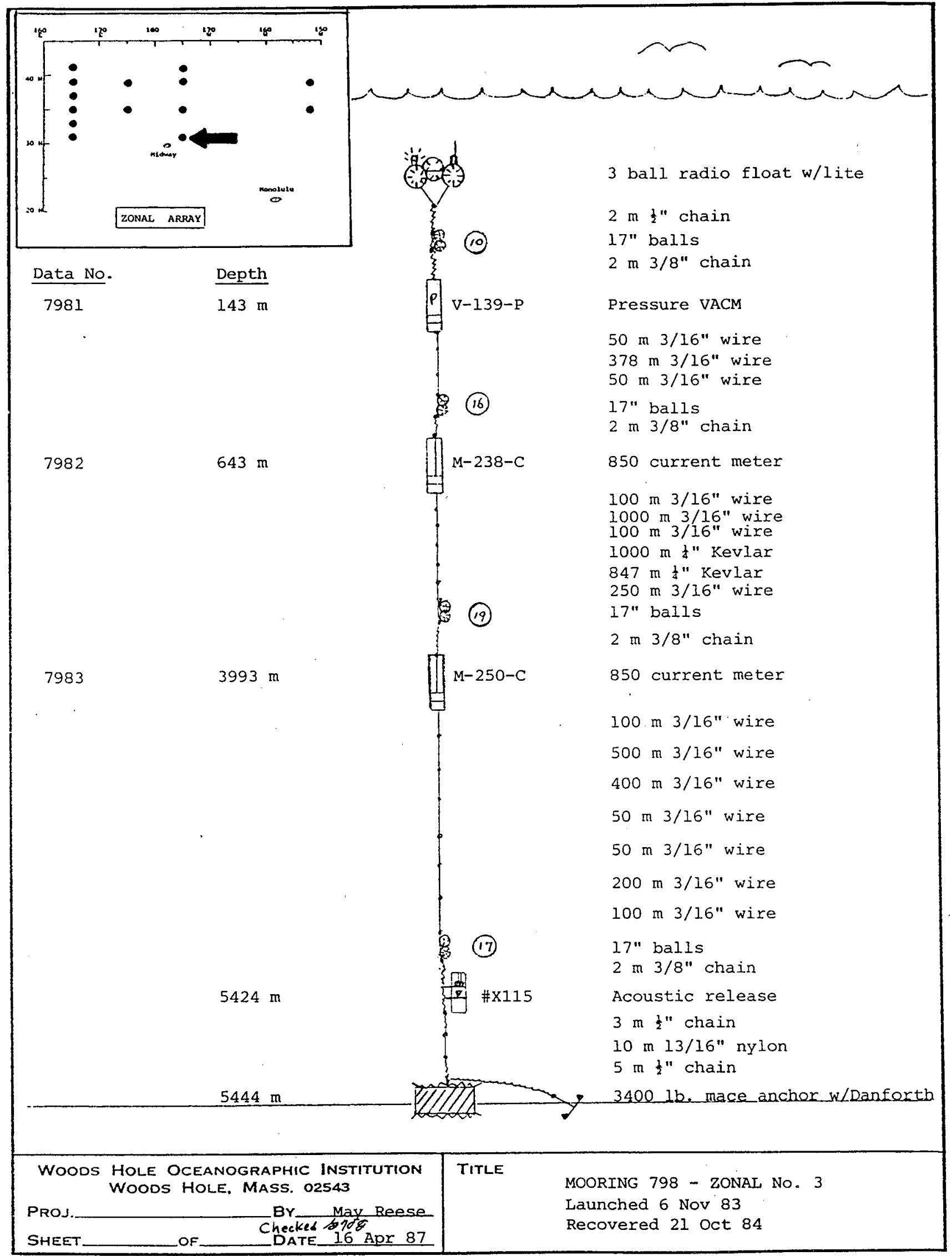

SP $11208 A$ 


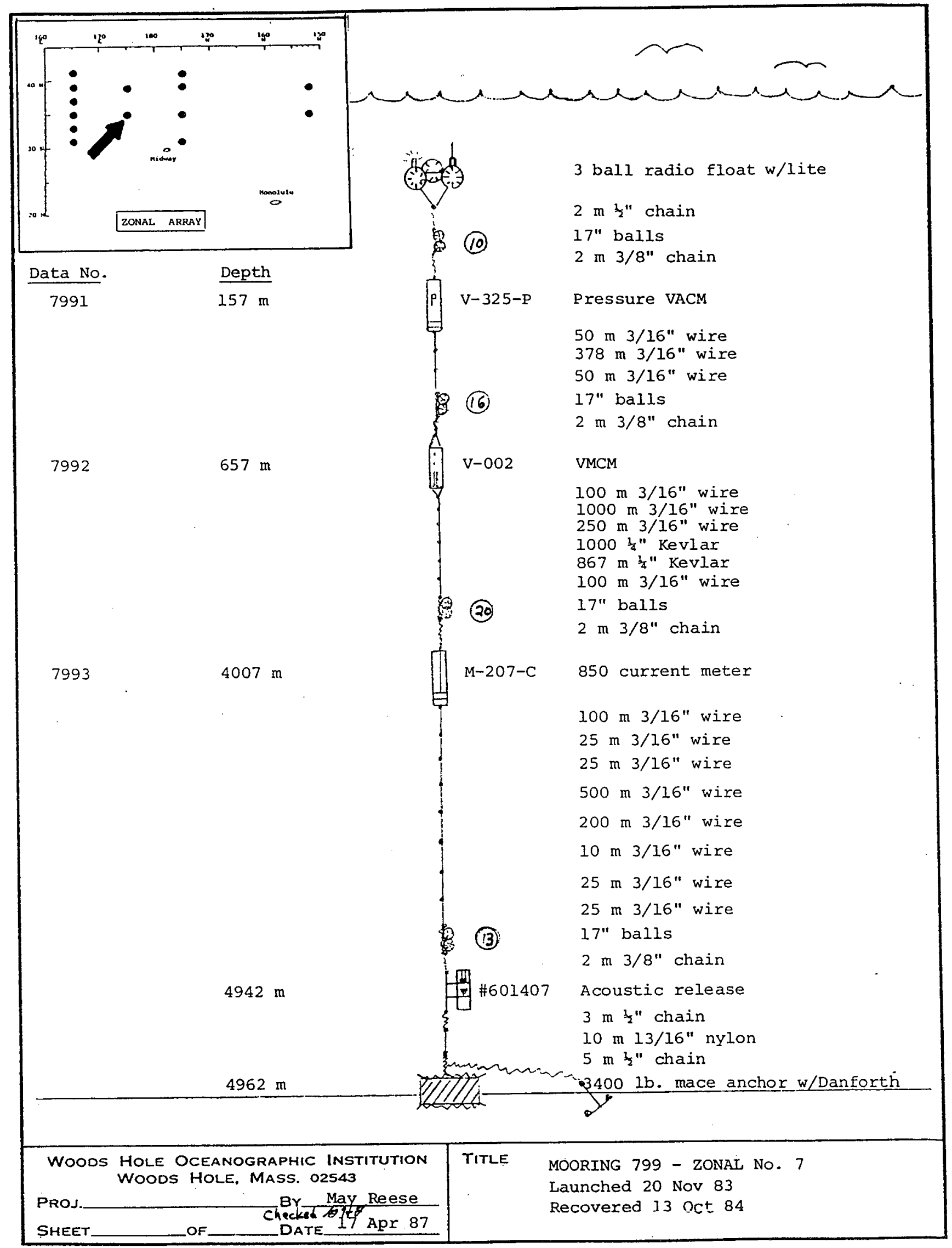

SP 11288 A 


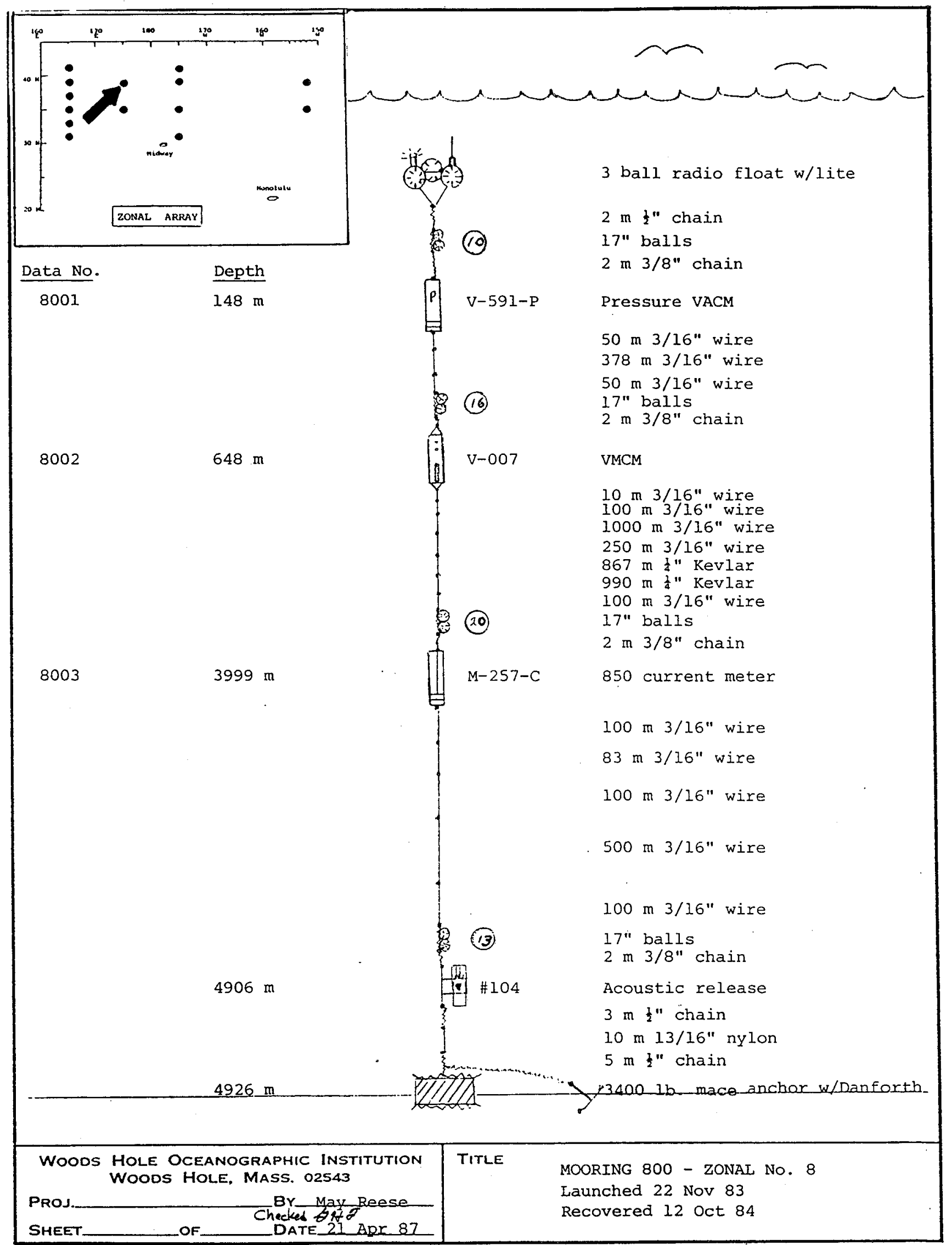

sp l12tu 


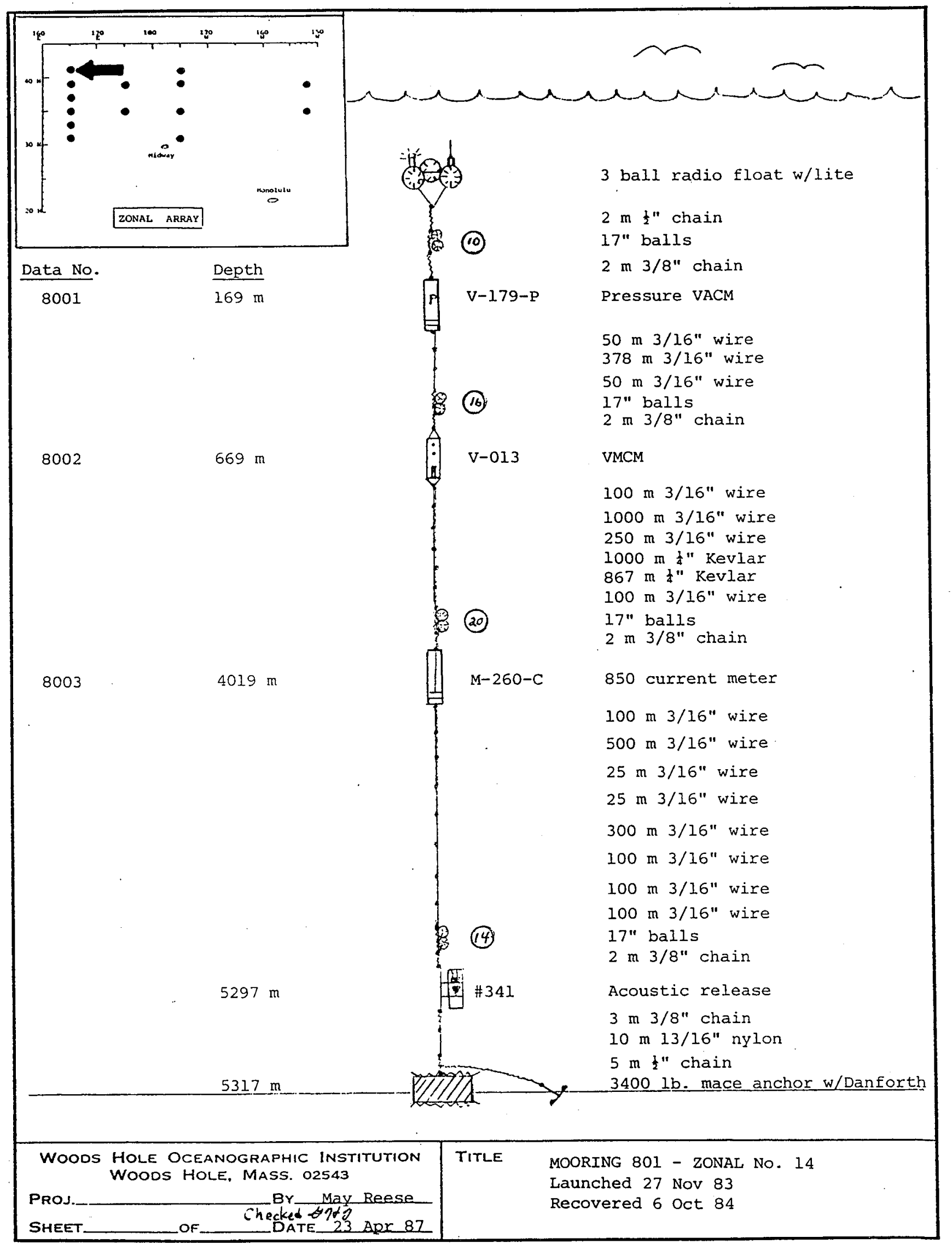

SP $1128 s$ A 


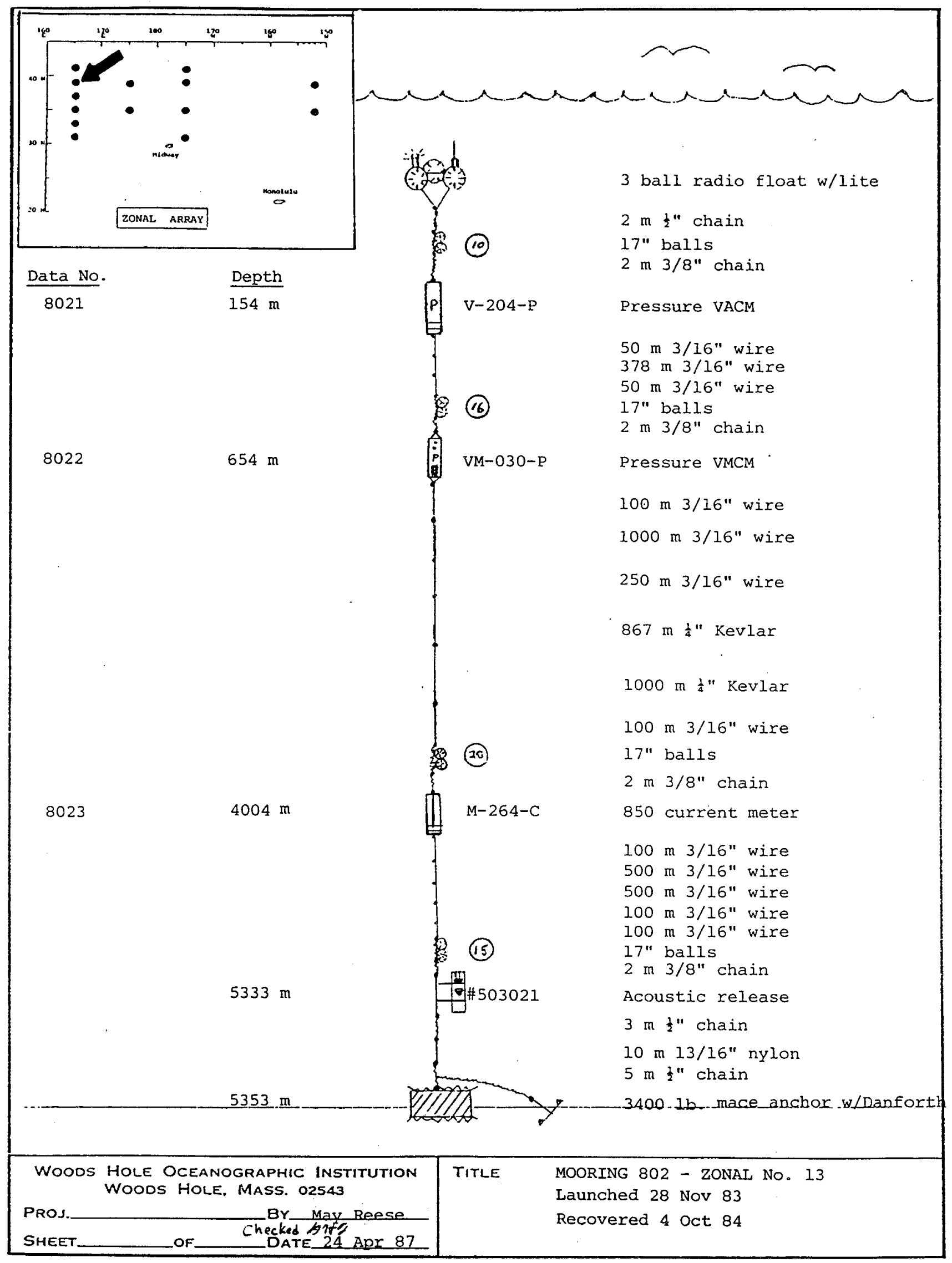

Sp 112001 


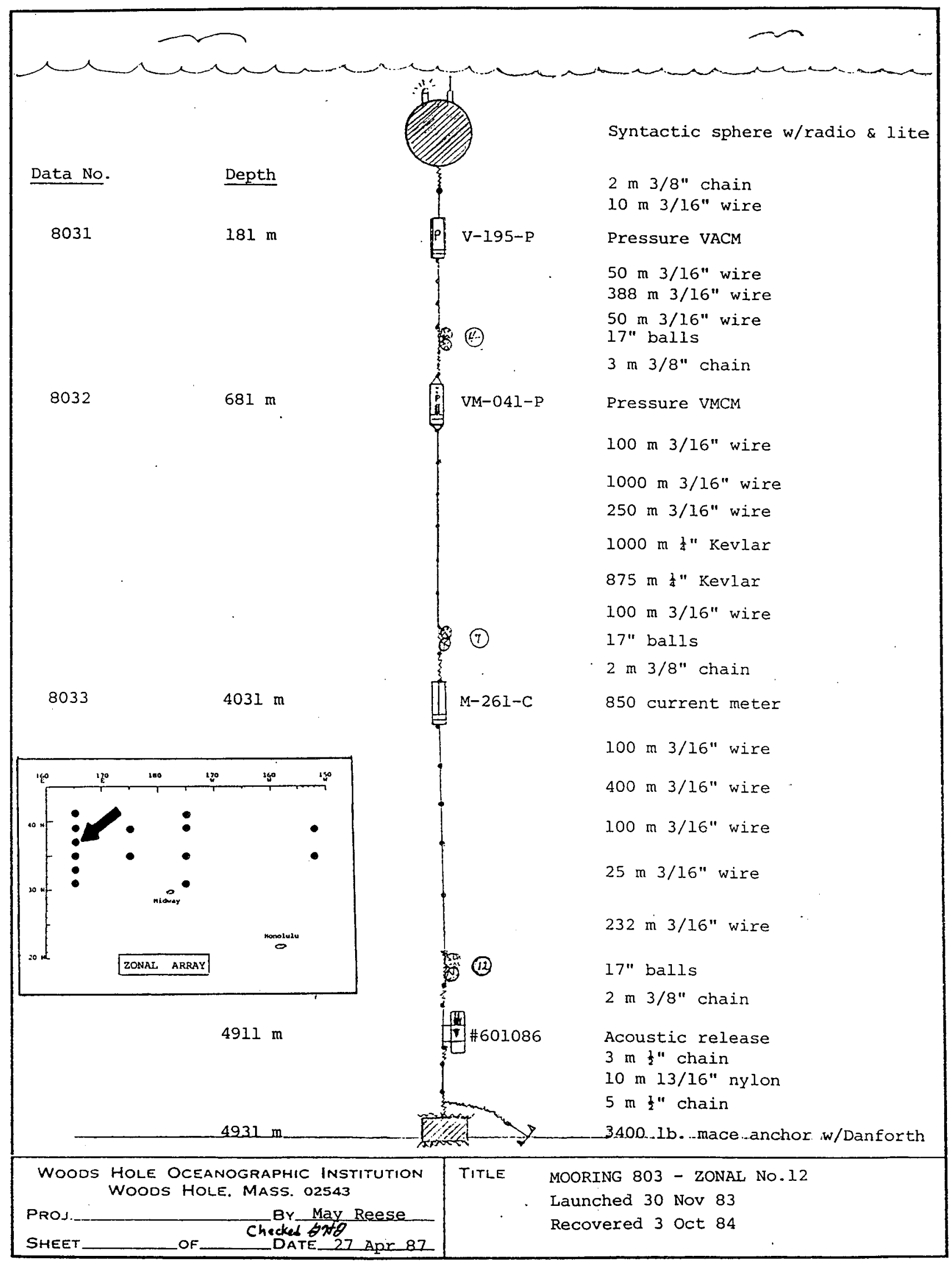

sP 11208 A 


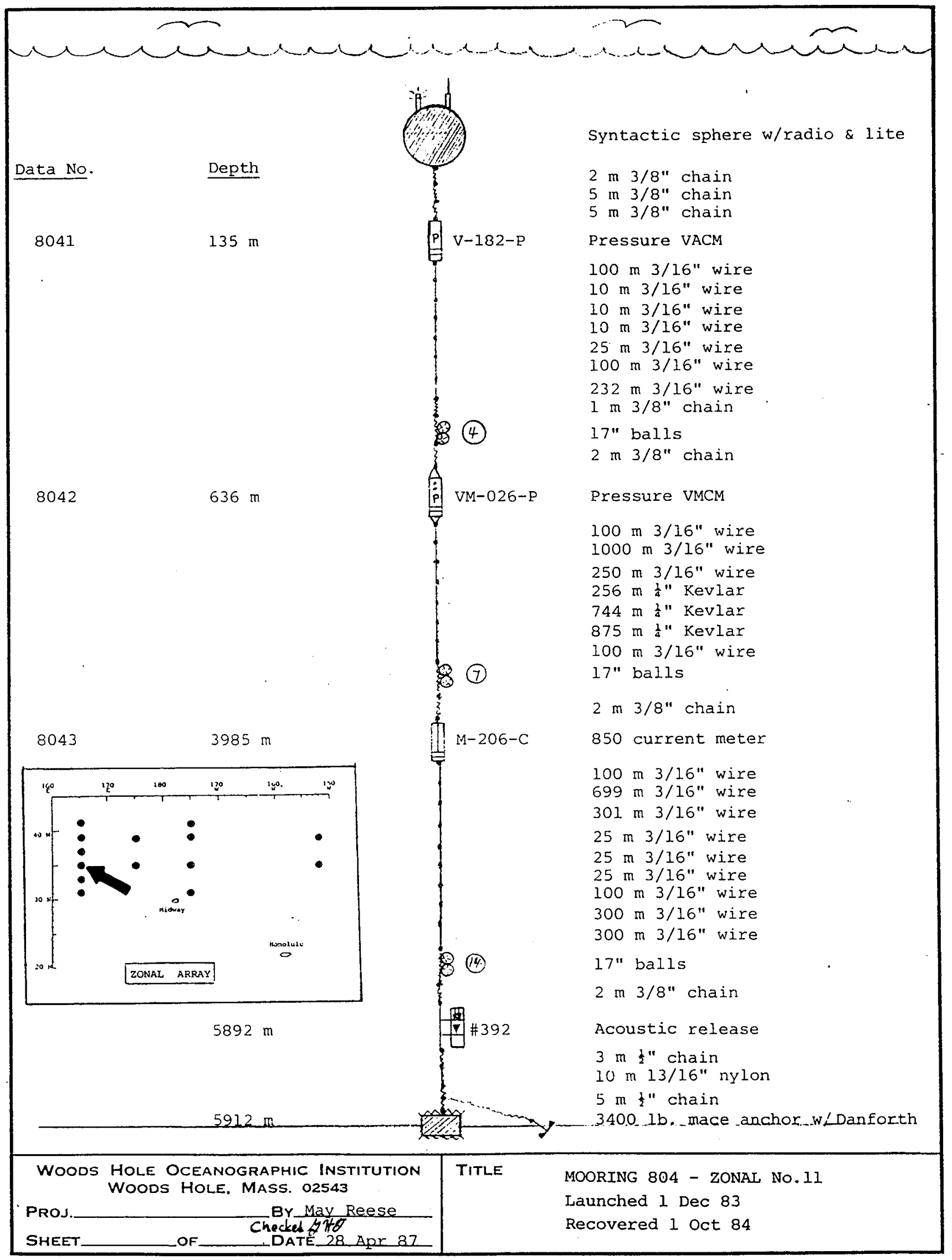

SP 11208 A 


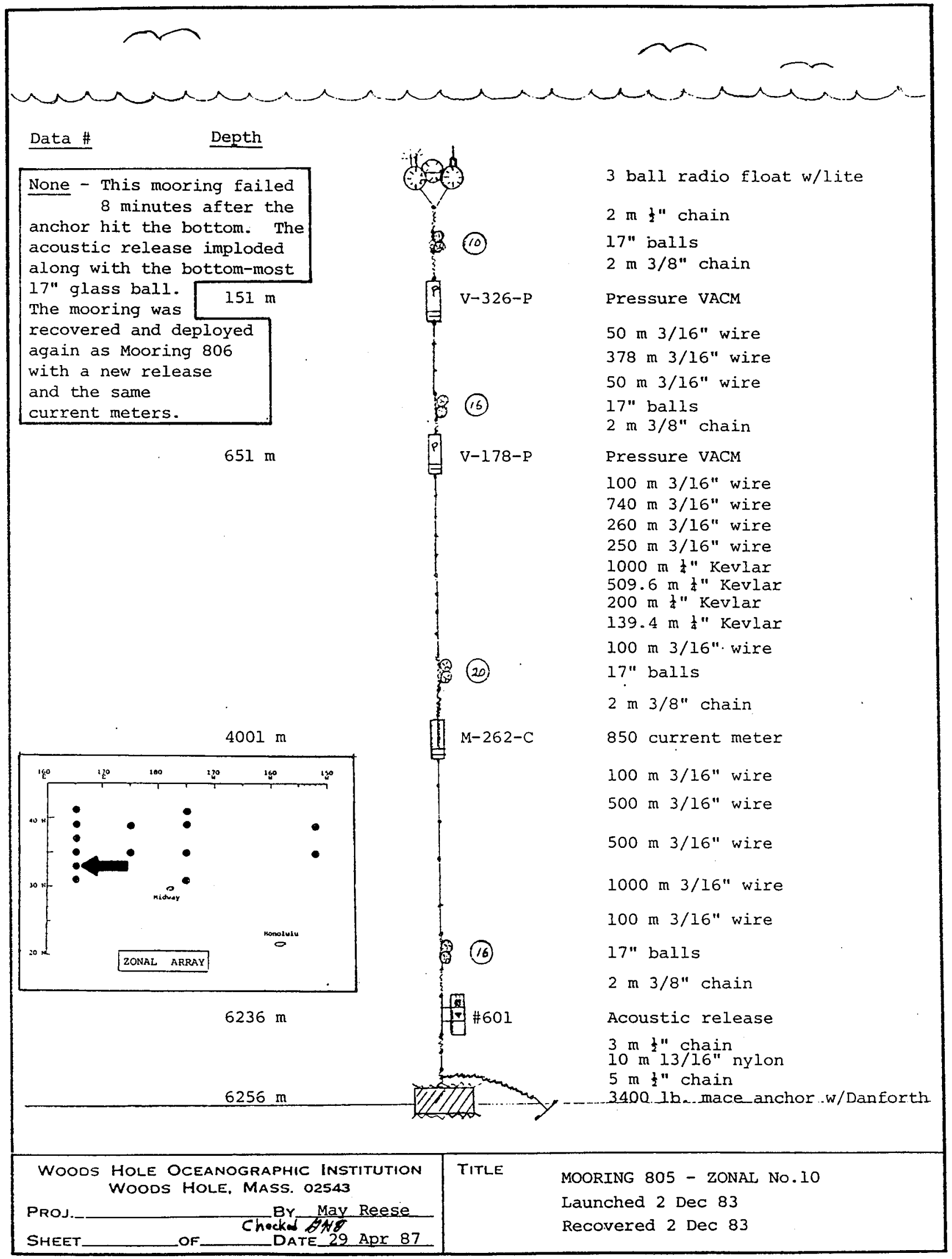

SP $11208 A$ 


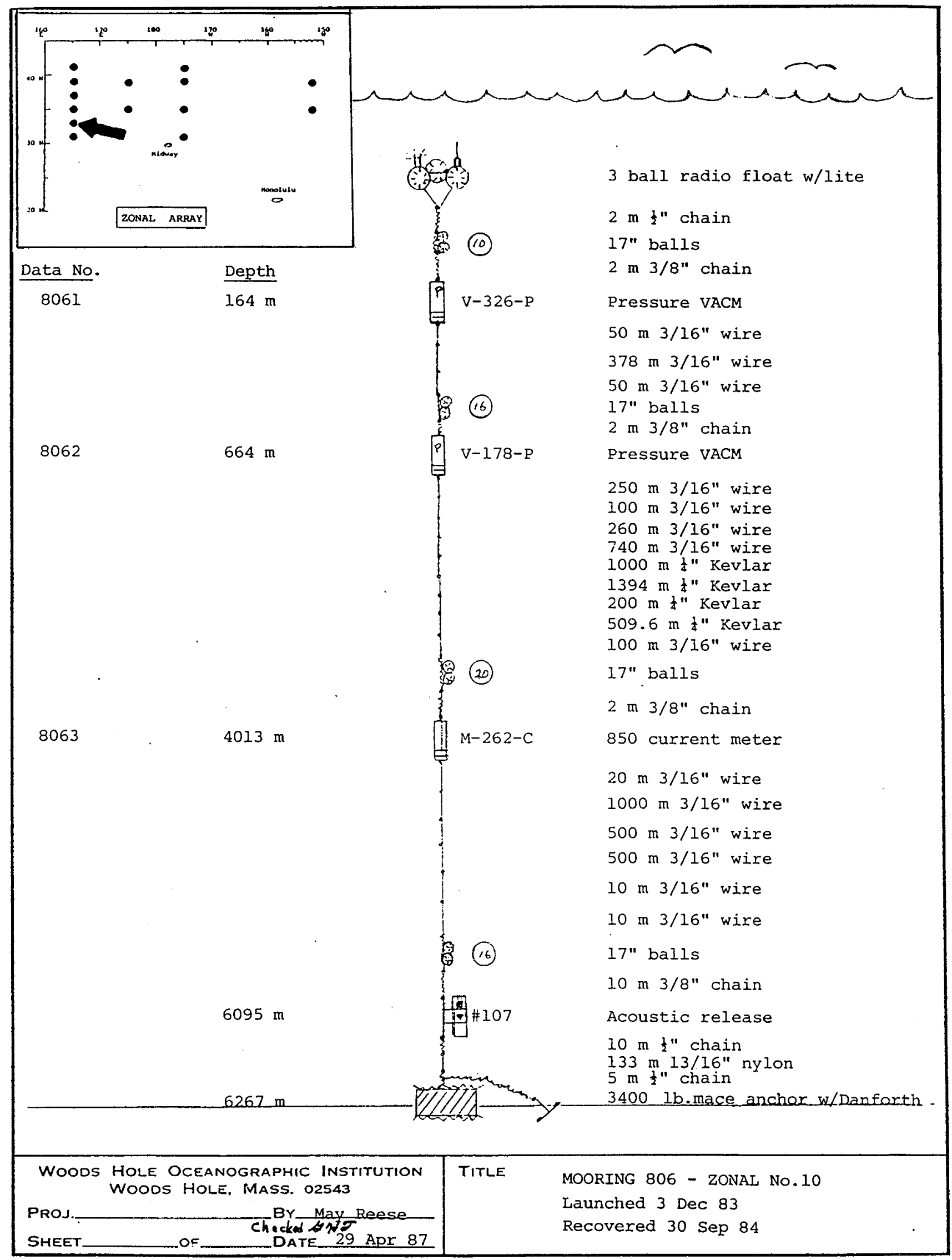

SP $11268 x$ 


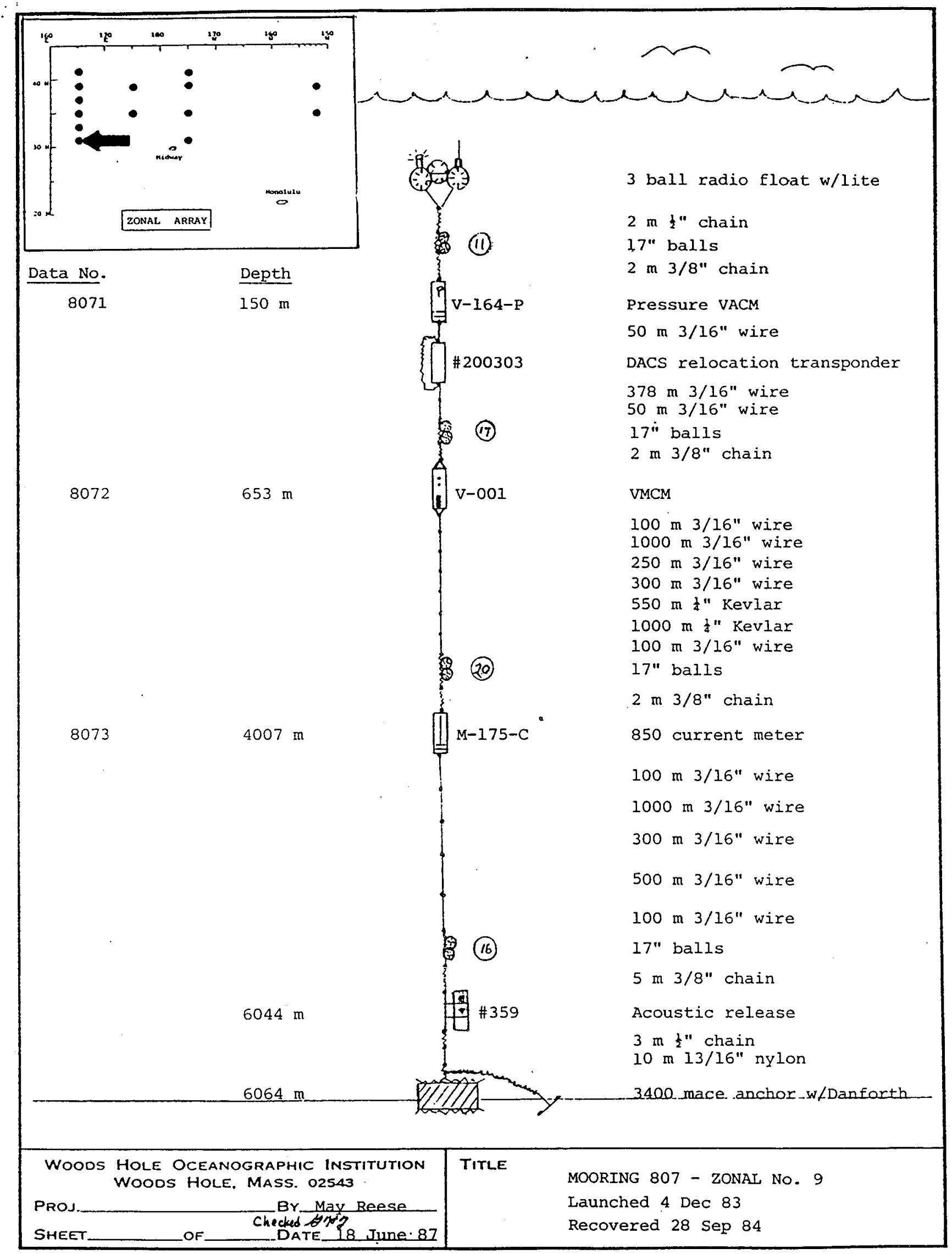

sp $1128 x$ 


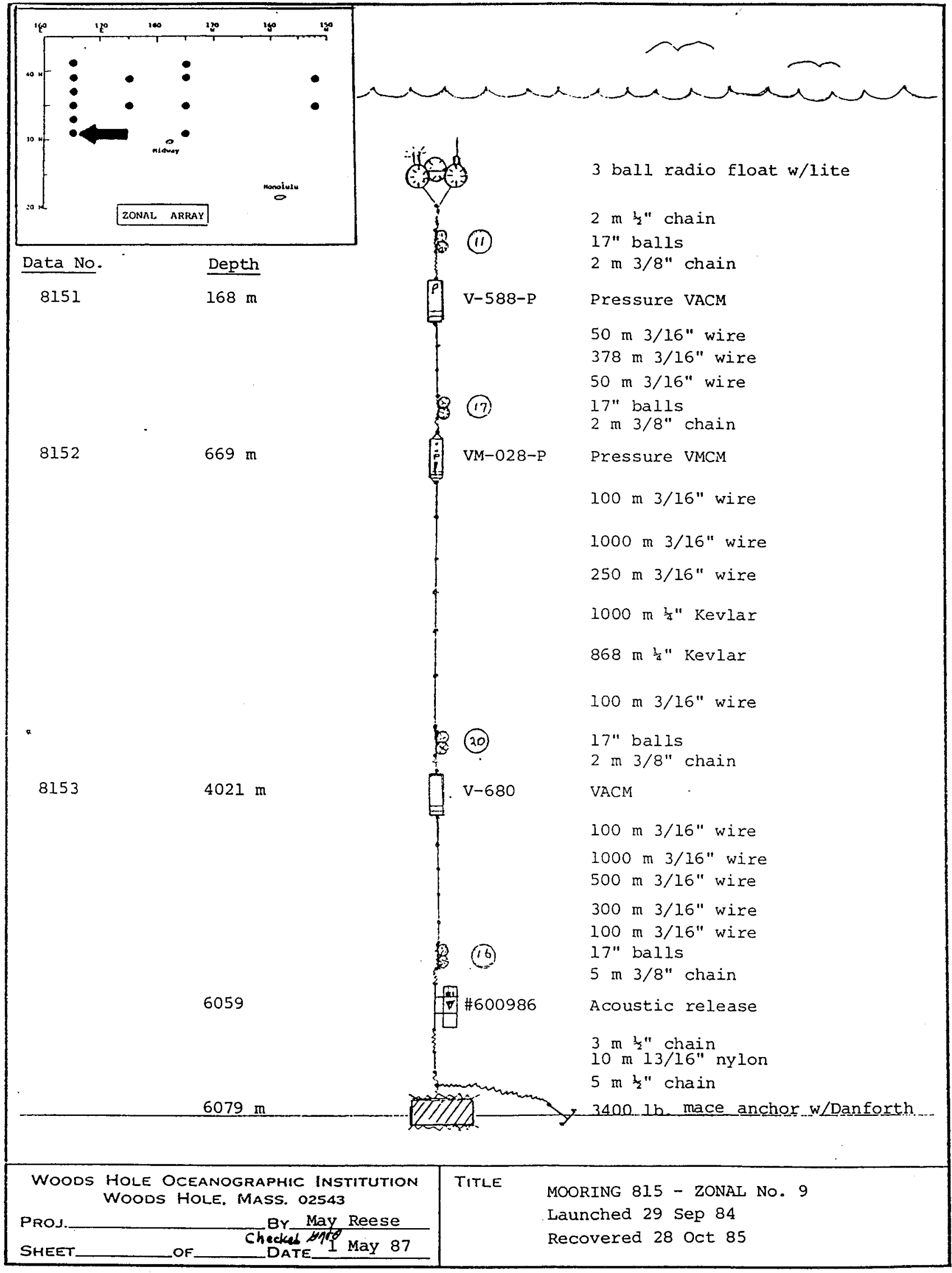

sp 11208 A 


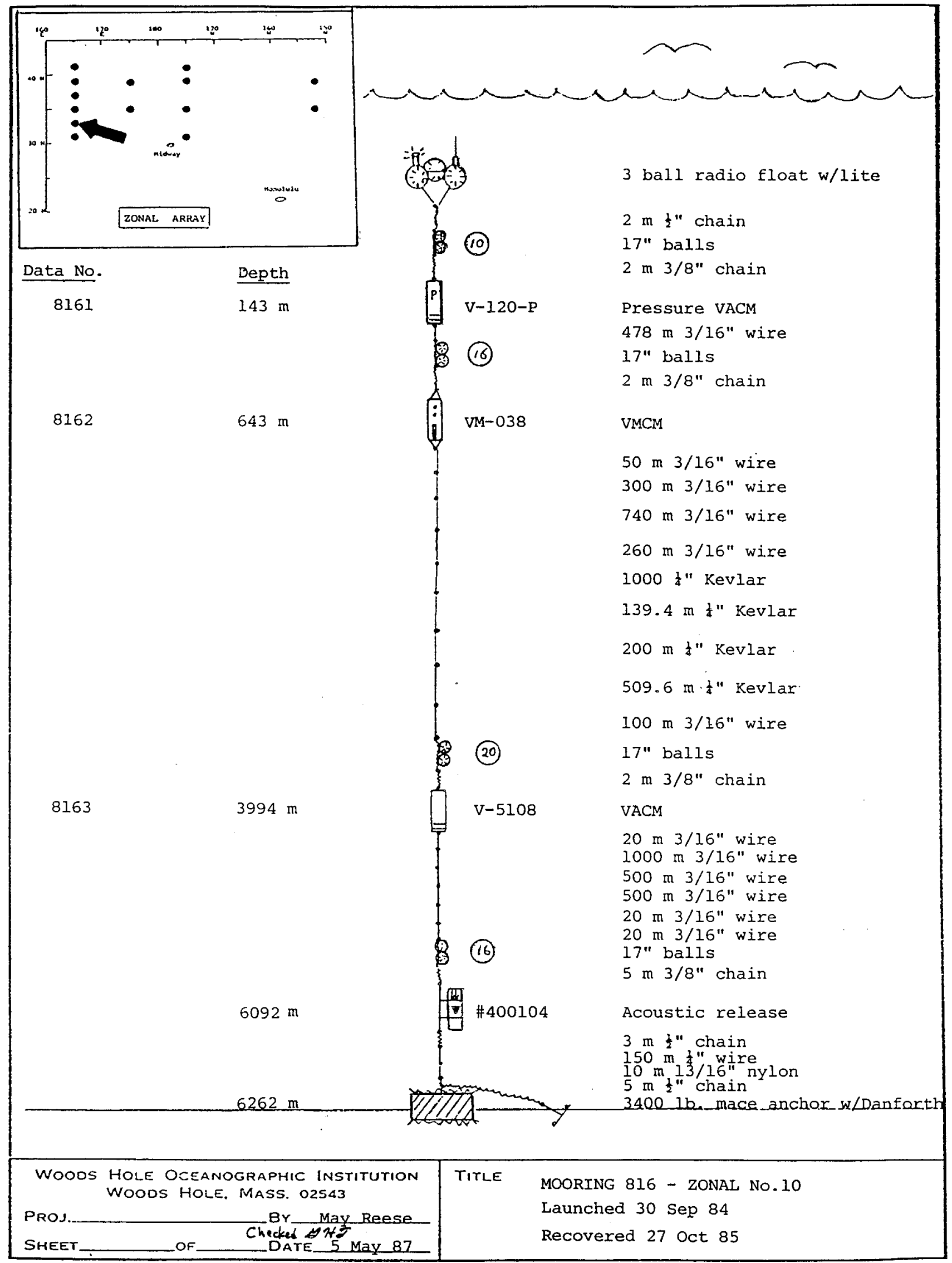

sp 11208s 


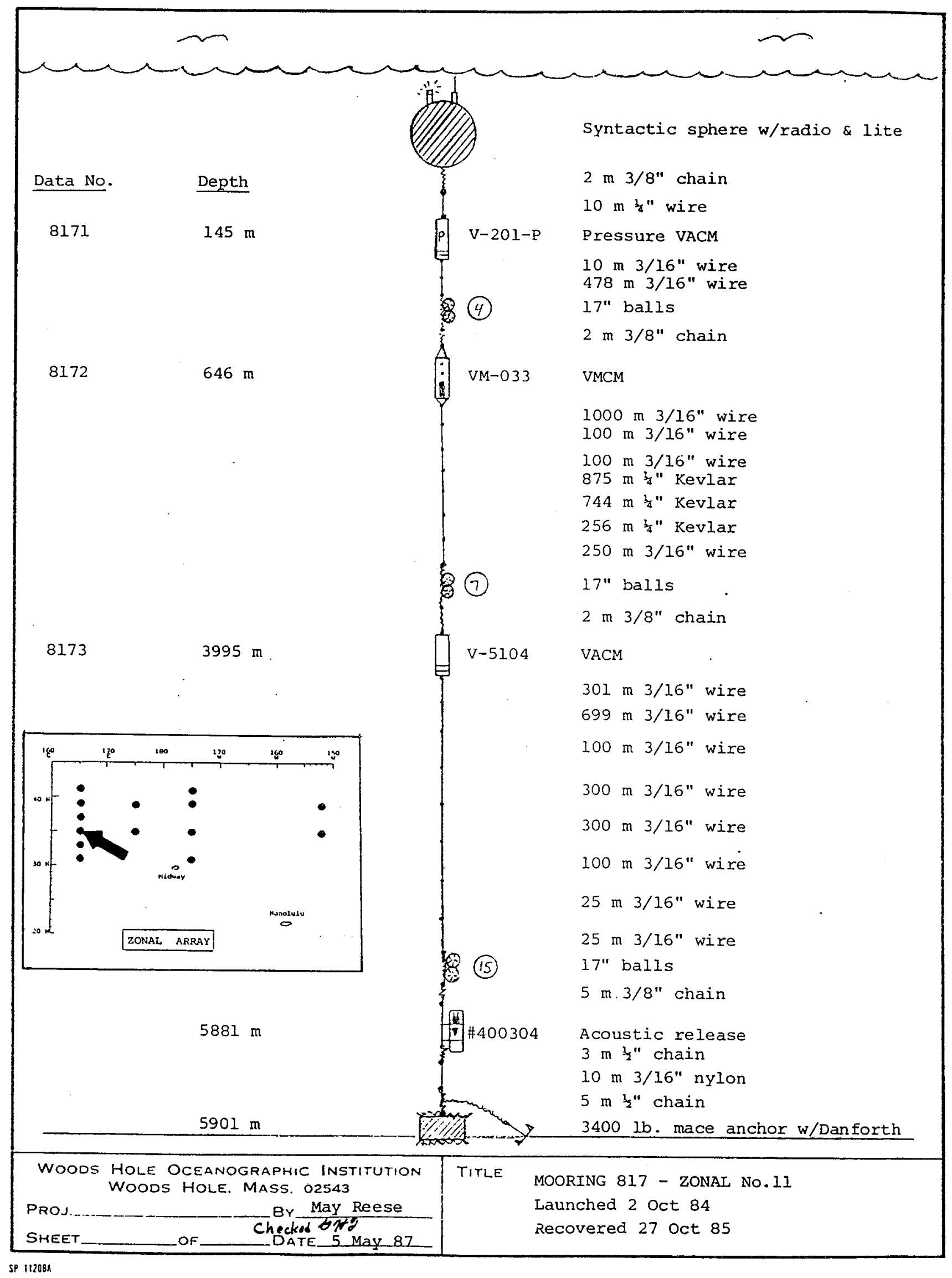




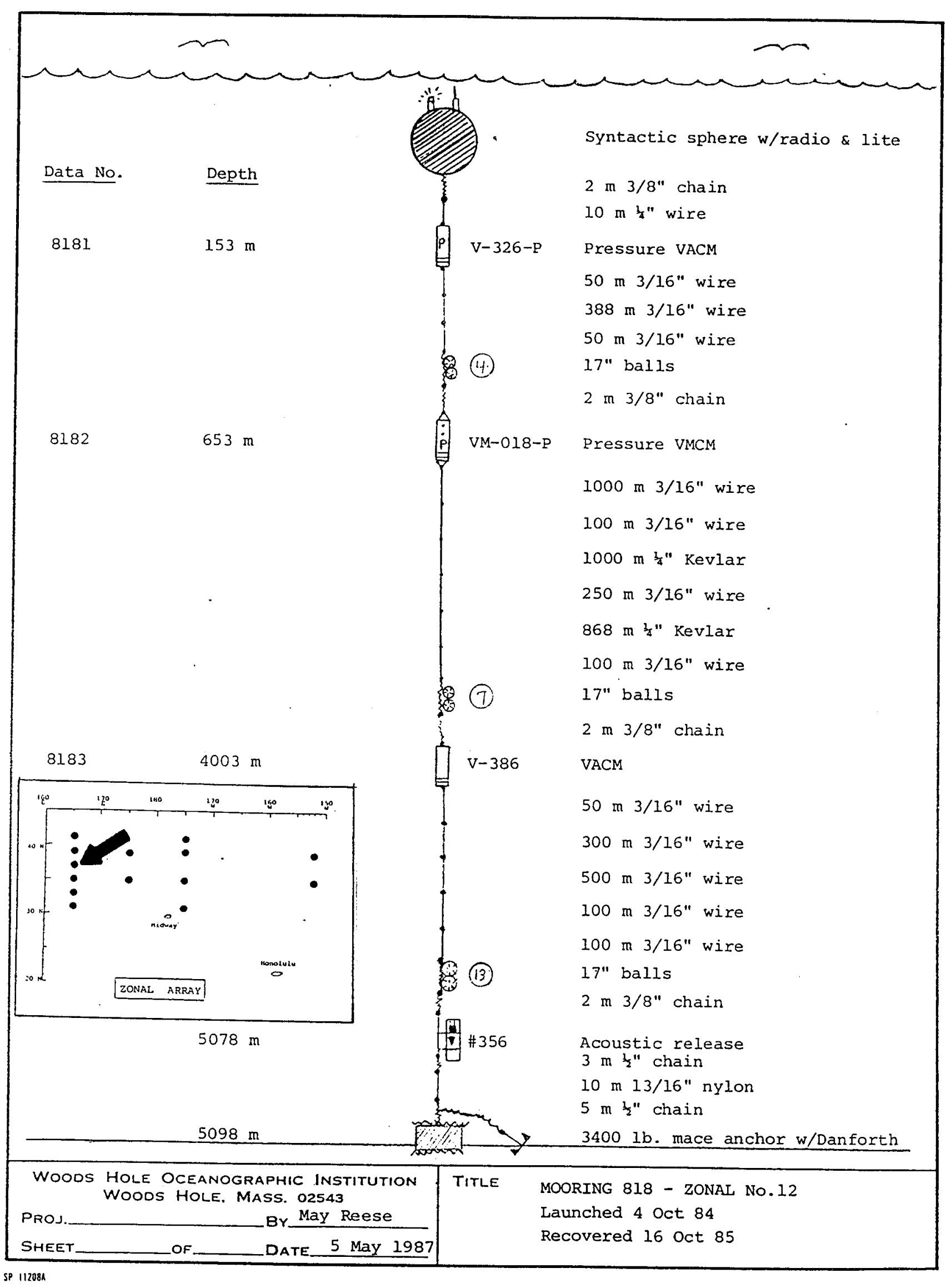




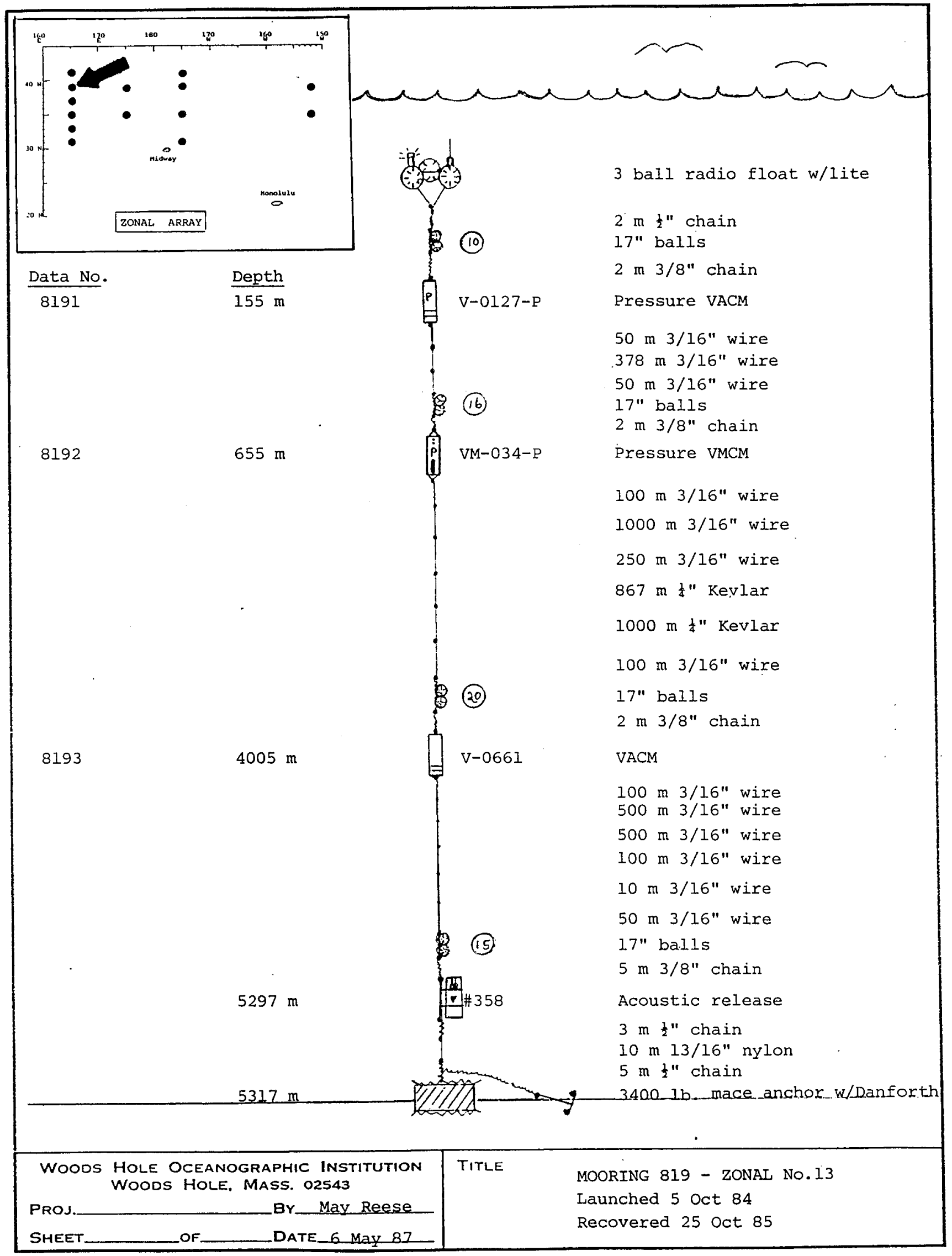

SP 1120 sA 


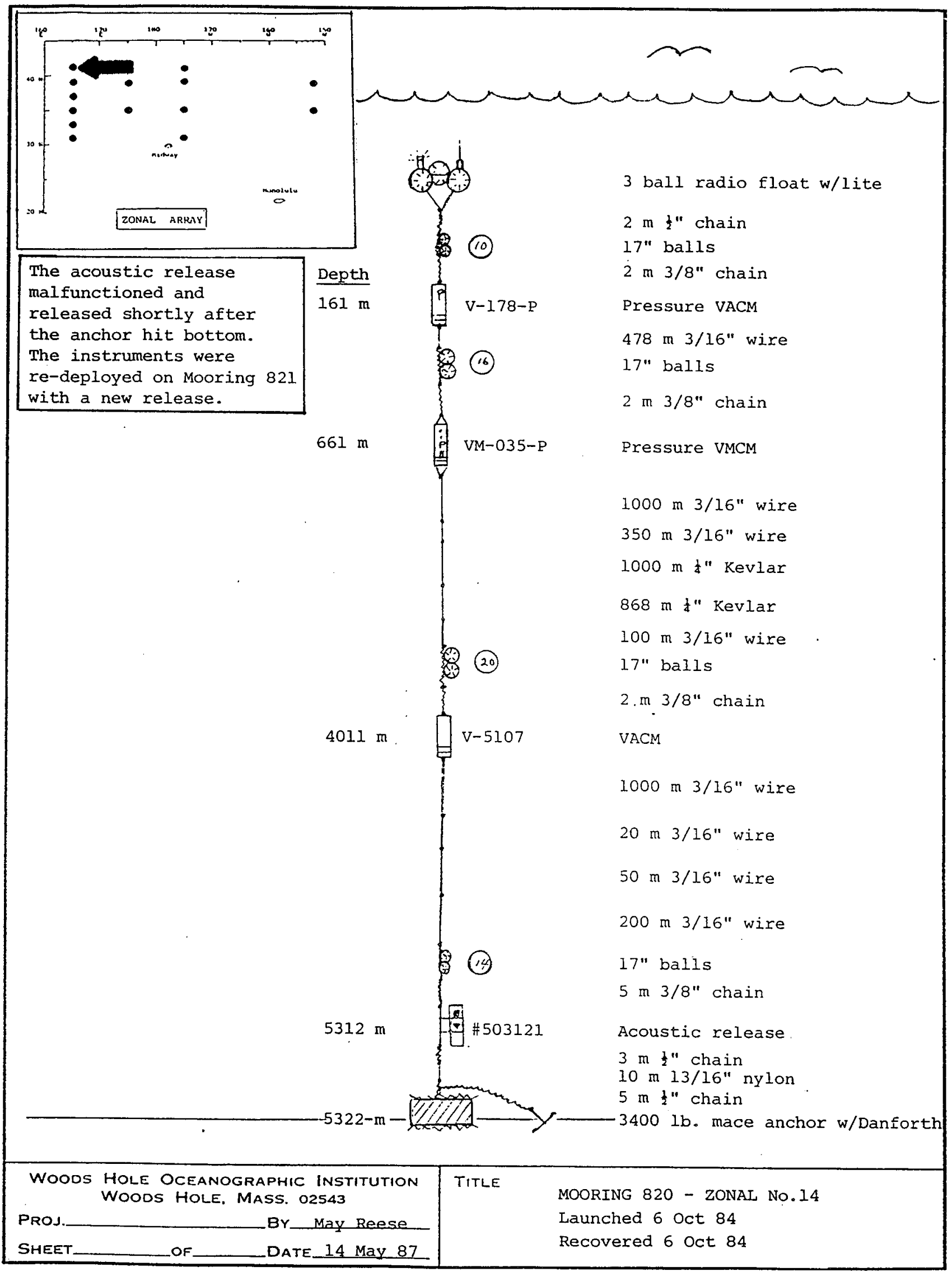

Sp :12003 


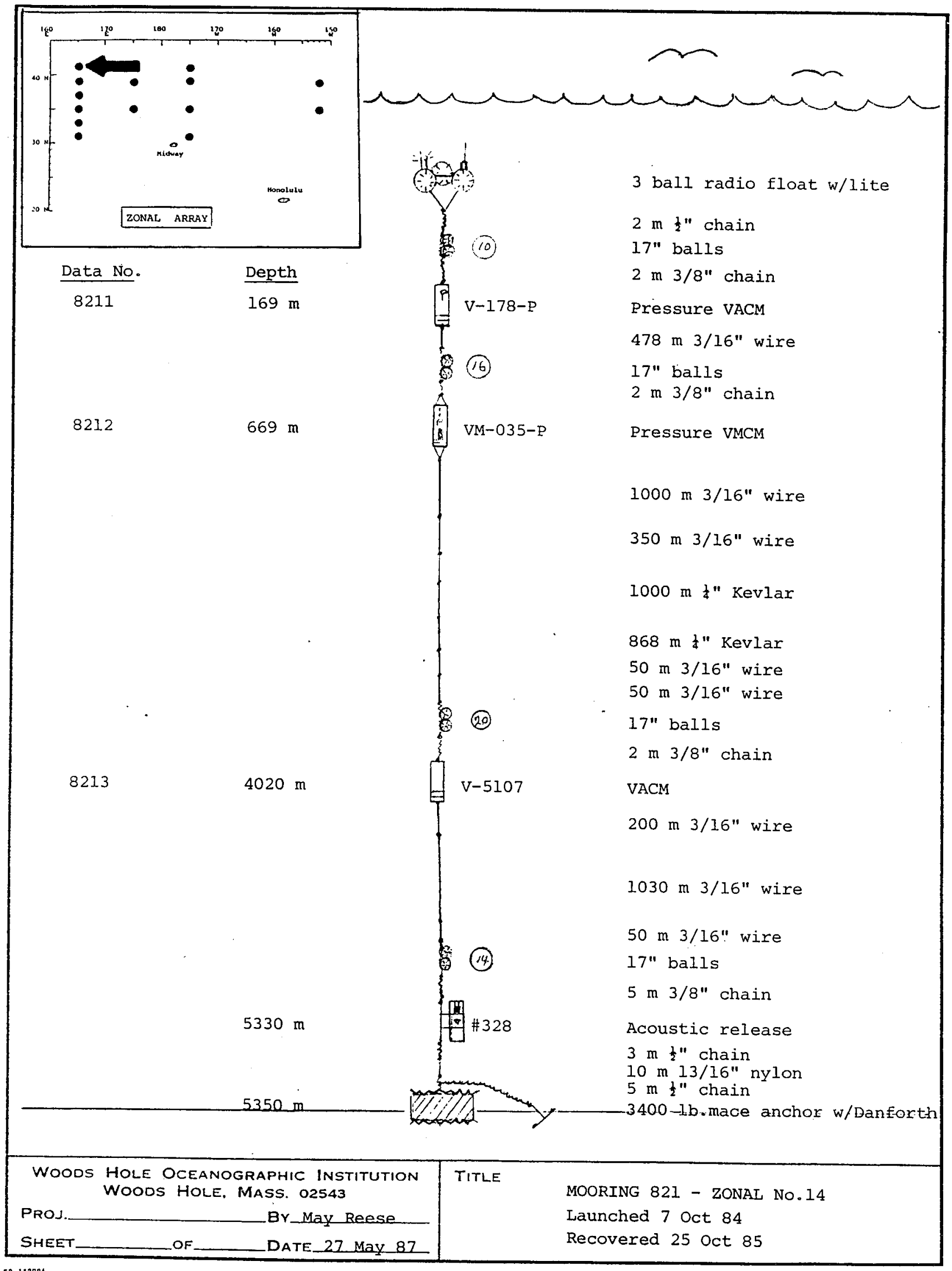

SP II2abA 


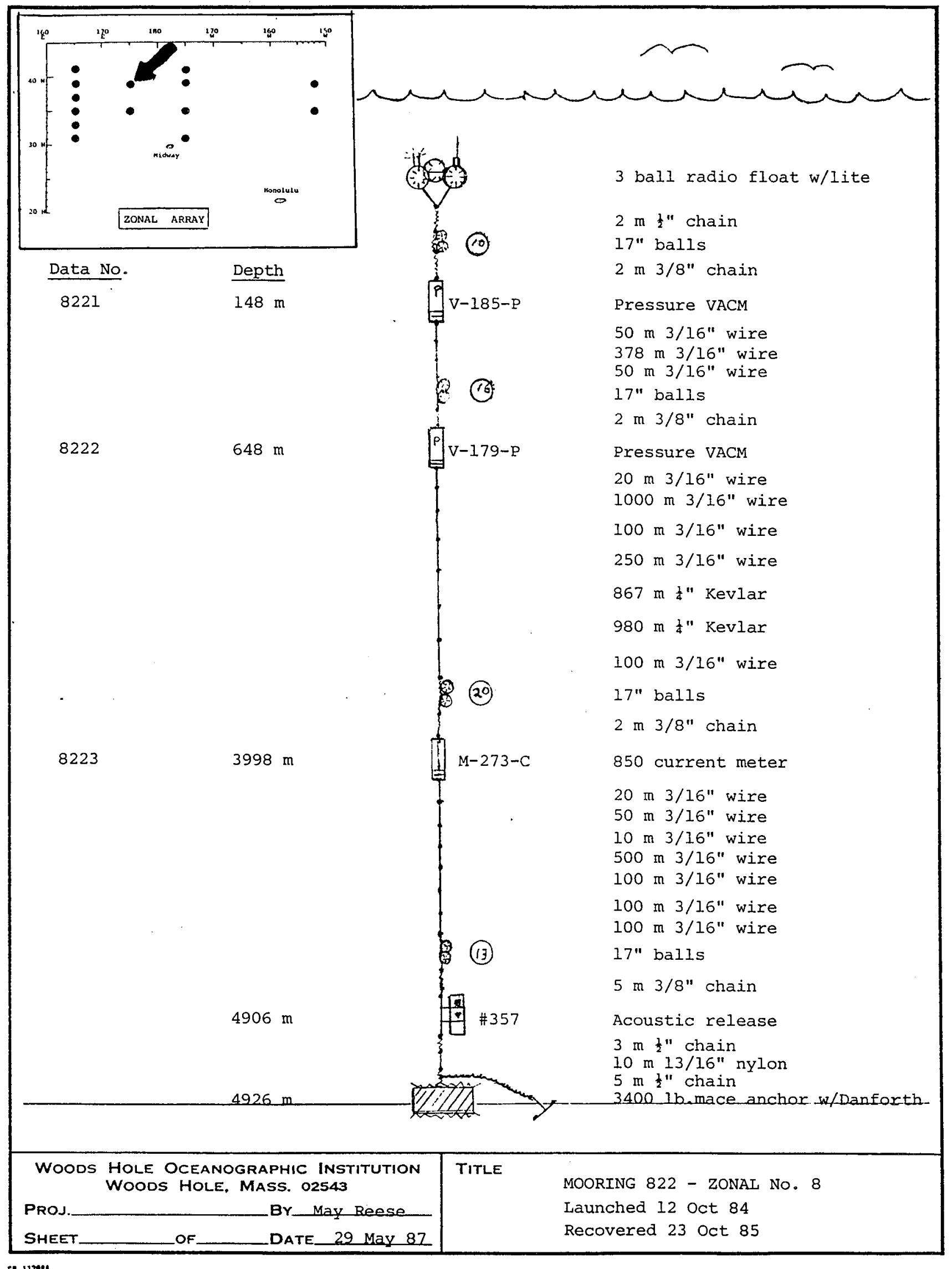

sp lizar 


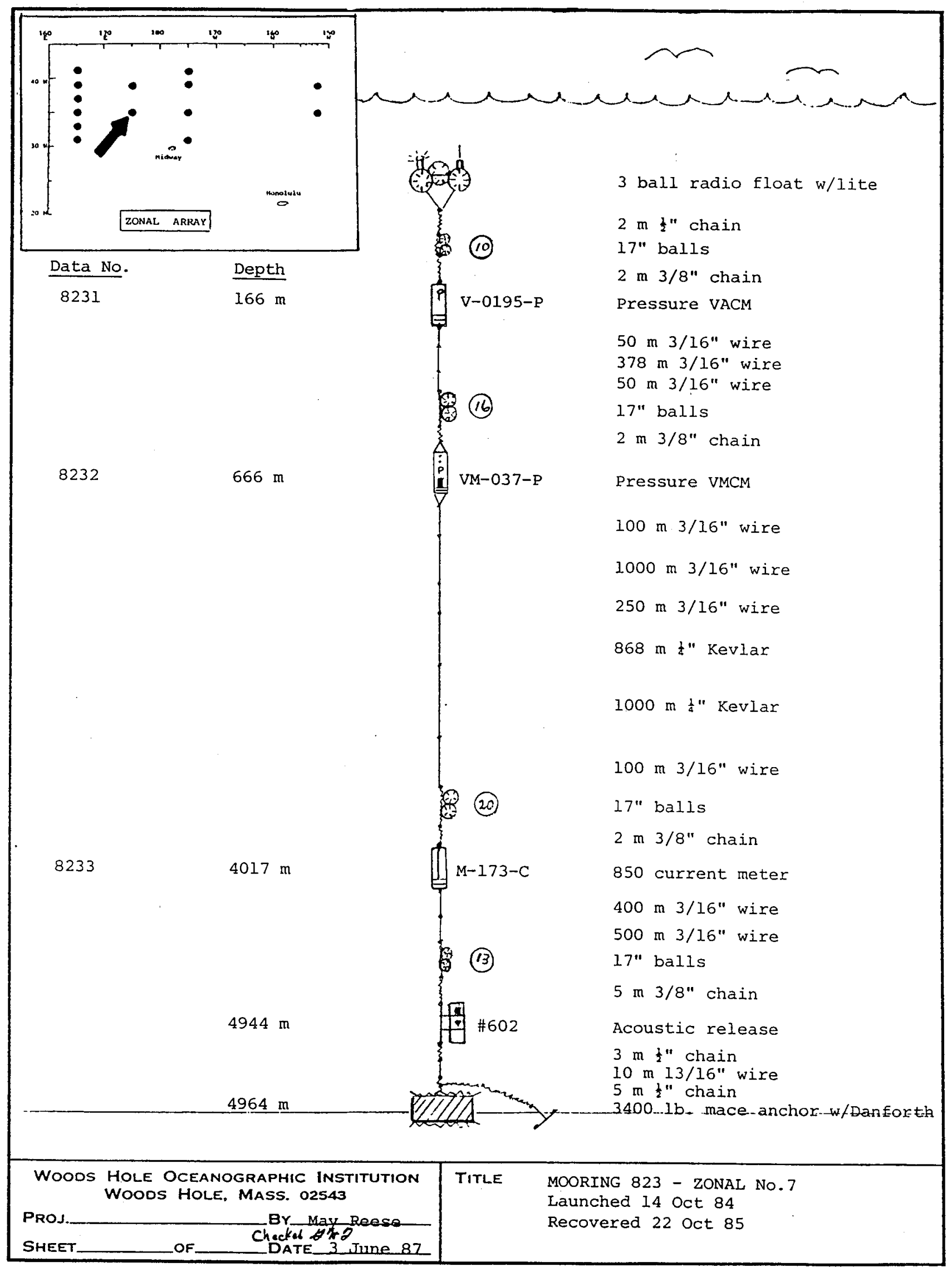

sp izatu 


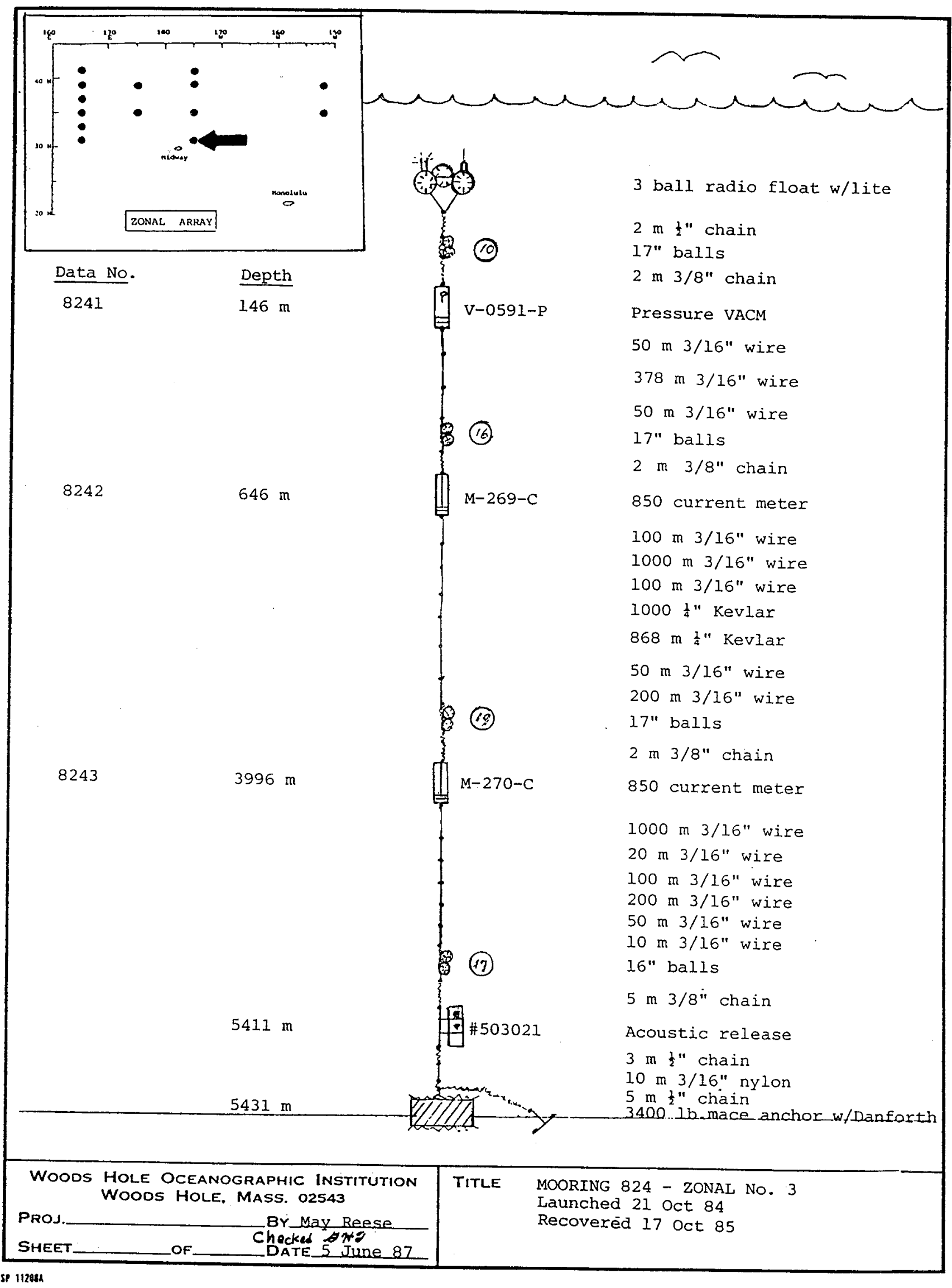




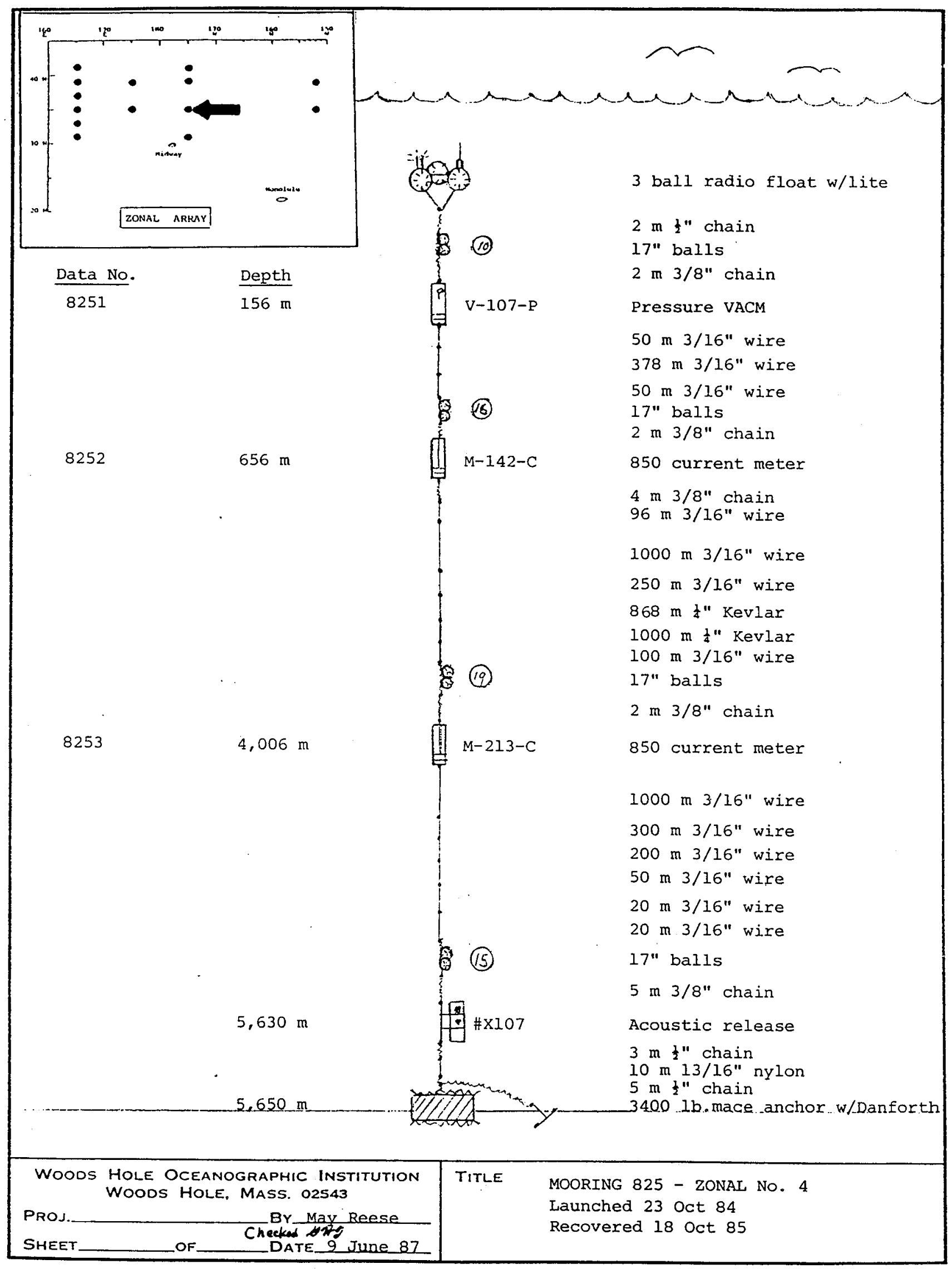

SP $1120 \mathrm{aA}$ 


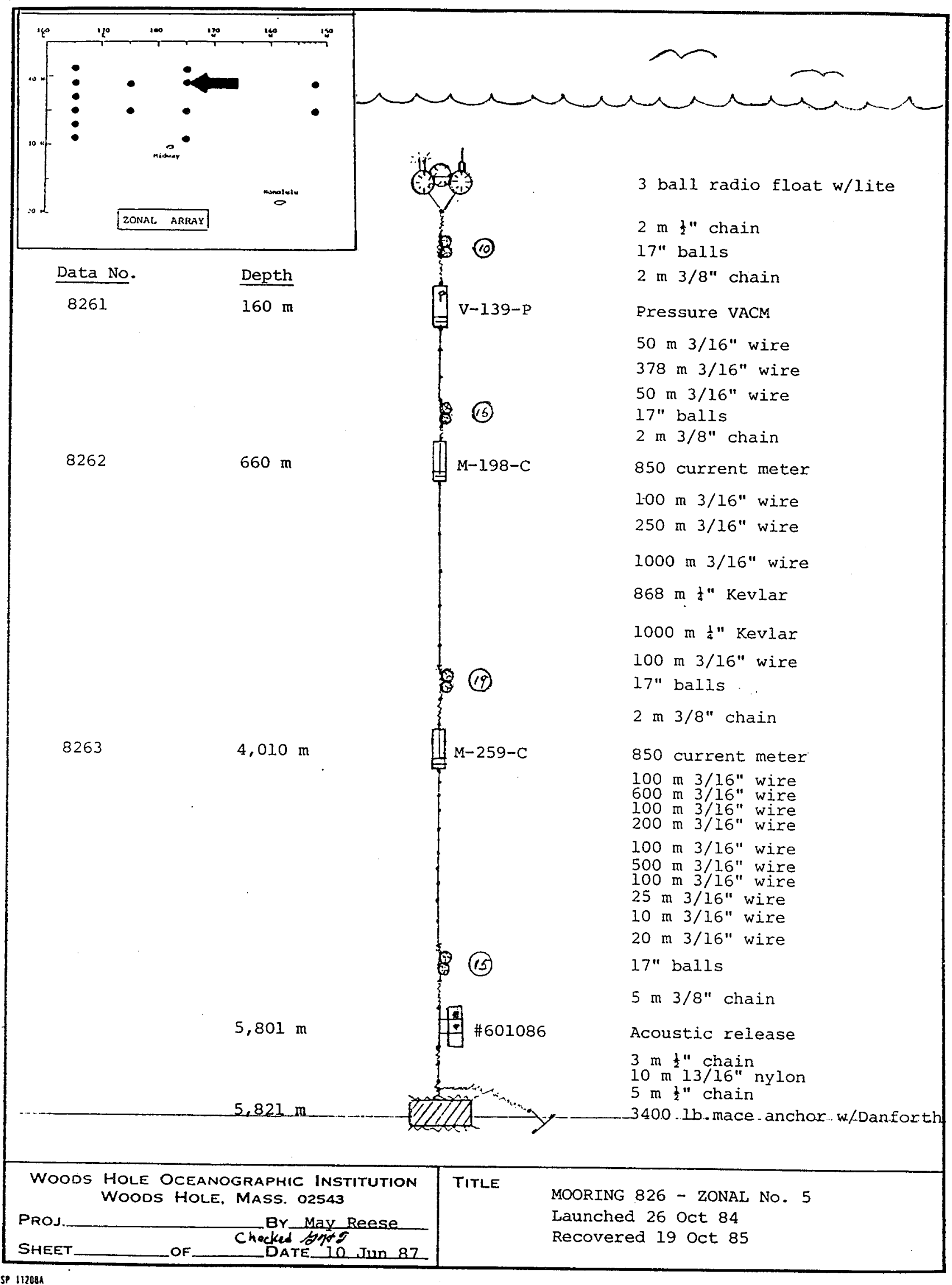




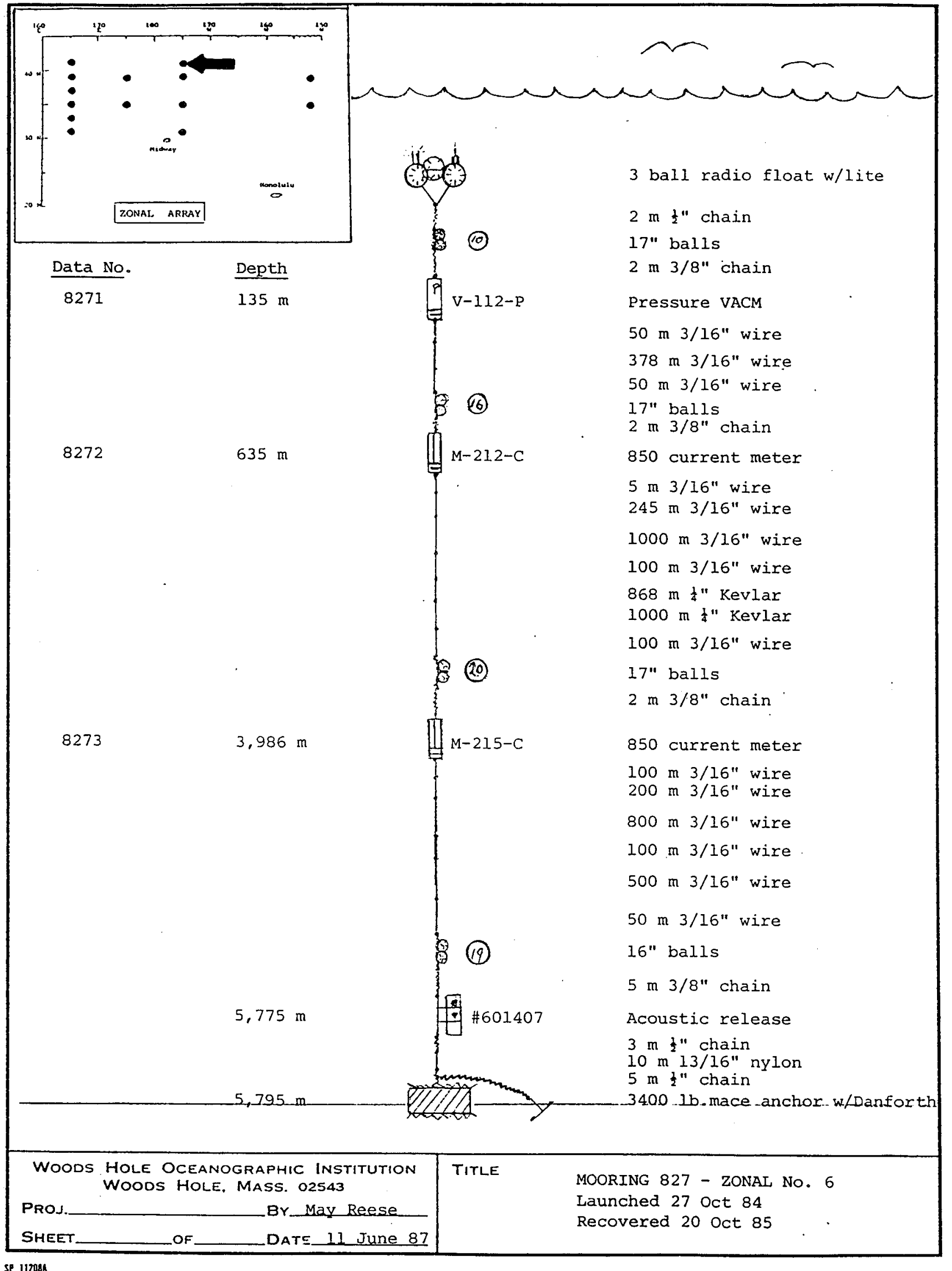




\section{Acknowledgements}

The success of this experiment is due to the efforts of a great many people. The dedication and professionalism of the people in the Buoy operations, Technical Support, and Data Processing groups are gratefully acknowledged. Special thanks are due to David Simoneau and Will ostrom for their outstanding performance supervising deck operations in sometimes abominable weather conditions, to Joe poirier for supervising the current meter preparations which led to the high data return, and Scott Worrilow and Roderigue LaRochelle for their expertise in acoustic release preparation which resulted in no lost moorings. Thanks also to May Reese, who made all the mooring drawings and helped enormously in editing and organizing this report. I also wish to thank all cruise participants for their efforts and cooperation in often less-than-ideal conditions.

Captain C. W. Clampitt and the officers and men of the R/V Thomas G. Thompson were greatly appreciated by all of us for their seamanship, professionalism, and general "can-do" attitude. In particular, Captain Clampitt's shiphandling when approaching moorings on the surface in rough weather was outstanding, resulting in successful pickup on the first approach in most cases. This, in turn, assured minimum tangling of the mooring and maximum re-usability of the mooring wire during the 1984 turnaround cruise.

The mooring work was supported by the office of Naval Research under Contracts N00014-76-C-0197, NR 083-400 and No0014-84-C-0134, Nr $0.83-400$ 
References

Berteaux, H.O. and B. Prindle (1987) Deep Sea Moorings Fishbite Handbook. Woods Hole Oceanogr. Inst. Tech. Rept. WHOI-87-8. Woods Hole, MA

Bradley, K.F. (1982) Technical activities associated with an exploratory array in the western North Pacific. Woods Hole Oceanogr. Inst. Tech. Rept. WHOI-82-41, Woods Hole MA

Chase, T.E., H.W. Menard and J. Mammerickx (1977) Topography of the North Pacific. Tech. Rep. Seri. TR-17, Inst. of Mar. Resources, Univ. of Calif., La Jolla

Holland, W.R. and W.J. Schmitz, Jr. (1985) Zonal penetration scale of model mid-latitude jets. J. Phys. Oceanogr. 15, 1859-1875

Koblinsky, C.J., R.L. Bernstein, W.J. Schmitz, Jr. and P.P. Niiler (1984) Estimates of the geostrophic stream function in the western North Pacific from XBT surveys. J. Geophys. Res. 89, 10451-10460

Levy, E. and S.A. Tarbell (1983) A compilation of moored current meter data from the western North Pacific, Volume XXXI, 1980-1982. Woods Hole Oceanogr. Inst. Tech. Rept. WHOI-83-30, Woods Hole, MA

Levy, E. and S.A. Tarbell (1987) A compilation of moored current meter data from the North Pacific (The "Zonal" Experiment, 1983-1985), Volume XLI. Woods Hole Oceanogr. Inst. Tech. Rept. WHOI-87-20, 54 pp. and 8 microfiche

Mollex, D.A. (1976) A computer program for the design and static analysis of single-point subsurface mooring systems: NOYFB. Woods Hole Oceanogr. Inst. Tech. Rept. WHOI-76-59, Woods Hole, MA

Niller, P.P., W.J. Schmitz, Jr. and D.K. Lee (1985) on the geostrophic volume transport in high eddy energy areas of the Kuroshio Extension and Gulf Stream. J. Phys. Oceanogr. 15, 825-843

Schmitz, W.J., Jr. (1984a) Abyssal eddy kinetic energy in the North Atlantic. J. Mar. Res. $42,509-536$

Schmitz, W.J., Jr. (1984b) Abyssal eddy kinetic energy levels in the western North Pacific. J. Phys. Oceanogr. 14, 198-201

Schmitz, W.J., Jr. (1984c) Observations of the vertical structure of the eddy field in the Kuroshio Extension. J. Geophys. Res. 89, 6355-6364

Schmitz, W.J., Jr. (1987) Observations of new, large, and stable abyssal currents at mid-latitudes along 165E. J. Phys. Oceanogr. 17, 1309-1315

Schmitz, W.J., Jx. (1988) Zonal exploration of the North Pacific. J.. Phys. Oceanogr. 18, in press 


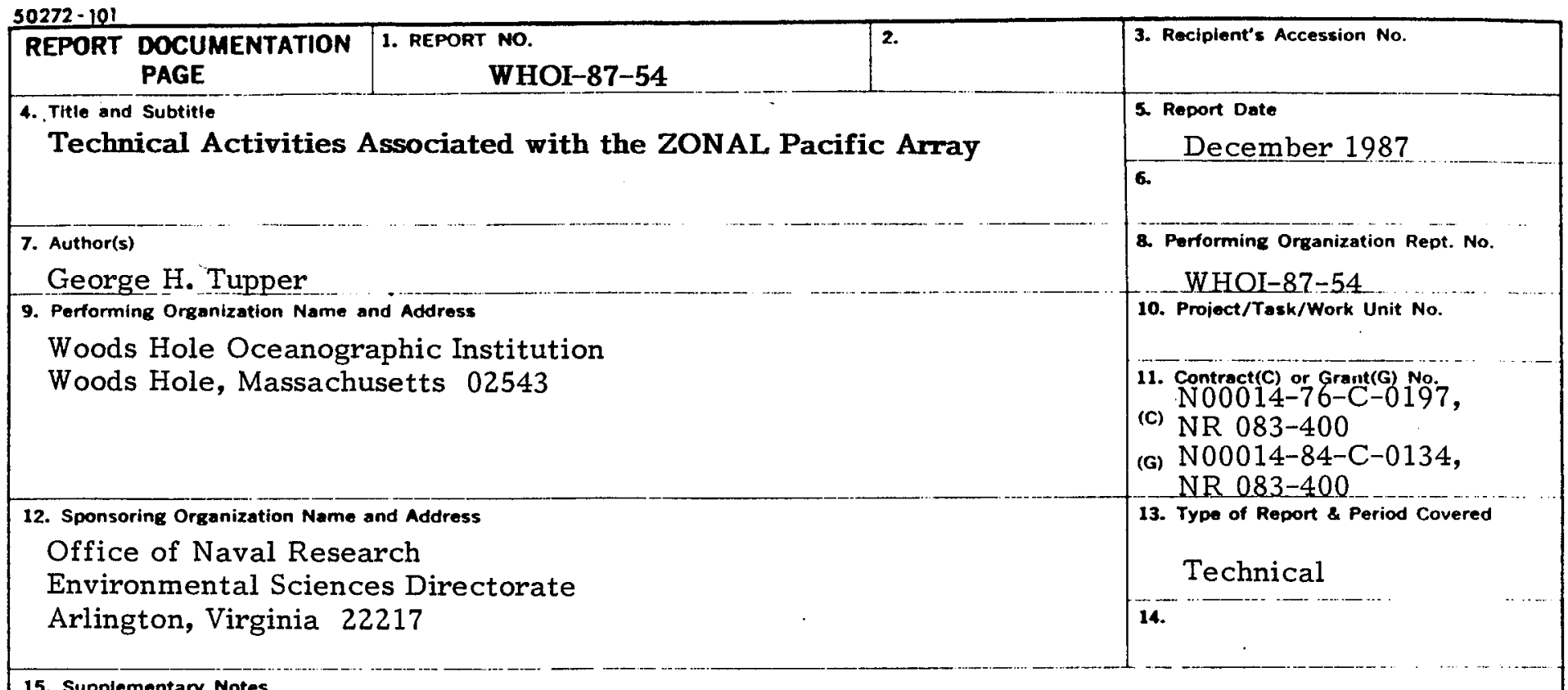

15. Supplementary Notes

This report should be cited as: Woods Hole Oceanog. Inst. Tech. Rept., WHOI-87-54.

16. Abstract (Limit: 200 words)

Geographical exploration of the eddy and mean fields in the world's oceans using moored instrumentation was concentrated in the North Atlantic in the 1970s. Initial efforts to obtain zeroorder coverage in the North Pacific were begun with an array across the Kuroshio Extension along $152^{\circ} \mathrm{E}$ with instruments in the water from mid-1980 to mid-1982. An array designed to extend this exploration zonally with long-term moorings east of $152^{\circ}$ at mid-latitudes was first set in the fall of 1983, redeployed in the fall of 1984, and recovered for the final time in late 1985. The array was located along four lines of longitude $165^{\circ} \mathrm{E}, 175^{\circ} \mathrm{E}, 175^{\circ} \mathrm{W}$, and $152^{\circ} \mathrm{W}$. Along the three westernmost longitudes, 24 one-year moorings were used, 12 each year, with three current meters per mooring at nominal depths of 150, 650, and 4,000 meters. The eastern longitude, $152^{\circ} \mathrm{E}$, was sampled by two additional moorings, each with 3 current meters at the above depths, which were deployed for a two-year period, a first for the Buoy Group.

This report addresses the technical activities associated with the 1983-1985 array, referred to hereafter as "ZONAL".

\section{Document Analysis a. Descriptors}

1. Current meters

2. Long-term moorings

3. Schmitz ZONAL Pacific 1983-1985

b. Identifiers/Open-Ended Torms

c. COSATI FIEld/Group

18. Avellability Statemen:

Approved for publication; distribution unlimited.

\begin{tabular}{|c|c|}
\hline $\begin{array}{l}\text { 19. Securtty Class (This Report) } \\
\text { UNCLASSIFIED }\end{array}$ & $\begin{array}{l}\text { 21. No. of Pages } \\
113\end{array}$ \\
\hline 20. Security Class (This Page) & 22. Price \\
\hline
\end{tabular}

